AUTARQUIA ASSOCIADA À UNIVERSIDADE DE SÃO PAULO

DOSIMETRIA TL EM CAMPOS MISTOS NO REATOR IPEN/MB-01

Tássio Antonio Cavalieri

Tese apresentada como parte dos
requisitos para obtenção do Grau de
$\begin{aligned} & \text { Doutor em Ciências na Área } \\ & \text { de Tecnologia Nuclear-Reatores }\end{aligned}$

Orientador:

Prof. Dr. Hélio Yoriyaz 
INSTITUTO DE PESQUISAS ENERGÉTICAS E NUCLEARES

Autarquia associada à Universidade de São Paulo

DOSIMETRIA TL EM CAMPOS MISTOS NO REATOR IPEN/MB-01

Tássio Antonio Cavalieri

Tese apresentada como parte dos requisitos para obtenção do Grau de Doutor em Ciências na Área de Tecnologia Nuclear - Reatores

Orientador:

Prof. Dr. Hélio Yoriyaz

Versão Corrigida

Versão Original disponível no IPEN

São Paulo

2018 
"Em algum lugar,

alguma coisa incrível está esperando

para ser descoberta."

Carl Segan 


\section{AGRADECIMENTOS}

Aos meus pais, Elourizel e Sandra, por todo o incentivo para que fosse possível completar mais esta etapa. Pela enorme compreensão e carinho nos períodos mais difíceis.

À minha esposa, Natália, por todo apoio e incentivo neste período, na paciência em tantos momentos e por todo amor e carinho compartilhados.

À minha irmã, Talissa, pelo apoio e por, a todo momento, me apresentar uma nova São Paulo.

Aos meus avós também pelo apoio e incentivo para que eu terminasse mais este estágio.

Ao meu orientador, Professor Doutor Hélio Yoriyaz, por toda a ajuda nas dificuldades iniciais deste trabalho, pelo auxílio durante todo meu processo de aprendizagem nestes quatro anos e pelo tempo que passou corrigindo todos os meus trabalhos, incluindo essa tese!

Aos professores Dr. Paulo de Tarso Dalledone Siqueira e Dr. Julian Marco Barbosa Shorto por toda a ajuda nas discussões e nas realizações das atividades envolvendo meus trabalhos nestes quatro anos.

Ao Dr. Iremar Alves, à Dra. Maíra Goes Nunes, ao Dr. Ulysses D’Utra Bitelli, ao Hugo Landim e ao Sr. Rogerio Jerez pelo auxílio nas discussões e realizações das irradiações desse trabalho.

A todos os bolsistas e amigos do CEN, Talita Coelho, Clayton Henrique, Renata Del Nero, Paula Antunes, Isabela Branco, Fábio de Paiva, Murilo Bellezzo, Felipe Cintra, Gregório de Souza e Gabriel Fonseca por todos os momentos compartilhados estes anos no IPEN, seja discutindo os trabalhos ou não!

Aos funcionários do IPEN, por manter o local sempre agradável para a realização de meus trabalhos.

Aos amigos Bruno Malvezi, Gabriel Ishida, Fábio Fernades e Leandro Carmo por toda a amizade, brincadeiras e diversão durante este período, além do apoio para que eu terminasse essa etapa.

Aos amigos Diego Fogaça, Rodrigo Ivata, Vitor Bassi, Jamyle Moretti, Paulo Vittor, Pedro Panhoza, Everson Bazetti, Marcela Tralli, Manuela Graton, Marina Oliveira, Ana Letícia Zanin, Caroline Amaro, Juliana Zulian e Luciana Bernal pelos churrascos, barzinhos...

E finalmente agradeço à CNPQ pela bolsa de estudo durante o desenvolvimento desse trabalho. 


\title{
DOSIMETRIA TL EM CAMPOS MISTOS NO REATOR IPEN/MB-
}

01

\author{
Tássio Antonio Cavalieri
}

\section{RESUMO}

A dosimetria de campos mistos de nêutrons e gamas é uma área de pesquisa que apresenta grande oportunidade de estudos devido ao aumento da utilização de procedimentos médicos como protonterapia e Terapia de Captura de Nêutrons (NCT Neutron Capture Therapy), além da importância para cálculo de doses ocupacionais e dos campos de irradiação em reatores nucleares.

Para a dosimetria de campos mistos de nêutrons e gamas, a Comissão Internacional de Unidades de Medidas (ICRU) recomenda o uso de dosímetros com sensibilidades distintas para cada componente do campo. Os dosímetros termoluminescentes (TLDs) apresentam-se como uma alternativa para a realização da dosimetria de campos mistos de nêutrons e gamas em particular à utilização do par de TLDs de LiF TLD 100 e TLD 700, que apresentam respostas distintas às componentes de campo em virtude da diferença na quantidade do isótopo ${ }^{6} \mathrm{Li}$ em suas composições. Porém, esta escolha apresenta algumas dificuldades pois a característica da resposta dos TLDs para cada componente de campo ainda não é totalmente compreendida.

Este trabalho apresenta primeiramente um estudo de um sistema para moderação de uma fonte de AmBe para realizar os estudos de sensibilidade e linearidade dos TLDs quando irradiados em um campo misto de nêutrons e gamas. O sistema de moderação se faz necessário pois a fonte de AmBe emite preferencialmente nêutrons com alta energia, e a sensibilidade dos TLDs de LiF é preferencialmente para nêutrons de baixa energia.

Entretanto, um dos objetivos do Grupo de Pesquisa em Física Médica do CEN/IPEN é a realização da dosimetria de campos mistos de alta intensidade, como por exemplo, o campo proveniente de um reator nuclear. Dessa forma esse trabalho realizou um estudo das respostas dos TLDs 100 e TLDs 700 quando irradiados no interior do núcleo do reator IPEN/MB-01 em duas diferentes configurações: cilíndrica com "flux trap" e retangular num arranjo de 26 x 28 varetas combustíveis. Esse trabalho contou com simulações com o código de Monte Carlo, MCNP5, para fornecer os fluxos e doses devido a cada componente de campo ao qual os TLDs estariam expostos. E a partir dos dados obtidos tanto através das simulações, quanto através dos experimentos, foi proposta uma metodologia para a utilização do TLD 100 para a dosimetria de nêutrons em campos com alta fluência de nêutrons, como é o caso do núcleo do reator IPEN/MB-01. 


\title{
MIX FIELD TL DOSIMETRY AT IPEN/MB-01 REACTOR
}

\author{
Tássio Antonio Cavalieri
}

\begin{abstract}
Mixed radiation field dosimetry is a research area that presents a great opportunity for studies due to the increased use on medical procedures such as proton therapy and Neutron Capture Therapy (NCT), as well as the importance of calculating occupational doses and radiation fields in nuclear reactors.

For the dosimetry of mixed fields of neutrons and gammas, the International Commission on Radiation Units and Measurements (ICRU) recommends the use of dosimeters with distinct sensitivities for each component of the field. Thermoluminescent dosimeters (TLDs) are presented as an alternative for the dosimetry of neutron and gamma-mixed fields. In particular, the use of LiF TLD pair TLD 100 and TLD 700, which present distinct responses to the field components due to the difference in the amount of the ${ }^{6} \mathrm{Li}$ isotope in its compositions. However, this choice presents some difficulties because the characteristic of the TLD response for each field component is not fully understood.

This work presents a study of a system for moderation of an AmBe source to perform the screening and linearity studies of the TLDs when irradiated in a mixed field of neutrons and gammas. The moderation system is necessary since the AmBe source preferably emits neutrons with high energy, and the sensitivity of the LiF TLDs is preferably for low energy neutrons.

However, one of the objectives of the Monte Carlo and Dosimetry for Medical Physics Research Group of CEN / IPEN is to perform the dosimetry of high intensity mixed fields, such as the field from a nuclear reactor. Thus, this work carried out a study of the responses of the TLDs 100 and TLDs 700 when irradiated inside the core of the IPEN/MB-01 reactor in two different configurations: cylindrical with flux trap and rectangular in an arrangement of $26 \times 28$ fuel rods. This work relied on simulations with the Monte Carlo code MCNP5 to provide the fluxes and doses due to each field component in which the TLDs would be exposed. From the data obtained, both through the simulations and through the experiments, a methodology was proposed for the use of the TLD 100 for the neutron dosimetry in fields with high neutron fluence, such as the IPEN/MB-01.
\end{abstract}




\section{Sumário}

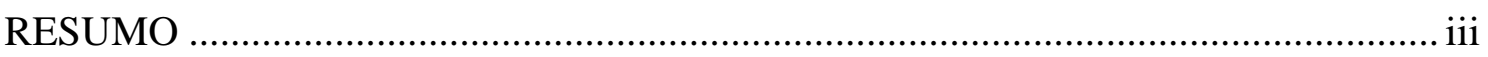

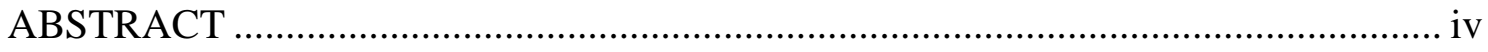

ÍNDICE DE FIGURAS ….............................................................................. vii

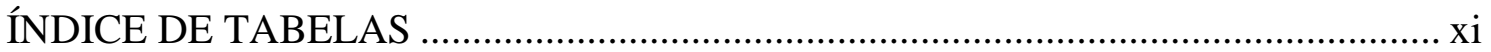

1. INTRODUÇÃ

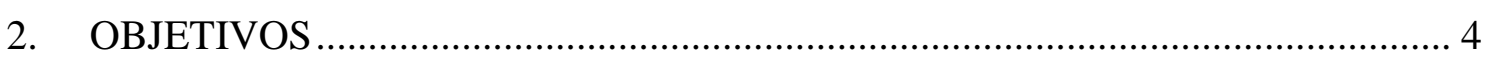

3. FUNDAMENTOS TEÓRICOS ….................................................................. 5

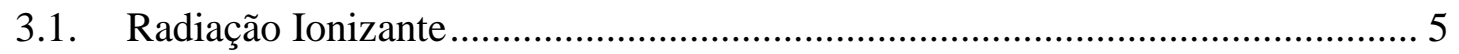

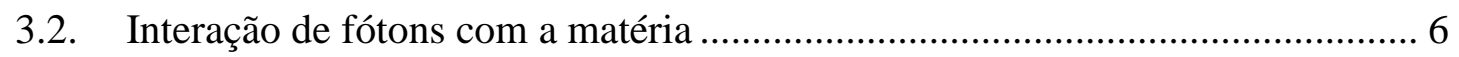

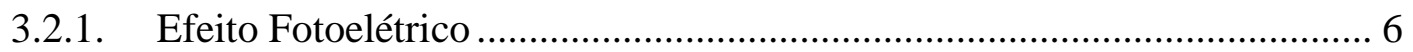

3.2.2. Efeito Compton ............................................................................ 7

3.2.3. Produção de Pares............................................................................... 9

3.3. Interação de nêutrons com a matéria ….......................................................... 9

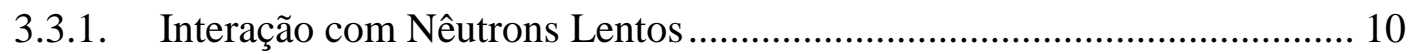

3.3.2. Interação com Nêutrons Rápidos ............................................................ 10

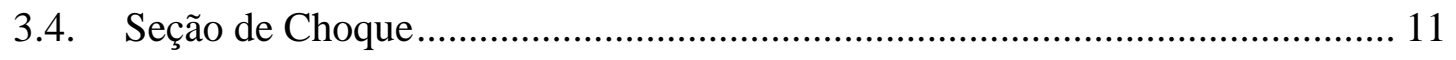

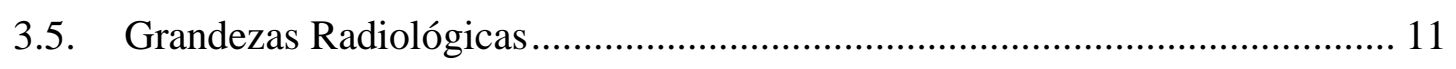

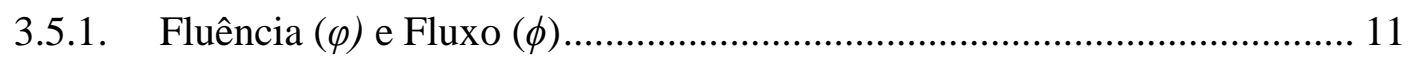

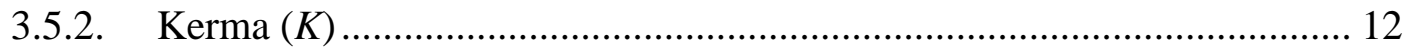

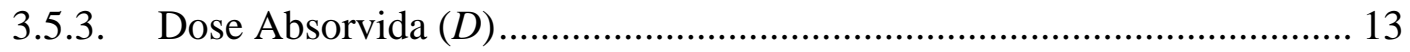

3.6. Dosímetros Termoluminescentes (TLDs) .................................................. 13

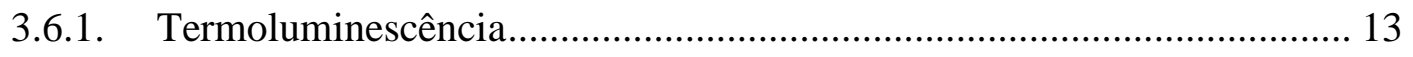

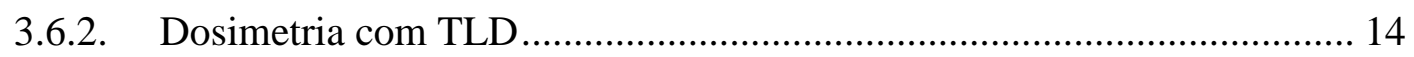

3.7. O Método de Monte Carlo ....................................................................... 15

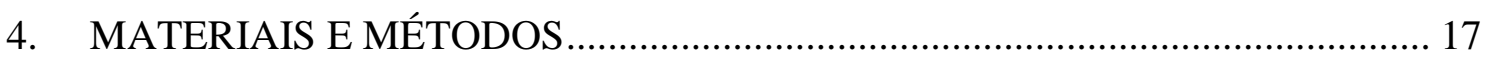

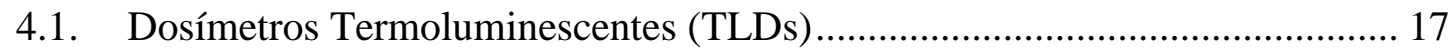

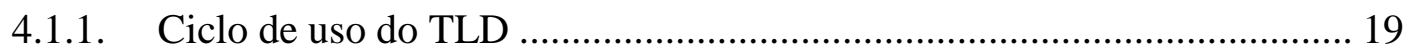

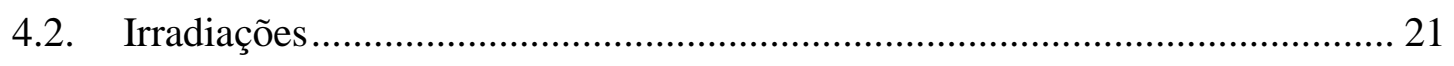

4.2.1. Irradiador com a fonte de AmBe ....................................................... 21

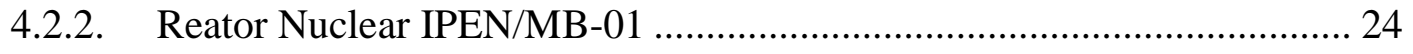

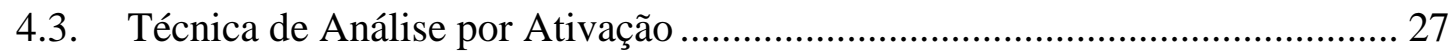

4.4. Código de Monte Carlo - MCNP5 ……............................................................ 29 


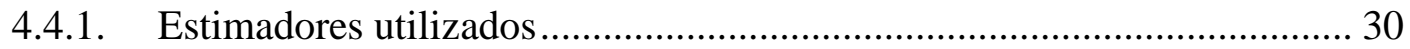

4.4.2. Simulações do Reator IPEN/MB-01 ….................................................. 32

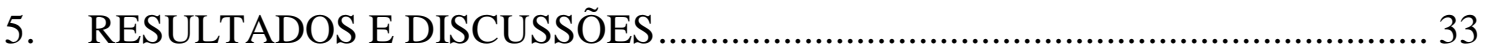

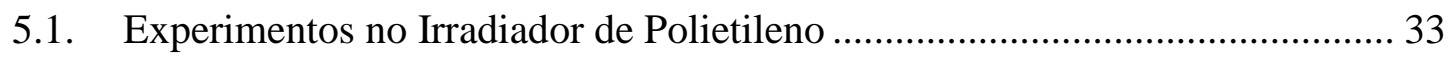

5.1.1. Caracterização do Irradiador de Polietileno ............................................ 33

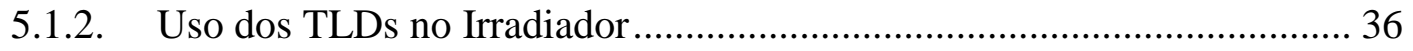

5.1.3. Estudo dos TLDs em diferentes posições do irradiador de polietileno .... 36

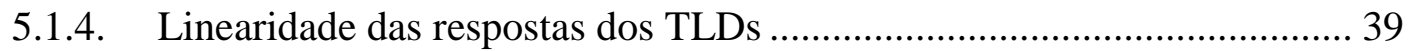

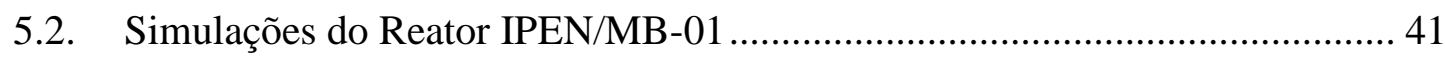

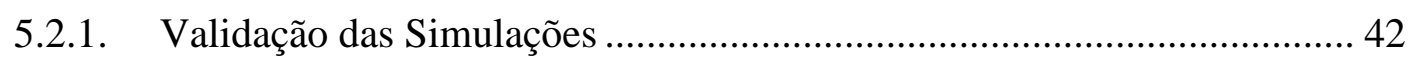

5.3. Experimentos com TLDs no reator IPEN/MB-01 ....................................... 44

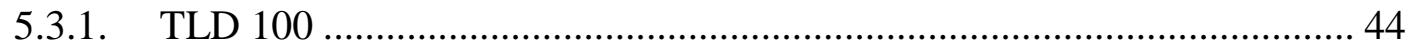

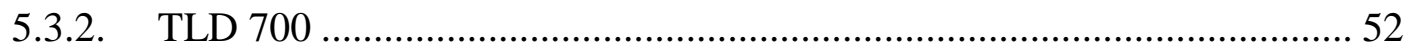

5.4. Metodologia para uso dos TLDs em Reatores ................................................ 58

5.4.1. Teste da utilização da metodologia proposta para o TLD 100 ................. 58

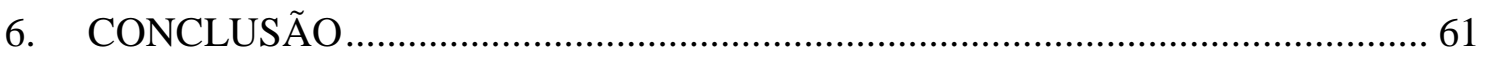

APÊNDICE A - Dependência Energética dos TLDs devido à Radiação Gama............. 63

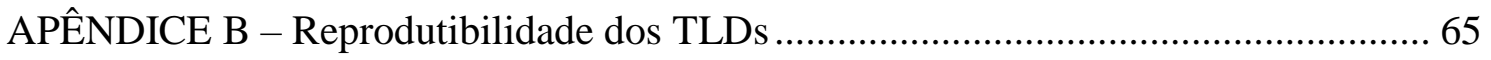

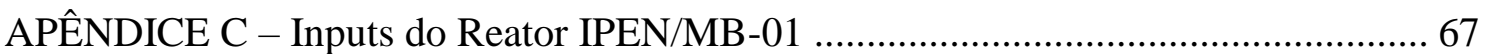

APÊNDICE D - Características do Campo do Reator IPEN/MB-01 na Configuração

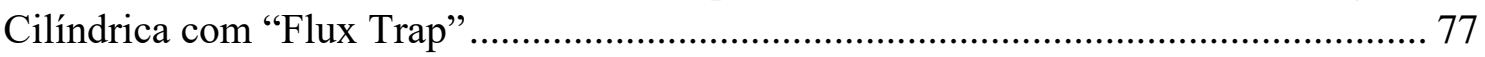

APÊNDICE E - Características do Campo do Reator IPEN/MB-01 na Configuração

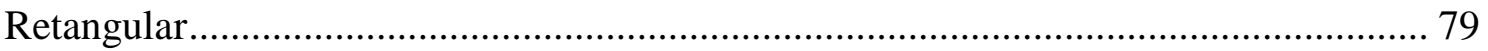

APÊNDICE F - Dados TLD 100 nas Irradiações no Reator IPEN/MB-01 ................... 81

APÊNDICE G - Dados TLD 700 nas Irradiações no Reator IPEN/MB-01 .................. 83

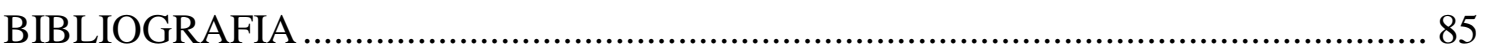




\section{ÍNDICE DE FIGURAS}

Figura 1 - Importâncias relativas dos diversos processos de interação dos fótons com a matéria em função da energia do fóton e do número atômico do material (Evans e Evans, 1955).

Figura 2 - Esquema do Efeito Fotoelétrico (Attix, 2004)........................................... 7

Figura 3 - Representação do Efeito Compton (Attix, 2004) ........................................... 8

Figura 4 - Representação da produção de pares (Attix, 2004)........................................ 9

Figura 5 - Processo termoluminescente (Tauhata, Salati, Prinzio, et al., 2003)............. 14

Figura 6 - Exemplo de curvas termoluminescentes de tipos diferentes de TLDs (Triolo et

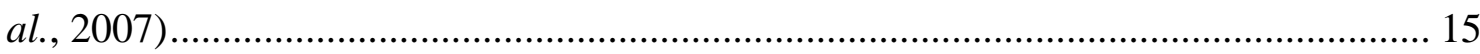

Figura 7 - Número de artigos publicados utilizando o método Monte Carlo no

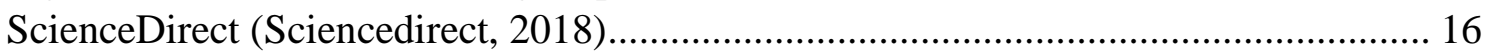

Figura 8 - Comparação do tamanho do TLD chip e uma moeda de dez centavos ........ 17

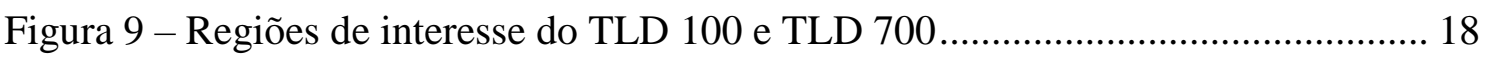

Figura 10 - Seção de choque total para nêutrons do ${ }^{6} \mathrm{Li}$ (azul) e ${ }^{7} \mathrm{Li}$ (vermelho) (Korea Atomic Energy Research Institute, 2000)............................................................ 19

Figura 11 - Muflas utilizadas para o tratamento térmico dos TLDs ............................. 20

Figura 12 - Leitora de TLD modelo Harshaw 3500 (Thermo Electron Corporation, 2005)

Figura 13 - Comparação dos diferentes espectros de nêutrons para a fonte de ${ }^{241} \mathrm{AmBe}$ apresentados na literatura: (Thompson e Taylor, 1965; Marsh et al., 1995; International Organization for Standardization, 1998; International Atomic Energy Agency, 2001). 22 Figura 14 - Imagem esquemática das peças que compõe o irradiador de polietileno.... 23 Figura 15 - Posicionamento das folhas de índio para obter o perfil axial de nêutrons .. 24 Figura 16 - Arranjos do núcleo do reator IPEN/MB-01 utilizados nesse trabalho: a) cilíndrico com "flux trap" (Silva, 2014); b) retangular 26x28 (Gonçalves, 2008)......... 25

Figura 17 - Canais de irradiação (planos axiais) do reator IPEN/MB-01. Posição Central - Canal 14-15 e posição lateral - Canal 2-3 ................................................................... 26

Figura 18 - a) Posições de irradiação dos TLDs no reator IPEN/MB-01 (vista axial do núcleo do reator) (Gonçalves, 2008); b) placa de posicionamento dos TLDs para a

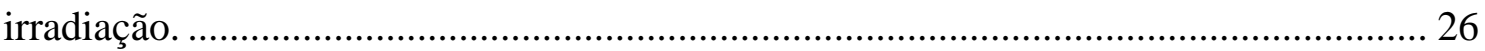

Figura 19 - Atividade da folha de ativação em função do tempo de irradiação $\left(t_{i}\right)$

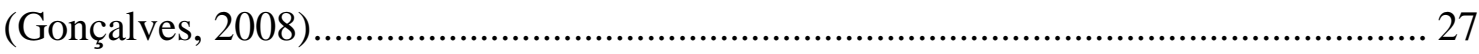

Figura 20 - Figura esquemática dos modelos geométricos para as simulações com o MCNP5 do núcleo do reator IPEN/MB-01 na configuração cilíndrica com "flux trap" (a) e retangular (b) 
Figura 21 - Atividade de saturação das folhas de Índio nuas irradiadas na posição central na lateral do irradiador.

Figura 22 - Perfil vertical axial de nêutrons térmicos na superfície lateral do irradiador de polietileno

Figura 23 - Reprodutibilidade dos TLDs no irradiador de polietileno com a fonte de AmBe. 36

Figura 24 - Perfil axial do fluxo de nêutrons e gamas no irradiador de polietileno. As linhas tracejadas verticais pretas representam as 3 posições dos TLDs nas irradiações ao longo da altura do irradiador. As incertezas são inferiores a $1 \%$. 37

Figura 25 - Linearidade da resposta do TLD 100 em irradiações no irradiador de polietileno com a fonte de $\mathrm{AmBe}$

Figura 26 - Linearidade da resposta do TLD 700 em irradiações no irradiador de polietileno com a fonte de $\mathrm{AmBe}$ 40

Figura 27 - Mapa de fluxo de nêutrons térmicos simulado, obtido no canal 14-15 com núcleo cilíndrico. As incertezas estatísticas máximas são de $1 \%$.

Figura 28 - Mapa do fluxo de gamas simulado, obtido no canal 14-15 com núcleo cilíndrico. As incertezas estatísticas máximas são de $1 \%$.

Figura 29 - Comparação entre as distribuições de fluxos de nêutrons térmicos e epitérmicos simulados e experimentais com folhas de ativação de ouro de trabalhos anteriores (Gonçalves, 2008) no arranjo retangular do núcleo na direção radial no canal 14-15 na altura de $273 \mathrm{~mm}$.

Figura 30 - Comparação entre as distribuições de fluxos de nêutrons térmicos e epitérmicos simulados e experimentais com folhas de ativação de ouro de trabalhos anteriores (Gonçalves, 2008) no arranjo retangular do núcleo na direção axial do canal 14-15 e posição horizontal $0 \mathrm{~cm}$.

Figura 31 - Fluxos de nêutrons e fótons calculados pelo MCNP5 (onde o $p$ da unidade significa partículas, nêutrons ou gamas) e as respostas dos TLDs 100 nos ROIs 1 e 2, para o canal 14-15 na posição $273 \mathrm{~mm}$ com o núcleo no arranjo cilíndrico com "flux trap". As incertezas máximas nos fluxos calculados são inferiores a $1 \%$.

Figura 32 - Comparação da dose depositada calculada devido aos nêutrons no TLD 100 e a resposta TL do ROI 1, no canal 14-15 na posição 273 mm do reator com o núcleo na configuração cilíndrica com 'flux trap. A incerteza máxima na dose calculada é inferior a $1 \%$.'

Figura 33 - Curva de calibração da dose devido à nêutrons térmicos no TLD 100 - ROI

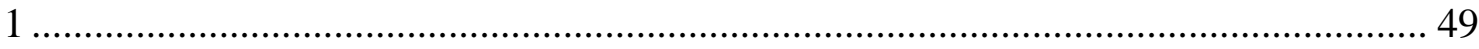

Figura 34 - Gráfico de resíduo das respostas TL do ROI 1 do TLD 100 pela curva ajustada pela equação polinomial de primeira ordem.

Figura 35 - Curva de calibração da dose devido à nêutrons térmicos no TLD 100 - ROI 
Figura 36 - Gráfico de resíduo das respostas TL do ROI 2 do TLD 100 pela curva ajustada pela equação polinomial de primeira ordem. 51

Figura 37 - Comparação entre os fluxos calculados pelo MCNP5 e a resposta TL no ROI 1 dos TLDs 700 para o canal 14-15 com o núcleo no arranjo cilíndrico com "flux trap". As incertezas máximas nos fluxos calculados são inferiores a $1 \%$.

Figura 38 - Comparação das doses calculadas devido aos nêutrons e devido à radiação gama no TLD 700 no canal 14-15 na posição $273 \mathrm{~mm}$ do reator com o núcleo na configuração cilíndrica com "flux trap" e a resposta TL do ROI 1 do TLD 700. As incertezas máximas nas doses calculadas são inferiores a $1 \%$.

Figura 39 - Comparação entre os fluxos calculados pelo MCNP5 e a resposta TL do ROI 1 dos TLDs 700 para o canal 2-3 com o núcleo no arranjo cilíndrico com "flux trap". As incertezas máximas nos fluxos calculados são inferiores a $1 \%$

Figura 40 - Comparação das doses calculadas devido aos nêutrons e devido à radiação gama no TLD 700 no canal 2-3 da posição $273 \mathrm{~mm}$ do reator com o núcleo na configuração cilíndrica com "flux trap" e a resposta TL do ROI 1 do TLD 700. As incertezas máximas nas doses calculadas são inferiores a $1 \%$.

Figura 41 - Gráfico comparando o valor de dose depositada devido aos nêutrons no TLD 100 a partir da resposta do ROI 1 do TLD 100 e a partir das simulações com o MCNP.

Figura 42 - Gráfico de resíduos da dose depositada de nêutrons térmicos no TLD 100 calculada pela curva de calibração do ROI 1 do TLD 100.

Figura 43 - Comparação dos resultados de $\mathrm{R}_{\mathrm{MC}}$ obtidos neste trabalho e no trabalho de Davis (Davis et al., 2003). 64

Figura 44 - Irradiação dos TLDs na fonte de ${ }^{137} \mathrm{Cs}$ para o estudo da reprodutibilidade. 65 Figura 45 - Dispersão das respostas dos TLDs 100 em relação à média em 3 diferentes irradiações na fonte de ${ }^{137} \mathrm{Cs}$ 66

Figura 46 - Histograma com as respostas dos TLDs 100 em uma determinada irradiação na fonte de ${ }^{137} \mathrm{Cs}$.

Figura 47 - Fluxos no interior do núcleo do reator IPEN/MB-01 na configuração cilíndrica com “flux trap' no canal 14-15 na posição $273 \mathrm{~mm}$

Figura 48 - Fluxos no interior do núcleo do reator IPEN/MB-01 na configuração cilíndrica com “flux trap' no canal 14-15 na posição $455 \mathrm{~mm}$...................................... 77

Figura 49 - Fluxos no interior do núcleo do reator IPEN/MB-01 na configuração cilíndrica com "flux trap' no canal 2-3 na posição $273 \mathrm{~mm}$

Figura 50 - Fluxos no interior do núcleo do reator IPEN/MB-01 na configuração cilíndrica com 'flux trap' no canal 2-3 na posição $455 \mathrm{~mm}$ 78

Figura 51 - Fluxos no interior do núcleo do reator IPEN/MB-01 na configuração retangular no canal 14-15 na posição $273 \mathrm{~mm}$. 
Figura 52 - Fluxos no interior do núcleo do reator IPEN/MB-01 na configuração retangular no canal 14-15 na posição $455 \mathrm{~mm}$.

Figura 53 - Fluxos no interior do núcleo do reator IPEN/MB-01 na configuração retangular no canal 2-3 na posição $273 \mathrm{~mm}$... 80

Figura 54 - Fluxos no interior do núcleo do reator IPEN/MB-01 na configuração retangular no canal 2-3 na posição $455 \mathrm{~mm}$..... 80 


\section{ÍNDICE DE TABELAS}

Tabela 1 - Parâmetros de operação da leitora de TLD Harshaw 3500 21

Tabela 2 - Fração de nêutrons térmicos calculados na lateral do irradiador na posição central com e sem (ar) o material termalizador utilizando os diferentes espectros da fonte de $\mathrm{AmBe}$ 33

Tabela 3 - Razão calculada entre a taxa de reação das folhas de Índio nuas pelas folhas de índio com cobertura de cádmio para os diferentes espectros da fonte. As incertezas são inferiores a $1 \%$

Tabela 4 - Doses depositadas calculadas e respostas TL normalizadas dos TLDs 100 nas irradiações axiais no irradiador de polietileno com a fonte de AmBe.

Tabela 5 - Doses depositadas calculadas e respostas TL normalizadas dos TLDs 700 nas irradiações axiais no irradiador de polietileno com a fonte de AmBe. 38

Tabela 6 - Comparação da relação entre as respostas dos ROIs do TLD 100 e a razão de doses calculadas devido a nêutron e gama no TLD 100. 38

Tabela 7 - Comparação da relação entre as respostas dos ROIs do TLD 700 e a razão de doses calculadas devido a nêutron e gama no TLD 700.

Tabela 8 - Comparação entre os fluxos de nêutrons e gamas e as respostas dos dois ROIs (1 e 2) do TLD 100 irradiados no arranjo cilíndrico com "flux trap" no canal 14-15 na posição $273 \mathrm{~mm}$. 45

Tabela 9 - Dose depositada calculada pelo MCNP5 no TLD 100 47

Tabela 10 - Comparação dos resultados de dose depositados simulados e resposta TL dos TLDs 100 no arranjo cilíndrico com "flux trap" normalizados pelos resultados da posição $0 \mathrm{~cm}$. 48

Tabela 11 - Comparação entre os fluxos de nêutrons e gamas calculados e as respostas dos ROI 1 e 2 do TLD 700

Tabela 12 - Comparação dos resultados de dose calculados e respostas TL dos TLDs 700 normalizados pelos dados da posição $0 \mathrm{~cm}$ (central).

Tabela 13 - Comparação dos dados de fluxo e dose depositados simulados e resposta TL dos TLDs 700 normalizados pelos dados da posição $0 \mathrm{~cm}$

Tabela 15 - Resposta termoluminescente das regiões de interesse do TLD 100 nas irradiações no reator IPEN/MB-01 na configuração cilíndrica com "flux trap". 81

Tabela 16 - Resposta termoluminescente das regiões de interesse do TLD 100 nas irradiações no reator IPEN/MB-01 na configuração retangular...

Tabela 17 - Resposta termoluminescente das regiões de interesse do TLD 700 nas irradiações no reator IPEN/MB-01 na configuração cilíndrica com "flux trap". 
Tabela 18 - Resposta termoluminescente das regiões de interesse do TLD 700 nas irradiações no reator IPEN/MB-01 na configuração retangular .................................... 84 


\section{INTRODUÇÃO}

Desde a descoberta da radioatividade no século XIX, as pesquisas envolvendo radiação vêm crescendo com o passar dos anos, porém, muitas vezes sem o completo entendimento dos efeitos biológicos que as radiações poderiam causar, sendo observados alguns efeitos danosos em pesquisas que eram realizadas. Foi observada a importância cada vez maior de se estudar, de maneira precisa, como a radiação poderia interagir com a matéria e os efeitos biológicos que essas interações poderiam causar. A parte da ciência responsável por estudar as radiações ionizantes e sua interação com a matéria, com especial interesse pela energia absorvida, é a Física das Radiações e a Dosimetria das Radiações que refere-se à determinação quantitativa desta energia (Attix, 2004).

Grandezas padrões para proteção contra a exposição a radiações ionizantes foram primeiramente propostas na década de 30. Desde então, os padrões radiológicos têm sido atualizados para diferentes unidades de radiação e estruturas conceituais que melhoram o entendimento dos efeitos biológicos da radiação (Hendee, 1993). Atualmente, as orientações para o trabalho com radiação ionizante são agrupadas em protocolos como a International Commission on Radiation Units - ICRU (International Commission on Radiation Units and Measurements, 2018) e a International Commission on Radiation Protection - ICRP (International Commission on Radiological Protection, 2018).

Nos dias atuais é grande o estudo em dosimetria das radiações ionizantes, porém há mais estudos para a dosimetria da radiação gama comparado aos da dosimetria de campos mistos de radiação contendo gamas e nêutrons. Para exemplificar este fato, uma rápida pesquisa no Google Acadêmico (Google, 2018) mostra um total de 17 mil pesquisas realizadas sobre dosimetria da radiação gama desde 2014 e apenas 7 mil pesquisas sobre a dosimetria de campos de radiação mistos de nêutrons e gamas no mesmo período.

Entretanto, nos últimos anos, esforços vêm sendo realizados para entender os efeitos da radiação de nêutrons nos tecidos. O progresso que se tem atingido é enorme, porém, muito ainda resta a ser feito. Devido à necessidade de compreensão dos efeitos da radiação de nêutrons em eletrônicos e em seres humanos, bem como o renovado interesse mundial em relação às usinas nucleares, o campo de pesquisa em nêutrons oferece um excelente campo de pesquisa e oportunidades para muitos estudos nas próximas décadas (Pomp, 2010). Dentre as áreas mais importantes para a dosimetria de nêutrons pode-se citar a dosimetria ocupacional em reatores e aceleradores (Králík e Vykydal, 2016), dosimetria em pacientes em procedimentos médicos como protonterapia (Trinkl et al., 2017) e na Terapia de Captura de Nêutrons (NCT - Neutron Capture Therapy) (Barth et al., 2012; Nedunchezhian et al., 2016).

Para a dosimetria de campos de radiação mistos, a ICRU recomenda a utilização de pares de detectores com sensibilidades distintas aos diferentes componentes do feixe (International Commission on Radiation Units and Measurements, 1984). Visando os estudos de campos mistos de nêutrons e gamas, os dosímetros termoluminescentes 
(TLDs) de LiF mostram-se uma ferramenta útil pois apresentam um tamanho reduzido, não necessitam de cabeamento e podem ser reutilizados, sendo que, diferentes tipos de dosímetros apresentam diferentes sensibilidades aos componentes do campo de irradiação. Os TLDs são amplamente utilizados em diversas áreas para dosimetria gama, e seu uso, há algum tempo, vem sendo realizado para a dosimetria de campos de radiação mistos de nêutrons e gamas.

Os estudos de TLDs para a dosimetria de campos mistos de nêutrons e gamas começaram na década de 70, buscando uma melhor compreensão dos dosímetros de albedo (Busuoli et al., 1970; Rank e Theus, 1979; Shachar e Horowitz, 1988) e apresentam estudos até hoje nesta área (Haninger e Henniger, 2016).

Porém, avanços nesta área apareceram junto com a necessidade de realizar a correta dosimetria dos feixes de radiação mistos nas instalações de NCT (Neutron Capture Therapy). Várias instalações de NCT ao redor do mundo passaram então a estudar o uso dos TLDs como alternativa para a realização dessa dosimetria (Hsu et al., 2008; Nagels et al., 2009). Dentre os diferentes estudos de dosimetria de campos mistos utilizando TLDs, podemos destacar os seguintes trabalhos: Gambarini et. al. (Gambarini et al., 2015) que mediu a componente gama no reator LVR-15 em um campo de nêutrons epitérmicos $\left(6,5.10^{8} \mathrm{~cm}^{-2} \cdot \mathrm{s}^{-1}\right)$ e térmicos $\left(3,8 \cdot 10^{7} \mathrm{~cm}^{-2} \cdot \mathrm{s}^{-1}\right)$; eles analisaram a adequação das respostas TL dos dosímetros TLD 600 e TLD 700 e dosímetros de freak gel para determinar a distribuição espacial de dose gama. Ekendahl et. al. (Ekendahl et al., 2017) estudaram a resposta $\mathrm{TL}$ do sal comum $(\mathrm{NaCl})$ em um campo misto de radiação e encontraram uma sensibilidade aos nêutrons no TLD 700; as irradiações foram realizadas no reator VR-1 na República Checa, onde o fluxo total de nêutrons térmicos era assumido como sendo de 5,55.10 $0^{8} \mathrm{~cm}^{-2} \cdot \mathrm{s}^{-1}$. Torkzadeh e Manouchehri (Torkzadeh e Manouchehri, 2006) utilizaram com sucesso o TLD 600 para a medição da fluência de nêutrons térmicos no reator Tehram na faixa de $10^{11}$ até $10^{13} \mathrm{n} . \mathrm{cm}^{-2}$; as diferenças entre as respostas TL quando nuas e com cobertura com cádmio foram estimadas para se obter a fluência de nêutrons térmicos. Tsai et. at. (Tsai et al., 2018) utilizaram o TLD 400 $\left(\mathrm{CaF}_{2}: \mathrm{Mn}\right)$ para medir a componente gama em um objeto simulador exposto ao feixe de BNCT (Boron Neutron Capture Therapy), sendo que o feixe foi gerado pelo reator THOR.

Em particular, a pesquisadora italiana Grazia Gambarini vem, desde o início dos anos 2000, se dedicando ao estudo das respostas termoluminescentes dos TLDs de LiF para a dosimetria de campos mistos de nêutrons e gamas provenientes de instalações de NCT (Gambarini et al., 2004; Gambarini et al., 2010; G. Gambarini et al., 2014; Gambarini et al., 2014).

O interesse no estudo de campos mistos de nêutrons e gamas no grupo de Física Médica do Centro de Engenharia Nuclear (CEN) do IPEN vem da necessidade da caracterização do feixe de irradiação proveniente da instalação de BNCT (Boron Neutron Capture Therapy - Terapia de Captura de Nêutrons pelo Boro) localizada no reator IEAR1 (Coelho et al., 2008). Desde então, vários estudos vêm sendo realizados na tentativa de criar uma metodologia para realizar a correta caracterização do feixe da instalação de BNCT. Incialmente, os estudos utilizavam o par TLD 600 e TLD 700 juntamente com o TLD 400 (Carneiro-Júnior, 2009; Muniz, 2010; Cavalieri, 2013), onde a tentativa era 
estimar a dose gama com o TLD 700 e TLD 400 e subtrair esta dose do TLD 600, restando assim somente a dose de nêutrons. Em alguns destes trabalhos foi observado que o TLD 600, quando irradiado em um campo com alta concentração de nêutrons, saturava sua resposta. Posteriormente, se deu início a um estudo utilizando o par TLD 100 e TLD 700 para a caracterização da instalação de BNCT (Paiva, 2016). O TLD 100 apresenta o isótopo ${ }^{6} \mathrm{Li}$ em sua composição, porém em uma concentração menor do que no TLD 600. Esta concentração de ${ }^{6} \mathrm{Li}$ faz com que o TLD 100 tenha uma sensibilidade aos nêutrons térmicos, porém, sem ocorrer sua saturação na resposta quando irradiados nas mesmas condições nas quais a resposta do TLD 600 saturava. Outro ponto a favor do uso do TLD 100 é o fato de ele ser consideravelmente mais barato que o TLD 600.

Porém, todos os estudos do uso dos TLDs de LiF, efetuados pelo grupo de estudos do IPEN, foram realizados em fontes de gama puro ou em fontes de AmBe com a utilização de moderadores. Como o objetivo de uso desses TLDs é, inclusive, em campos provenientes de reatores nucleares, há a necessidade de expandir esse estudo dos TLDs para a análise da resposta desses TLDs quando irradiados em diferentes espectros provenientes de um reator nuclear. Para este fim, o reator nuclear IPEN/MB-01 (Bitelli e Giada, 2000) mostra-se adequado para a realização deste estudo, uma vez que os fluxos de nêutrons (experimental e simulado) são amplamente conhecidos para diferentes arranjos de núcleo e, portanto, fornecem diferentes campos mistos de radiação.

O reator IPEN/MB-01 permite que seu núcleo seja montado em diferentes arranjos, sendo possível fornecer diferentes espectros de nêutrons e gamas dependendo do arranjo. Além dos diferentes arranjos de núcleo, o reator IPEN/MB-01 permite o posicionamento dos TLDs em uma grande variedade de posições no interior do seu núcleo, sendo que cada uma dessas posições apresenta um espectro de nêutrons e gamas diferente das outras posições. Portanto, o reator IPEN/MB-01 é uma ótima ferramenta para realizar as irradiações dos TLDs nos mais variados espectros e, assim, permitir um estudo mais detalhado das diferenças das respostas dos TLDs em consequência dos diferentes espectros nos quais este TLD foi irradiado. 


\section{OBJETIVOS}

O objetivo deste trabalho de doutorado é criar uma metodologia de uso do TLD de LiF para a realização da dosimetria em campos mistos de nêutrons e gamas de alta intensidade (um fluxo de aproximadamente $10^{7} \mathrm{n} \cdot \mathrm{cm}^{-2} \cdot \mathrm{s}^{-1}$ ), e que apresentem a mesma ordem de grandeza entre os fluxos dos nêutrons térmicos e dos gamas. Este interesse vem do fato de que há diferentes trabalhos que utilizam os TLDs para caracterizar os feixes de radiação provenientes de um reator, porém, ainda não há uma maneira padrão de se realizar estas caracterizações. Cada trabalho utiliza uma metodologia diferente que se aplica exclusivamente para o campo proveniente do reator nuclear utilizado no estudo.

Com a finalidade de se alcançar o objetivo desse trabalho, foi realizado primeiramente um estudo da caracterização do irradiado de polietileno, que é utilizado para um primeiro estudo dos TLDs. Esse trabalho visava analisar se o campo de irradiação do irradiador era simétrico e assim garantir que todos os TLDs dispostos na sua lateral receberiam o mesmo fluxo. Tendo este irradiador caracterizado, foi possível realizar, com maior segurança, um estudo de reprodutibilidade e a linearidade das respostas do TLDs em campo misto.

Na tentativa de se criar uma metodologia de uso dos TLDs em campos mistos com diferenças no espectro das componentes nêutron e gama, foi realizado o estudo dos TLDs quando irradiados no núcleo do reator IPEN/MB-01. Em virtude da possibilidade de variar o arranjo do núcleo do reator e de posicionar os TLDs em diferentes locais no inteiro do núcleo, foi possível irradiar os TLDs nos mais diferentes espectros de campo misto, e assim realizar um estudo mais detalhado da variação das respostas dos TLDs com a diferença nas componentes do campo. Este estudo se mostra inédito, pois não é encontrado na literatura nenhum estudo que utiliza os TLDs em campos com espectros diferentes. Normalmente, os TLDs são irradiados apenas em uma posição de irradiação que sempre fornece o mesmo espectro, sendo possível apenas alterar a fluência total na qual os TLDs são expostos.

Para auxiliar esse estudo, foi utilizado o código baseado no método de Monte Carlo MCNP5 (X-5 Monte Carlo Team, 2005) para calcular os fluxos e as doses que os TLDs foram expostos nas irradiações tanto no irradiador de polietileno, quanto nas irradiações no núcleo do reator IPEN/MB-01. 


\section{FUNDAMENTOS TEÓRICOS}

\subsection{Radiação Ionizante}

Radiações ionizantes são caracterizadas pela capacidade de excitar e ionizar os átomos da matéria que ela interage. A energia necessária para fazer com que um elétron da camada de valência escape do átomo é da ordem de 4 a $25 \mathrm{eV}$, portanto, a radiação deve carregar um energia cinética ou energia quântica superior a esta magnitude para ser chamada de radiação ionizante (Attix, 2004). As radiações ionizantes incluem as radiações eletromagnéticas raio-X e radiação gama $(\gamma)$ e também as partículas atômicas e subatômicas como elétrons, pósitrons, próton, alfa, nêutrons, íons pesados e mésons (Tsoulfanidis, 2010).

A grande variedade de radiações torna complexo os efeitos físicos que podem ocorrer na interação com a matéria. E é devido a essa grande variedade de efeitos que a física nuclear se torna tão interessante e com várias aplicações possíveis.

O tipo de interação que ocorrerá entre a radiação ionizante e a matéria irá depender do tipo de radiação, da energia dessa radiação e do material em questão. Os mais importantes tipos de radiações ionizantes para este trabalho são:

i. Raios $\gamma$ : Radiação eletromagnética provenientes de transições nucleares ou da reação de aniquilação entre matéria e antimatéria (Attix, 2004). Esse tipo de radiação não apresenta carga elétrica e massa de repouso. Sua energia é dada por:

$$
E_{\gamma}=h v=\frac{h c}{\lambda}=\frac{12,398}{\lambda}(\mathrm{keV})
$$

onde $h$ é a constante de Plank $\left(4,136.10^{-17} \mathrm{keV}\right), v$ é a frequência do fóton $(\mathrm{Hz})$, $c$ é a velocidade da luz no vácuo $\left(2,998.10^{8} \mathrm{~m} / \mathrm{s}\right), \lambda$ é o comprimento de onda $(\AA)$.

ii. Raios-x: Radiação eletromagnética emitida por partículas carregadas quando ocorre a troca de nível energético ou quando é "freada" por forças Coulombianas. Os raios-x e raios $\gamma$ apresentam as mesmas propriedades, só diferenciados pelo modo de produção.

iii. Nêutrons: Partículas neutras produzidas por reações nucleares, já que não é possível que elas sejam aceleradas eletrostaticamente. 


\subsection{Interação de fótons com a matéria}

Há algumas possibilidades de interação dos fótons com a matéria, mas as três principais interações são o Efeito Fotoelétrico, Efeito Compton e Produção de Pares. Essas três interações são os resultados da transferência de energia do fóton para o elétron e suas ocorrências dependerão da energia do fóton incidente e do número atômico $(Z)$ do material alvo.

As interações fotoelétricas têm predominância para fótons de baixa energia ( $E \leq$ $50 \mathrm{keV}$ ). À medida que a energia do fóton aumenta, a probabilidade de ocorrência do efeito fotoelétrico diminui, dando lugar ao efeito Compton. Para energias do fóton superiores a alguns $\mathrm{MeV}$, a interação por produção de pares torna-se a interação predominante. A Figura 1 apresenta as regiões dominantes de ocorrência de cada uma destas interações de acordo com a energia do fóton e o número atômico $(Z)$ do material.

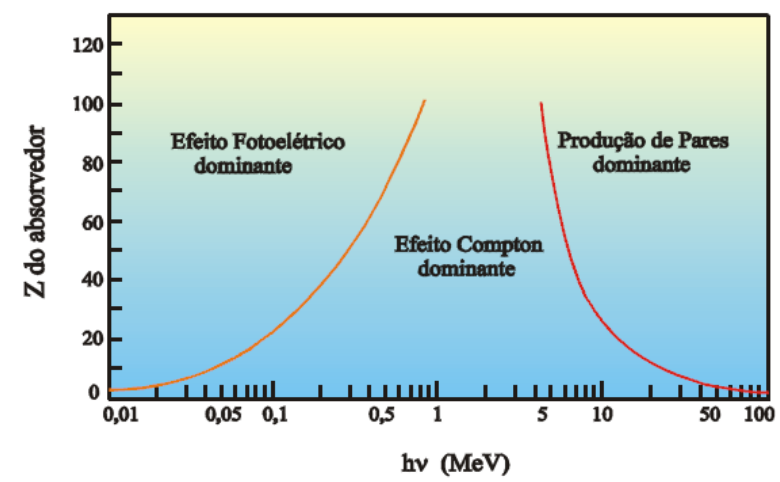

Figura 1 - Importâncias relativas dos diversos processos de interação dos fótons com a matéria em função da energia do fóton e do número atômico do material (Evans e Evans, 1955)

A seguir, estes três processos de interação serão melhor detalhados.

\subsubsection{Efeito Fotoelétrico}

O efeito fotoelétrico é caracterizado pela interação entre o fóton e um elétron orbital do átomo (geralmente das camadas $\mathrm{K}$ ou L). Neste efeito o fóton desaparece, fornecendo toda sua energia para o elétron, que é ejetado com uma energia cinética bem definida (T), Eq. 3-2. Este elétron ejetado, por vezes, é chamado de fotoelétron.

$$
T=h v-B_{e}
$$


onde $T$ é a energia cinética com que o elétron foi ejetado, $h$ é a constante de Planck, $v$ é a frequência do fóton incidente e $B_{e}$ é a energia de ligação do elétron orbital. O valor da multiplicação de $h$ por $v$ fornece a energia do fóton incidente.

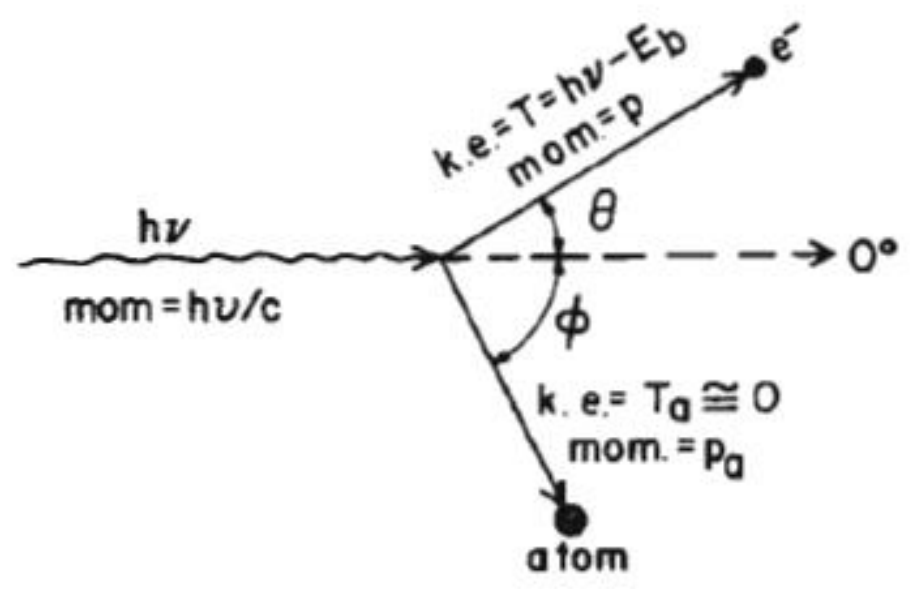

Figura 2 - Esquema do Efeito Fotoelétrico (Attix, 2004) ${ }^{1}$.

A direção de saída do elétron em relação à de incidência do fóton (ângulo $\theta$ na Figura 2) varia com a energia. Para altas energias (acima de $3 \mathrm{MeV}$ ), a probabilidade de o elétron sair na direção e sentido do fóton é alta; e para baixas energias (abaixo de 20 $\mathrm{keV}$ ) a maior probabilidade é a de o elétron sair com um ângulo de $70^{\circ}$. Isto devido à ação dos campos elétricos e magnéticos (Tauhata, Salati, Di Prinzio, et al., 2003).

\subsubsection{Efeito Compton}

No efeito Compton ocorre a interação de um fóton com um elétron de baixa energia de ligação (alguns eV). O fóton não desaparece após a interação, ele apenas tem sua direção de propagação alterada e cede parte de sua energia para o elétron, conforme apresentado na Figura 3. Conforme a energia de ligação do elétron se torna desprezível frente à energia do fóton incidente, a probabilidade de que ocorra o espalhamento Compton cresce consideravelmente.

\footnotetext{
${ }^{1} \mathrm{O}$ termo mom refere-se ao momento linear da partícula.
} 


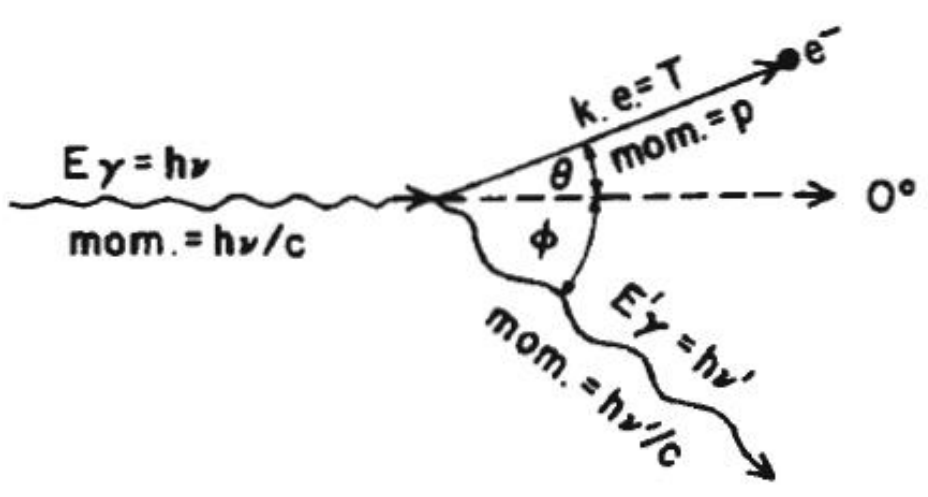

Figura 3 - Representação do Efeito Compton (Attix, 2004).

A energia do fóton é reduzida de certa quantidade após a colisão, portanto, a conservação de energia mostra que a energia que o elétron terá após a interação será dada por:

$$
T=E_{\gamma}-E_{\gamma}^{\prime}
$$

onde $T$ é a energia cinética do elétron após a interação e $E_{\gamma}$ e $E_{\gamma}^{\prime}{ }_{\gamma}$ são respectivamente a energia do fóton incidente e a energia do fóton espalhado. Essa derivação considera o elétron como não ligado, ou seja, que a energia de ligação do elétron é muito menor que a energia do fóton.

Levando-se em conta também a conservação do momento, pode-se calcular a energia do fóton espalhado $\left(E_{\gamma}^{\prime}\right)$ e a energia cinética do elétron $(T)$ a partir do ângulo de espalhamento do fóton $(\theta)$,

$$
\begin{aligned}
& E^{\prime}{ }_{\gamma}=\frac{E_{\gamma}}{1+(1-\cos \theta) E_{\gamma} / m c^{2}} \\
& E_{c}=\frac{(1-\cos \theta) E_{\gamma} / m c^{2}}{1+(1-\cos \theta) E_{\gamma} / m c^{2}} E_{\gamma}
\end{aligned}
$$

O mais importante para a medição de radiação são os casos de máxima e mínima energia do fóton espalhado após a colisão. A energia mínima do fóton após a colisão (máxima energia do elétron) ocorre quando $\theta=\pi$, que de acordo com a Eq. 3-4 é de E $/$ $\left(1+2 \mathrm{E} \gamma / \mathrm{mc}^{2}\right)$, existe então uma energia mínima do fóton espalhado, diferente de zero e, portanto, no espalhamento Compton, é impossível que toda energia do fóton incidente seja transferida para o elétron. A máxima energia do fóton após a colisão ocorre para $\theta=$ 
0 , que significa essencialmente que a colisão não existiu e o fóton espalhado continua com a mesma energia do fóton incidente (Tauhata, Salati, Di Prinzio, et al., 2003).

\subsubsection{Produção de Pares}

Para energias superiores a alguns $\mathrm{MeV}$, uma das formas predominantes de interação de fótons é a produção de pares elétron-pósitron. A produção de pares é uma interação entre o fóton e um núcleo, onde o fóton desaparece dando origem ao par elétronpósitron, porém o núcleo não sofre nenhuma alteração, pois sua presença só é necessária para que haja a conservação de momento, Figura 4.

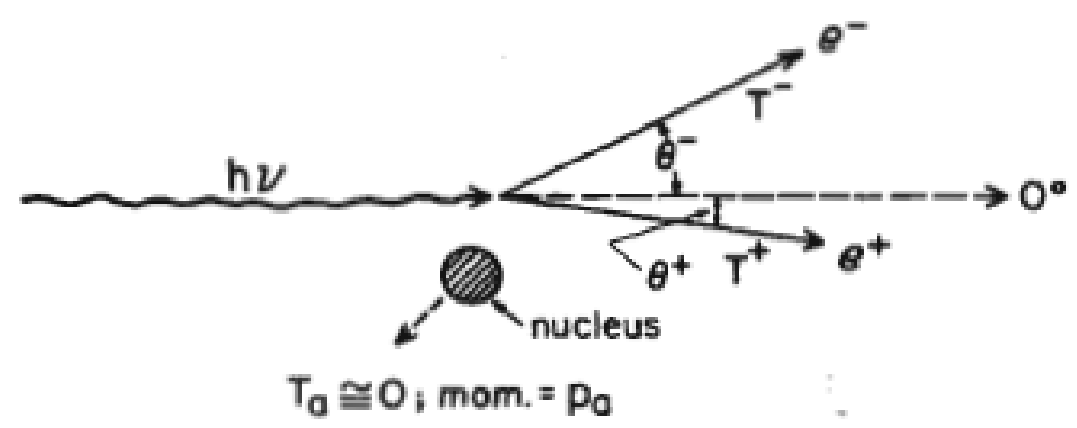

Figura 4 - Representação da produção de pares (Attix, 2004)

Para ocorrer este tipo de interação, o fóton deve ter uma energia inicial igual ou maior que $1,022 \mathrm{MeV}$ (duas vezes a massa de repouso do elétron), e a partir da conservação da energia temos a energia cinética do elétron $\left(T^{-}\right)$e do pósitron $\left(T^{+}\right)$ gerados, conforme a Eq. 3-6.

$$
T^{+}=T^{-}=\frac{1}{2}\left(E_{\gamma}-1,022 \mathrm{MeV}\right)
$$

A produção de pares elimina o fóton original, mas dois novos fótons são gerados quando o pósitron é aniquilado. Estes fótons são chamados de fótons de aniquilação.

\subsection{Interação de nêutrons com a matéria}

Os nêutrons, como os fótons, não têm carga elétrica e, portanto, não interagem com a matéria através de força coulombiana, tornando-se muito penetrantes. $\mathrm{O}$ nêutron 
interage com os núcleos atômicos através de forças nucleares. Como resultado dessa interação, os nêutrons podem desaparecer completamente e dar origem a radiações secundárias (absorção) ou apenas alterar a sua energia e direção (espalhamento) (Knoll, 2000).

A probabilidade de interação dos nêutrons com a matéria pode mudar drasticamente com o nuclídeo alvo e com a energia do nêutron. Para simplificar a apresentação das interações, os nêutrons comumente são divididos em duas faixas de energia: os nêutrons lentos, com energia inferior a $0,5 \mathrm{eV}$, e nêutrons rápidos, com energia superior a $0,5 \mathrm{eV}$.

A seguir serão apresentadas as interações dos nêutrons com a matéria de acordo com sua faixa de energia.

\subsubsection{Interação com Nêutrons Lentos}

As interações mais prováveis para nêutrons nesta faixa energética são o espalhamento elástico ou um grande número de reações induzidas por nêutrons. Devido à baixa energia cinética desses nêutrons, pouca energia é transferida para os núcleos no espalhamento elástico, sendo que, dependendo do alvo, este serve apenas para trazer os nêutrons para o equilíbrio térmico com o meio antes que diferentes tipos de reações ocorram (Knoll, 2000).

\subsubsection{Interação com Nêutrons Rápidos}

Para esta faixa energética dos nêutrons após a interação, o núcleo recebe uma significativa quantidade de energia e então é chamado de núcleo de recuo. Em cada colisão os nêutrons vão perdendo sua energia, sendo então moderados até baixas energias. Materiais com grande quantidade de átomos de hidrogênio são considerados melhores moderadores para nêutrons, isto porque o nêutron pode perder quase toda sua energia com apenas uma colisão com o átomo de hidrogênio (Knoll, 2000). Vale ressaltar que os espalhamentos elásticos são o principal mecanismo de perda de energia dos nêutrons em um reator nuclear.

Se a energia do nêutron for suficientemente alta, o espalhamento inelástico passa a ser a interação mais provável. Neste caso, o núcleo que sofre a colisão vai para um estado excitado, e quando este núcleo volta para seu estado fundamental, acaba emitindo raios gama. 


\subsection{Seção de Choque}

No caso de nêutrons ou fótons com uma energia determinada, a probabilidade de interação é constante para cada tipo de interação. E esta probabilidade é normalmente expressa em termos da seção de choque por núcleos ou seção de choque microscópica $(\sigma)$ para cada tipo de interação. A seção de choque microscópica tem unidade de área e comumente é utilizado o barn em suas medidas, em que 1 barn equivale a $10^{-28} \mathrm{~m}^{2}$.

A seção de choque macroscópica $(\Sigma)$ é definida como sendo a seção de choque microscópica multiplicada pelo número de núcleos presentes por unidade de volume $(\mathrm{N})$, tendo como unidade o inverso do comprimento.

$$
\Sigma=N . \sigma
$$

A interpretação de seção de choque macroscópica é a probabilidade por unidade de comprimento de certa interação ocorrer. Pode ser calculada a seção de choque macroscópica total, em que são somadas as seções de choque macroscópicas de cada interação [Eq.3-8]. Esta seção de choque macroscópica total representa a probabilidade de que qualquer tipo de interação ocorra por unidade de comprimento.

$$
\Sigma_{\text {total }}=\Sigma_{\text {espalhamento }}+\Sigma_{\text {captura }}+\cdots \quad \text { Eq. } 3-8
$$

\subsection{Grandezas Radiológicas}

Neste tópico serão apresentadas algumas grandezas radiológicas de interesse para este trabalho.

\subsubsection{Fluência $(\varphi)$ e Fluxo $(\phi)$}

A fluência é o número de partículas $d N$, que incidem sobre uma seção de área $d A$; a unidade utilizada para fluência no Sistema Internacional é o $\mathrm{m}^{-2}$.

$$
\varphi=\frac{d N}{d A}
$$


Define-se a grandeza fluxo (ou taxa de fluência), como a razão entre a grandeza fluência pelo tempo decorrido. Normalmente a unidade utilizada é $\mathrm{m}^{-2} \cdot \mathrm{s}^{-1}$.

$$
\phi=\frac{d \varphi}{d t}
$$

Eq. $3-10$

\subsection{2. $\operatorname{Kerma}(K)$}

Kerma é um acrônico em inglês para Energia Cinética Liberada na Matéria. É um valor não estocástico relevante apenas para radiações indiretamente ionizantes, como nêutrons e fótons, ou para quaisquer outras fontes que emitam radiações ionizantes dentro do próprio meio absorvedor (Attix, 2004).

Kerma é definido como a energia transferida pela radiação não ionizante para partículas carregadas, $E_{t r}$, por unidade de massa, $m$.

$$
K=\frac{d E_{t r}}{d m}
$$

A unidade de medida utilizada para o kerma é o gray (Gy), que corresponde a 1 $\mathrm{J} / \mathrm{kg}$.

O kerma apresenta duas componentes, pois a energia pode ser dissipada de dois modos: uma através de interações com a força coulombiana dos elétrons do material absorvedor, resultando em uma dissipação de energia próxima ao local do caminho do elétron; este modo é chamado de interação por colisão. O outro modo ocorre através da interação radioativa com o campo coulombiano do átomo, onde raios-X são emitidos pelos elétrons ao serem desacelerados, e assim carregam a energia mais longe do que o caminho da partícula carregada; este modo é chamado de interação radioativa.

Portanto, o kerma total pode ser dividido em duas partes: o kerma de colisão $\left(\mathrm{K}_{\mathrm{c}}\right)$ e o kerma radioativo $\left(K_{r}\right)$.

$$
K=K_{c}+K_{r}
$$




\subsubsection{Dose Absorvida $(D)$}

A dose absorvida é relevante para todos os tipos de radiações, tanto direta como indiretamente ionizantes, e por qualquer fonte de radiação distribuída dentro do material absorvedor (Attix, 2004).

A dose absorvida em um certo ponto é definida como a energia depositada localmente, $d \varepsilon$, em um volume infinitesimal $d v$ de massa $d m$.

$$
D=\frac{d \varepsilon}{d m}
$$

A unidade de medida de dose absorvida também é o gray (Gy).

\subsection{Dosímetros Termoluminescentes (TLDs)}

Os dosímetros termoluminescentes (TLDs) são cristais ou policristais inorgânicos dopados com quantidades adequadas de ativadores e, como o próprio nome já diz, funcionam baseados na propriedade termoluminescente que apresentam.

\subsubsection{Termoluminescência}

Certos cristais apresentam a propriedade de reter parte da energia absorvida durante a irradiação em estados metaestáveis de energia, e posteriormente liberar essa energia na forma de luz. O fenômeno da luminescência se divide em dois tipos: fluorescência, se a emissão de luz se dá entre $10^{-10}$ e $10^{-8}$ segundos após a irradiação (luminescência opticamente estimulada - OSL), e fosforescência, que pode ser estimulada pela luz ou pelo calor (termoluminescência - TL) (Mckeever et al., 1995).

Portanto, a termoluminescência é entendida como a propriedade de certos materiais após serem expostos à radiação, emitirem luz conforme são aquecidos. A intensidade de luz emitida pelo material é função da temperatura e da dose na qual o material foi exposto (Oberhofer e Scharmann, 1979).

Os materiais termoluminescentes sofrem grandes mudanças em sua rede cristalina ao serem irradiados. Estas mudanças, juntamente com os ativadores presentes no cristal, fazem com que "armadilhas" sejam criadas na banda energética proibida. Os elétrons, ao mudarem de bandas energéticas, podem ficar presos nestas armadilhas. Se o material for mantido em temperatura ambiente constante, estes elétrons podem permanecer nas armadilhas por longos períodos.

Para serem presos nas armadilhas, os elétrons devem primeiramente receber energia da radiação incidente no cristal. Dependendo do tipo de cristal, diferentes tipos 
de radiação podem fornecer energia para a sua estrutura eletrônica. No caso dos fótons, com energias superiores a alguns quilo elétron-volts, eles podem transferir suas energias para o sistema de inúmeras formas, como efeito fotoelétrico e efeito Compton. Já os nêutrons térmicos, sofrem algum tipo de reação por algum núcleo presente no cristal, gerando assim um isótopo que, ao decair, fornece energia para a excitação (Oberhofer e Scharmann, 1979).

O elétron, ao ser armadilhado, deixa um "buraco" de carga energética oposta à sua em sua posição anterior na banda de valência. Quando ocorre a recombinação entre este elétron e este buraco, há a emissão de um fóton.

Supondo então que um material previamente irradiado seja aquecido, ocorre a relaxação térmica, que é o mecanismo dominante em processos com dependência com a temperatura. Com isto, o elétron pode escapar da armadilha e se recombinar com um buraco, emitindo luz no processo (Figura 5).

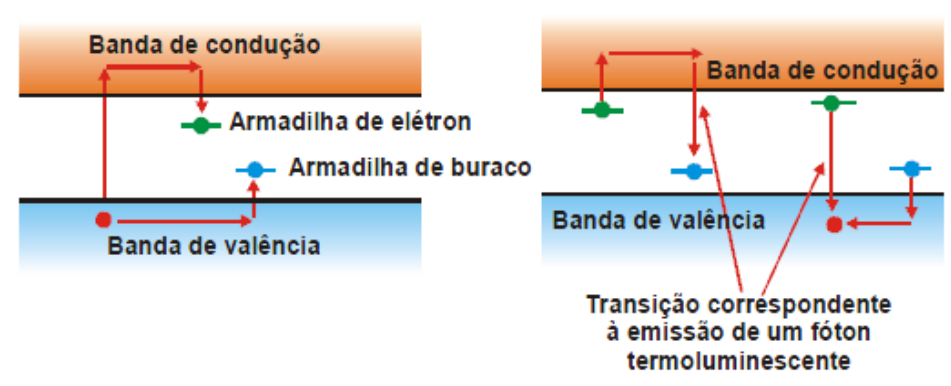

Figura 5 - Processo termoluminescente (Tauhata, Salati, Prinzio, et al., 2003)

A sensibilidade da termoluminescência de um material está diretamente relacionada com a quantidade de luz liberada, quando aquecido, por unidade de dose de radiação absorvida.

\subsubsection{Dosimetria com TLD}

O procedimento de uso dos TLDs consiste em realizar primeiramente o tratamento térmico dos dosímetros. Esse tratamento térmico visa restabelecer as condições do fósforo, esvaziando e estabilizando as armadilhas do material (Dewerd, 1986), eliminando assim sinais residuais da termoluminescência do cristal e restaurando a sua sensibilidade.

Para que o procedimento de uso dos TLDs seja reprodutível é indispensável a utilização de fornos para o tratamento térmico, que consigam manter temperaturas prédefinidas em intervalos precisos de tempo. As condições do tratamento térmico variam de acordo com o cristal utilizado. 
Após a irradiação dos TLDs, são realizadas as medições com uma leitora de TLD, que aquece os TLDs de forma controlada e mede a intensidade de luz emitida. A intensidade luminosa é fornecida pela curva de emissão termoluminescente (Figura 6), que pode apresentar vários picos. Entre esses picos, aqueles que apresentam boa sensibilidade e estabilidade são selecionados para a realização das medidas dosimétricas, podendo ser definidas regiões na qual se encontram esses picos dosimétricos. Essas regiões são denominadas de Regiões de Interesse (ROI - Region on Interest).

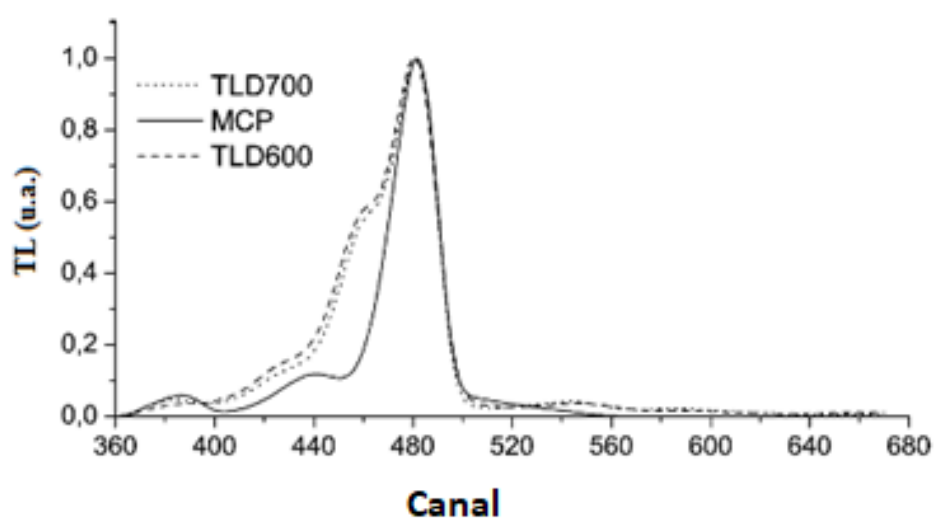

Figura 6 - Exemplo de curvas termoluminescentes de tipos diferentes de TLDs (Triolo et al., 2007)

A grande vantagem do uso dos TLDs é que eles podem ser reutilizados e, para isso, basta realizar o tratamento térmico antes da próxima irradiação. Assim, a utilização dos TLDs compreende um ciclo: tratamento térmico, irradiação e leitura.

Porém, deve-se ficar atento com a perda de sinal do TLD após a irradiação. Alguns tipos de TLDs apresentam uma forte perda de sinal nas primeiras horas após a irradiação, sendo adequado realizar a leitura após este período inicial.

Altas temperaturas e exposição à luz também podem levar à perda de sinal do TLD. Desta maneira, é adequado guardar e transportar os TLDs em um ambiente seguro contra o excesso de calor e de luz.

\subsection{O Método de Monte Carlo}

O método de Monte Carlo vem se mostrando, ao longo dos últimos tempos, uma ótima ferramenta para a solução de problemas na área de dosimetria, e grande parte dos avanços observados está relacionada com os avanços no poder de processamento dos computadores. A Figura 7 apresenta o número de artigos publicados, quando realizada a pesquisa no ScienceDirect (Sciencedirect, 2018) sobre o método Monte Carlo. 


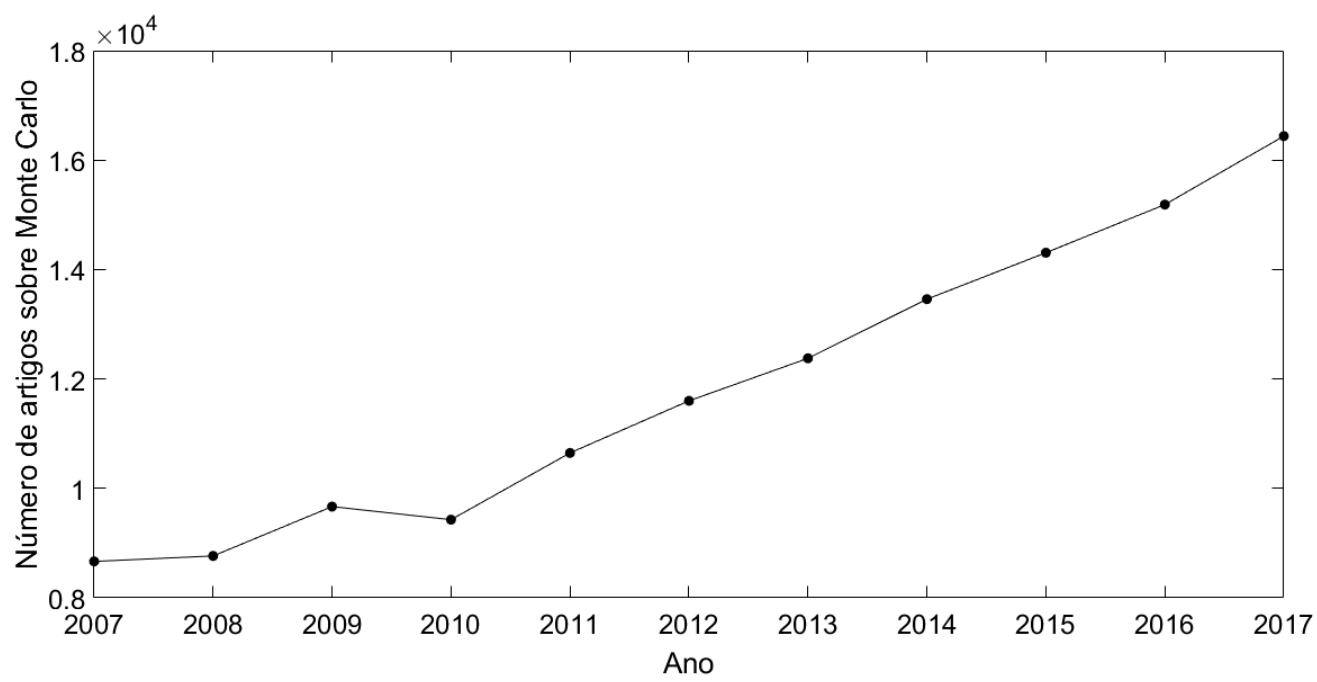

Figura 7 - Número de artigos publicados utilizando o método Monte Carlo no ScienceDirect (Sciencedirect, 2018)

O método de Monte Carlo baseia-se na solução numérica (estocástica) de problemas que modelam as interações das radiações com objetos, a partir de funções de probabilidades para as diferentes interações possíveis (Bielajew, 2016). O método Monte Carlo é comumente utilizado em diversos segmentos da ciência e da engenharia, que podem ser representados por processos estocásticos. Entre estes, se destaca seu uso em física médica, em que é "uma ferramenta fundamental para cálculos de dose absorvida e outras grandezas de interesse relacionadas ao tratamento do câncer por radiação" (Yoriyaz, 2009).

O uso do método de Monte Carlo está atrelado à possibilidade do fenômeno físico a ser estudado poder ser descrito por meio de funções de probabilidade (FDP). A partir das FDPs, os processos são simulados em sequência e seu processo de amostragem é realizado a partir de números aleatórios.

Apesar de haver várias áreas para o uso do método de Monte Carlo, como ciências sociais, controle de tráfico, crescimento populacional, finanças, entre outras, seu uso neste trabalho se restringe ao transporte de radiação ionizante pela matéria. Nesse caso são geradas partículas numa certa região e essas partículas são acompanhadas através de todo o sistema geométrico. As partículas geradas interagem com a matéria, e sempre que isso ocorre, novos números aleatórios são gerados para avaliar a energia depositada, as novas partículas geradas e as direções e energias que as partículas seguirão.

A precisão dos cálculos realizados pelo método de Monte Carlo está relacionada com o número de interações ocorridas na região de interesse, pela qualidade da modelagem e pela seção de choque utilizada. Portanto, é importante avaliar o número de histórias que o método realizará para obter incertezas estatísticas aceitáveis para o fenômeno estudado. 


\section{MATERIAIS E MÉTODOS}

Nesta seção serão apresentados os materiais e metodologias utilizadas durante a elaboração deste trabalho.

\subsection{Dosímetros Termoluminescentes (TLDs)}

Neste trabalho foram utilizados dosímetros termoluminescentes (TLDs) da Thermofisher® no formato de discos com 3,0 mm de diâmetro e 0,38 $\mathrm{mm}$ de espessura, conforme mostrado na Figura 8. Foram utilizados TLDs de fluoreto de Lítio dopados com Magnésio e Titânio (LiF:Mg;Ti) de dois tipos diferentes, com diferença na dopagem isotópica de $\mathrm{Li}$ e que, segundo a fabricante (Thermofisher, 2018), podem ser utilizados com dose de 10 pGy até 10 Gy com uma taxa de perda de sinal de $5 \%$ ao ano a uma temperatura de $20^{\circ} \mathrm{C}$.

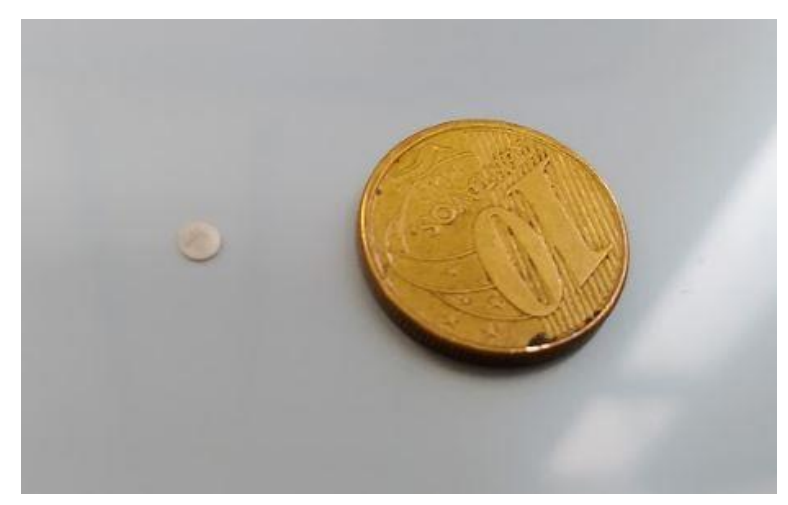

Figura 8 - Comparação do tamanho do TLD chip e uma moeda de dez centavos

Os TLDs de LiF apresentam duas regiões de interesse (ROIs) principais: uma iniciando-se em torno dos $195^{\circ} \mathrm{C}$ (que é comumente utilizada como pico dosimétrico) (Pradhan, 1981) e outro iniciando-se em torno dos $250^{\circ} \mathrm{C}$, sendo que estas regiões são formadas por vários picos dosimétricos. A Figura 9 apresenta esses ROIs do TLD $100 \mathrm{e}$ TLD 700 irradiados em campos misto de nêutrons e gamas. Vale ressaltar que na Figura 9, a temperatura mostrada é a temperatura da bandeja onde está posicionado o TLD, e não a real temperatura do TLD. Por isso, pode haver algumas discrepâncias entre as temperaturas em que ocorrem as regiões de interesse. 

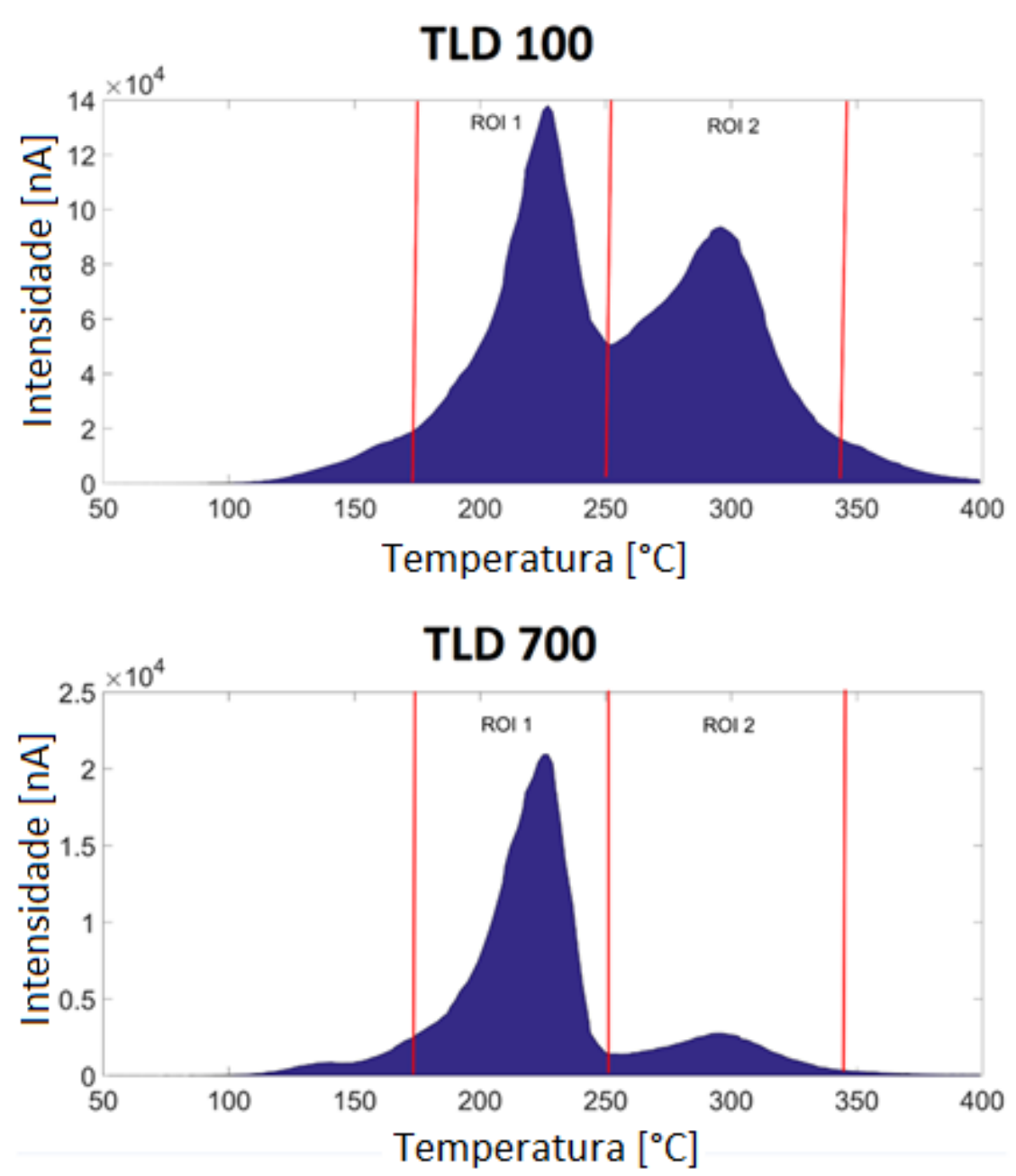

Figura 9 - Regiões de interesse do TLD 100 e TLD 700

Neste trabalho foram utilizados dois tipos de TLDs de LiF:Mg,Ti, o TLD 100 e o TLD 700. A diferença entre esses dois tipos de TLD está na proporção entre os isótopos de Li em suas composições. O TLD 100 apresenta a abundância isotópica natural do Li (7,5\% de ${ }^{6} \mathrm{Li}$ e $92,5 \%$ de $\left.{ }^{7} \mathrm{Li}\right)$ enquanto o TLD 700 é enriquecido com ${ }^{7} \mathrm{Li}(99,93 \%)$. O ${ }^{7} \mathrm{Li}$ tem baixa sensibilidade a nêutrons térmicos e o ${ }^{6} \mathrm{Li}$ apresenta alta sensibilidade a nêutrons térmicos, conforme mostrado na Figura 10. Portanto, o TLD 100 apresenta uma sensibilidade muito maior a nêutrons térmicos quando comparado ao TLD 700. 


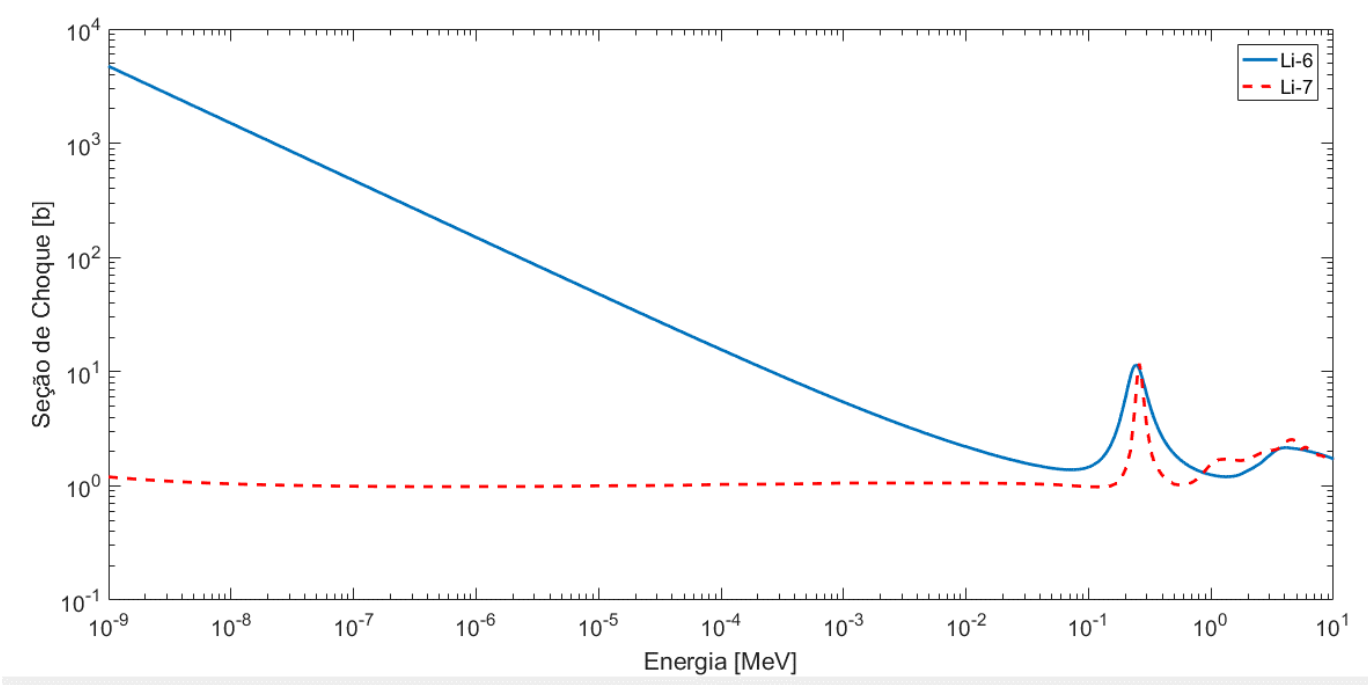

Figura 10 - Seção de choque total para nêutrons do ${ }^{6} \mathrm{Li}$ (azul) e ${ }^{7} \mathrm{Li}$ (vermelho) (Korea Atomic Energy Research Institute, 2000)

Nas irradiações em campo misto, o perfil da resposta TL dos dois tipos de TLD são bem diferentes, conforme apresentado na Figura 9. O ROI 1 do TLD 100 é superior ao ROI 1 do TLD 700 em virtude dessa região responder também para a nêutrons no TLD 100. O ROI 2 é uma região que aparece principalmente no TLD 100 e está associada à presença de nêutrons no campo. Sua aparição ocorre em virtude da interação com a rede cristalina do TLD.

O par TLD 100 e TLD 700 apresenta então uma resposta distinta para nêutrons e para gamas, e dessa forma possibilita seu uso para a dosimetria de campos mistos. Grande parte do esforço científico atualmente visa a criação de uma metodologia eficiente, utilizando o par de TLDs para realizar a dosimetria de campos mistos de gamas e nêutrons.

\subsubsection{Ciclo de uso do TLD}

Para a utilização do TLD, é necessário realizar o tratamento térmico antes da irradiação e posteriormente realizar sua leitura. Neste trabalho foi adotado um ciclo de uso do TLD de três dias, em que no primeiro dia era realizado o tratamento térmico, no segundo dia era realizada a irradiação e no terceiro dia, a leitura. Essa metodologia foi empregada, pois os TLDs de LiF têm uma alta perda de sinal nas primeiras oito horas, portanto, ao se esperar um dia para a realização das leituras, já teria passado esse período mais crítico de perda de sinal, sendo que esta perda de sinal não acarreta na perda de informação.

Para a etapa de tratamento térmico, foram utilizadas duas muflas (Figura 11) configuradas para as temperaturas de tratamento térmico especificados pelo fabricante dos TLDs (Harshaw). No caso dos TLDs de LiF:Mg,Ti a recomendação de tratamento 
térmico é de $1 \mathrm{~h}$ a $400^{\circ} \mathrm{C}$ e posteriormente 2 horas a $100^{\circ} \mathrm{C}$. Após o tratamento, o TLD era deixado em repouso para resfriar até a temperatura ambiente.
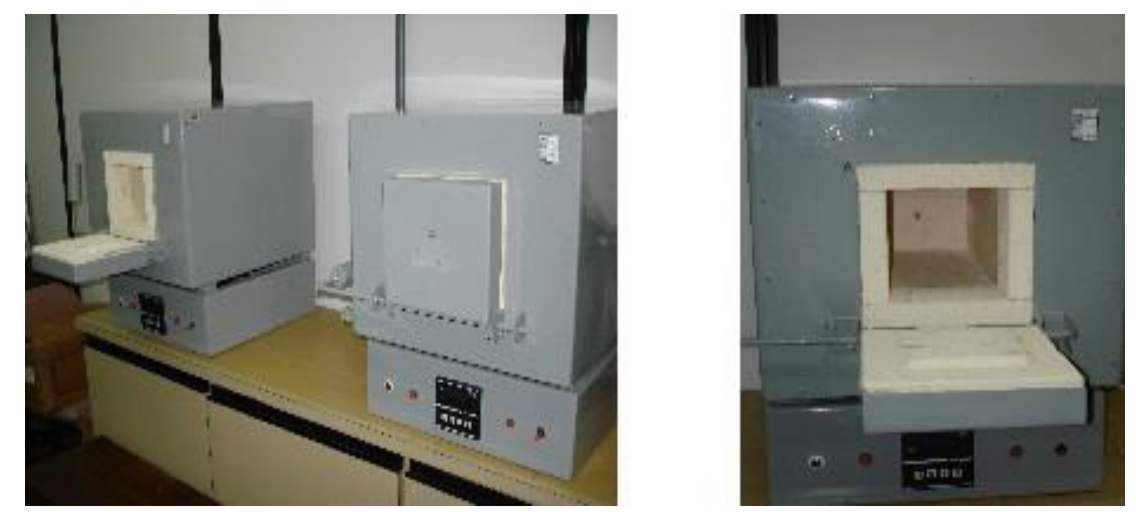

Figura 11 - Muflas utilizadas para o tratamento térmico dos TLDs

Para a leitura dos TLDs, é necessária a utilização de uma leitora de TLD. Neste trabalho, foi utilizado a leitora de TLD modelo Harshaw 3500, mostrada na Figura 12. Seu mecanismo de funcionamento consiste em uma prancheta para o aquecimento do TLD, o que libera os elétrons presos nas armadilhas dos TLDs, e estes elétrons, ao retornarem a banda de valência, emitem fótons. Estes fótons emitidos incidem sobre uma fotomultiplicadora que gera um sinal elétrico, que é enviado para o sistema de aquisição e análise que, no nosso caso, era o programa WinRems (Thermo Electron Corporation, 2005) da própria fabricante dos TLDs. Neste programa, é possível visualizar a curva termoluminescente do TLD, que apresenta o sinal produzido após a amplificação do sinal pela fotomultiplicadora, em função da temperatura na prancheta de aquecimento.

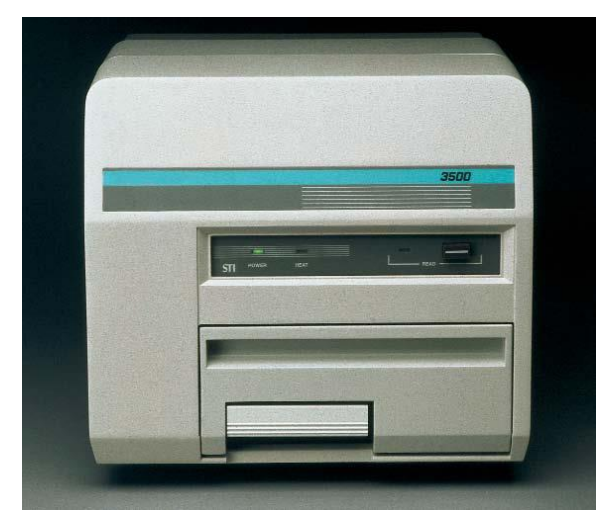

Figura 12 - Leitora de TLD modelo Harshaw 3500 (Thermo Electron Corporation, 2005)

Para o funcionamento dessa leitora, é necessário definir certos parâmetros de aquecimento e leitura. Esse trabalho utilizou os mesmos parâmetros empregados em 
trabalhos anteriores do grupo de Física Médica do CEN/IPEN (Cavalieri, 2013; Paiva, 2016) e que estão apresentados na Tabela 1.

Tabela 1 - Parâmetros de operação da leitora de TLD Harshaw 3500

\begin{tabular}{lc}
\hline Parâmetros & Valor \\
Temperatura Inicial & $60^{\circ} \mathrm{C}$ \\
Temperatura Final & $400^{\circ} \mathrm{C}$ \\
Taxa de Aquecimento & $10^{\circ} \mathrm{C} / \mathrm{s}$ \\
Tempo de Leitura & $45 \mathrm{~s}$ \\
\hline
\end{tabular}

A análise das respostas dos TLDs é realizada a partir da análise do total de cargas acumuladas em cada uma das regiões de interesse (ROIs) do TLD.

\subsection{Irradiações}

Neste trabalho, os TLDs foram utilizados em duas instalações distintas como fontes de irradiação: um irradiador de polietileno com uma fonte de AmBe e o reator nuclear IPEN/MB-01.

\subsubsection{Irradiador com a fonte de AmBe}

O grupo de Física Médica tem acesso a algumas fontes de AmBe de diferentes atividades. Neste trabalho, foi utilizada uma fonte de $\mathrm{AmBe}$ de $2 \mathrm{Ci}$ de atividade dentro de um irradiador de polietileno. Essa fonte possui dimensões de 2,2 cm de altura e 2,24 cm de diâmetro.

A emissão de nêutrons é proveniente da reação ${ }^{9} \mathrm{Be}(\alpha, n){ }^{12} \mathrm{C}$ que é gerada pela partícula alfa do decaimento do ${ }^{241} \mathrm{Am}\left(T_{1 / 2}=432,6\right.$ anos $)$ e, segundo a literatura, apresenta um fluxo por atividade entre 2,0 e 2,4 . $10^{6}$ nêutrons por segundo por Curie $(\mathrm{Ci})$ de atividade da fonte (Nuclear Regulatory Commision, 2010). Já a emissão gama é produzida pela desexcitação do ${ }^{12} \mathrm{C}$; esse gama é produzido com uma energia de $4,4 \mathrm{MeV}$ (Vega-Carrillo et al., 2002).

Para os cálculos de dose e fluxo, foram utilizadas quatro referências para o espectro de emissão de nêutron da fonte de AmBe: ISO (International Organization for Standardization, 1998), Thompson (Thompson e Taylor, 1965), Marsh (Marsh et al., 
1995) e IAEA (International Atomic Energy Agency, 2001). A Figura 13 apresenta os quatro espectros de emissão de nêutron utilizados nas simulações.

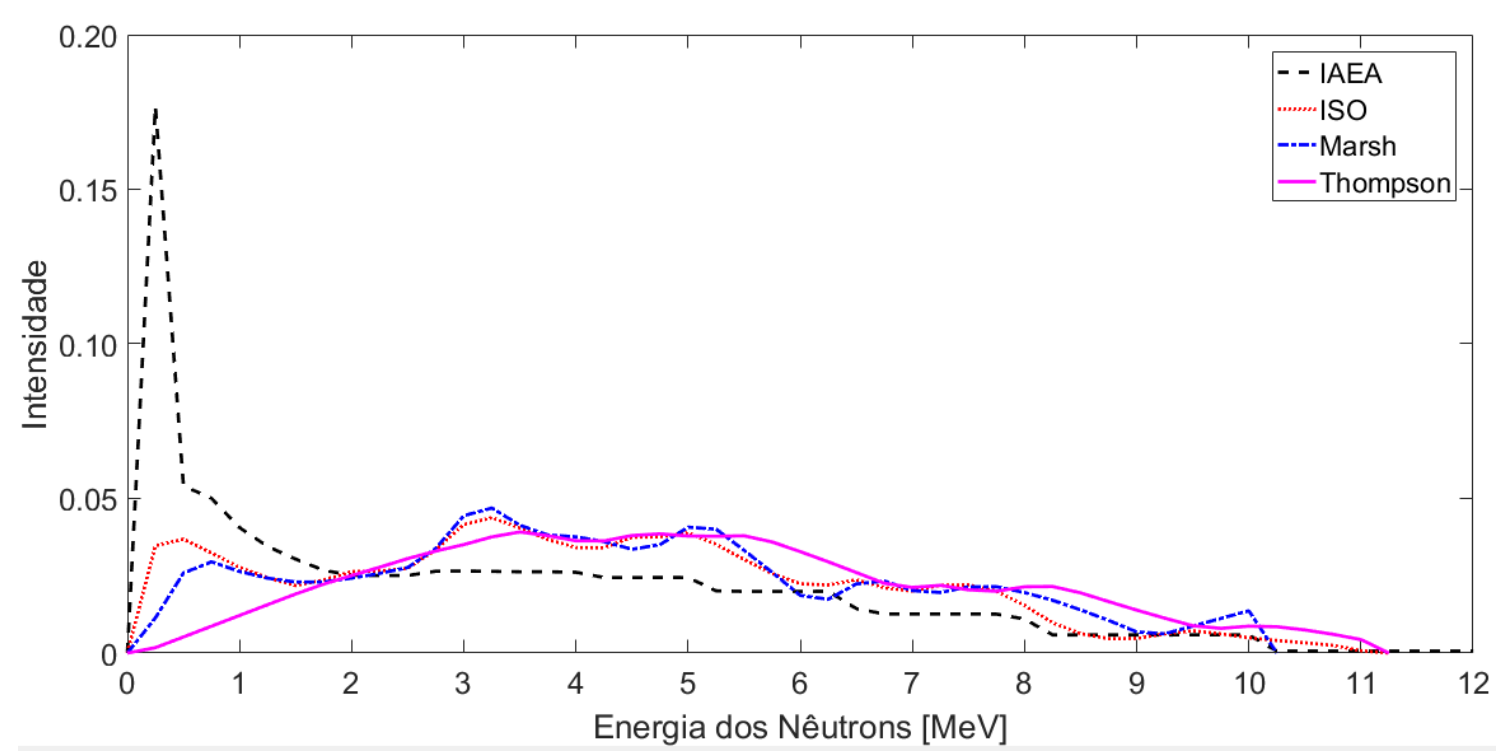

Figura 13 - Comparação dos diferentes espectros de nêutrons para a fonte de ${ }^{241} \mathrm{AmBe}$ apresentados na literatura: (Thompson e Taylor, 1965; Marsh et al., 1995; International Organization for Standardization, 1998; International Atomic Energy Agency, 2001)

As energias médias de emissão de nêutron de cada espectro são 3,25; 3,99; 4,20 e 5,21 MeV, respectivamente para o IAEA, ISO, Marsh e Thompson.

Como esse trabalho visa o estudo dos TLDs que apresentam maior sensibilidade para nêutrons térmicos, é necessário reduzir a energia dos nêutrons rápidos obtidos pela fonte de AmBe, num processo conhecido como termalização. Para isso, foi desenvolvido um irradiador de polietileno para realizar a termalização desses nêutrons.

O polietileno é um excelente material para diminuir a energia dos nêutrons rápidos por apresentar uma alta concentração de átomos de hidrogênio. Como já citado na seção 3.3.2, o nêutron pode perder em média metade de sua energia numa colisão elástica com um átomo de hidrogênio.

Este irradiador é formado por duas peças de polietileno que são agrupadas após a inserção da fonte de AmBe. A configuração de operação do irradiador possui o formato cilíndrico de $21 \mathrm{~cm}$ de altura por 13,5 $\mathrm{cm}$ de diâmetro. A cavidade para posicionamento da fonte encontra-se no centro geométrico do irradiador e possui $5,2 \mathrm{~cm}$ de altura por 2,3 $\mathrm{cm}$ de diâmetro. 

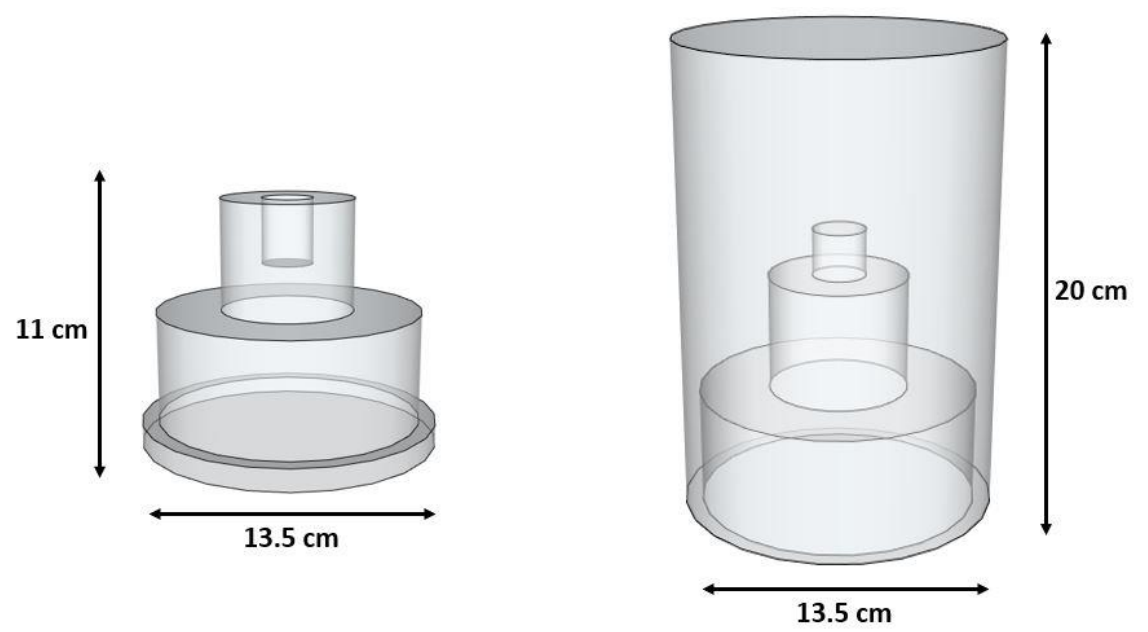

Figura 14 - Imagem esquemática das peças que compõe o irradiador de polietileno

Foi realizado o estudo para obter o poder de moderação do irradiador. Esse estudo foi feito a partir de simulações das frações de nêutrons térmicos na meia altura da superfície lateral do irradiador, quando tinha o material termalizador (polietileno) e no caso da ausência do material termalizador, mas à mesma distância da fonte.

Para analisar a quantidade de nêutrons de diferentes energias na meia altura da superfície lateral do irradiador, também foi realizado um estudo através de simulações e de experimentos com as folhas de ativação de índio nuas e com cobertura de cádmio. Nesse estudo, foi obtida a razão entre a atividade de saturação da folha de índio nua e com a cobertura de cádmio. Esta razão fornece uma relação entre a quantidade de nêutrons com uma energia maior que a energia de corte do cádmio e o total de nêutrons. Também foi realizado um estudo do perfil angular de nêutrons ao longo da circunferência a meia altura do irradiador, bem como do perfil vertical axial de nêutrons.

No estudo do perfil angular, foram realizadas irradiações das folhas de índio nuas em seis diferentes posições ao redor do irradiador. Esse estudo tinha como objetivo verificar a simetria do perfil de nêutrons ao redor da superfície lateral do irradiador.

No estudo do perfil vertical axial, foram realizadas irradiações das folhas de índio nuas em cinco diferentes alturas do irradiador, conforme apresentado na Figura 15. O objetivo desse estudo era identificar as diferenças do perfil de nêutrons quando se alterava a altura de irradiação. 


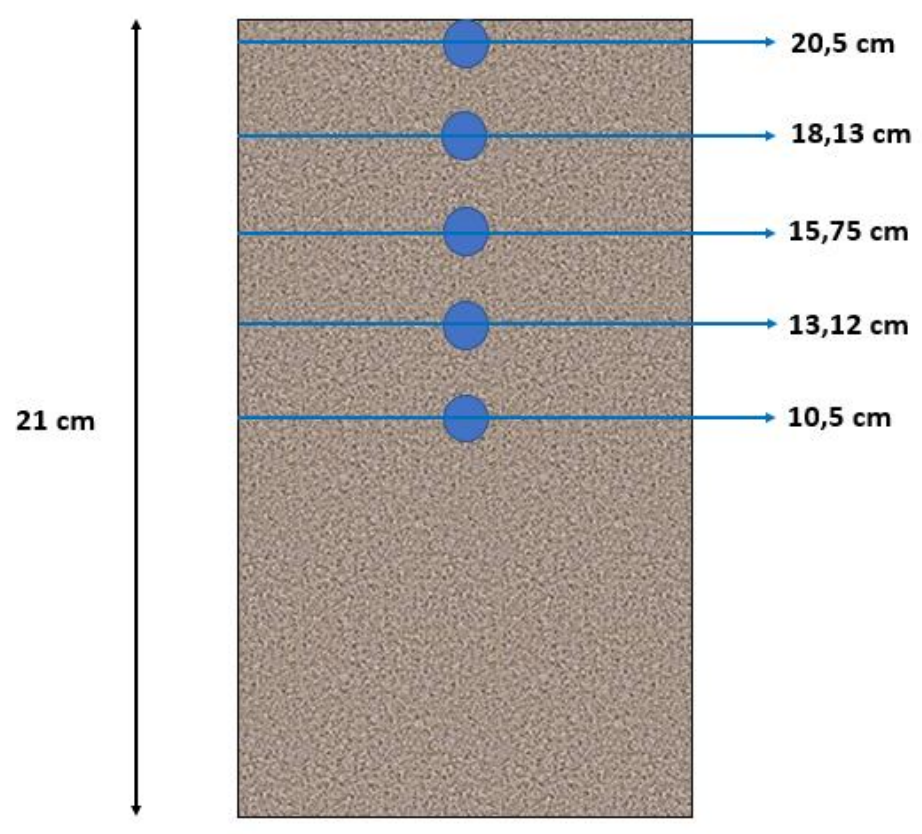

Figura 15 - Posicionamento das folhas de índio para obter o perfil axial de nêutrons

Todos os resultados dos experimentos com as folhas de índio foram comparados com os dados obtidos através das simulações com o MCNP5.

Posteriormente, foram realizados experimentos com os TLDs nesse irradiador. Primeiramente, foi realizado um estudo das respostas termoluminescentes dos TLDs quando irradiados em diferentes alturas ao longo da lateral do irradiador. Os TLDs foram colocados nas alturas de 10,$5 ; 15,75$ e $20,5 \mathrm{~cm}$ e foram irradiados durante quatorze dias. Esses experimentos tiveram como objetivo verificar a dispersão das respostas dos diferentes TLDs, a reprodutibilidade e a resposta dos TLDs em pequenas variações do espectro. Também foi realizado um estudo de linearidade das respostas dos TLDs em campos mistos de nêutrons e gamas. Este estudo foi realizado a partir de irradiações com diferentes números de dias de exposição.

\subsubsection{Reator Nuclear IPEN/MB-01}

O reator nuclear IPEN/MB-01 é um reator genuinamente brasileiro, construído em parceria entre o IPEN-CNEN/SP e o CTMSP e está em operação desde 1988. O reator IPEN/MB-01 é uma instalação nuclear que permite a simulação de características nucleares de um reator de grande porte em escala reduzida, sem que haja a necessidade de construir um complexo sistema de remoção de calor. Esse tipo de reator é conhecido mundialmente como reator de potência zero ou Unidade Crítica, sendo neste caso, projetado para operar a uma potência máxima de $100 \mathrm{~W}$ (Bitelli e Giada, 2000). 
O núcleo do reator IPEN/MB-01 permite a montagem de diferentes arranjos críticos, sendo que a placa matriz que sustenta o núcleo do reator possui 900 furos espaçados $15 \mathrm{~mm}$ entre si, em um arranjo quadrado de 30x30 furos (Ipen, 2017).

Os experimentos realizados neste trabalho foram para dois diferentes arranjos do núcleo: cilíndrico com "flux trap" (uma região com apenas água e sem a presença de varetas combustíveis, formando uma região de maior incidência de nêutrons térmicos) e retangular, em um arranjo de 26x28 varetas combustíveis, conforme apresentados na Figura 16.

a)

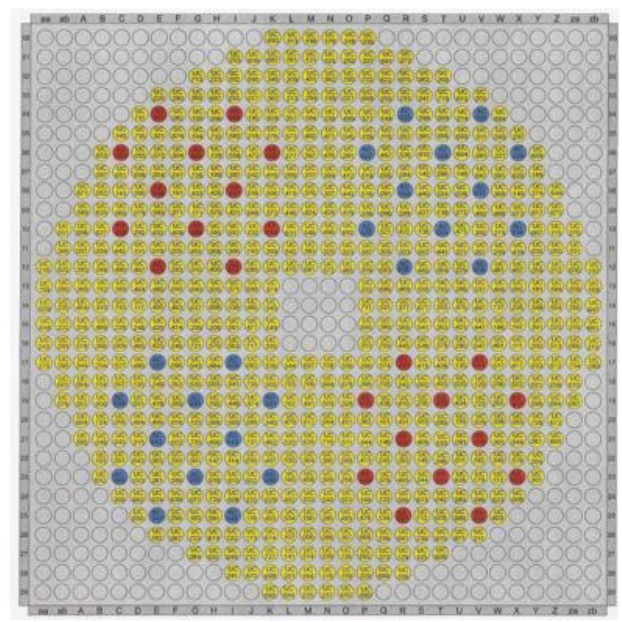

b)

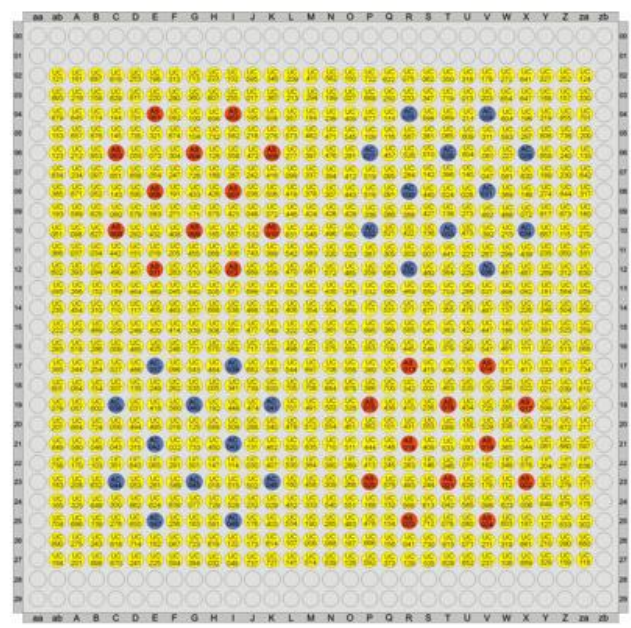

Figura 16 - Arranjos do núcleo do reator IPEN/MB-01 utilizados nesse trabalho: a) cilíndrico com "flux trap" (Silva, 2014); b) retangular 26x28 (Gonçalves, 2008)

Na Figura 16, a região central do núcleo do reator cilíndrico corresponde ao "flux trap". Os pontos em amarelo correspondem às varetas combustíveis, os em vermelho, às barras de segurança e os em azul, às barras de controle.

O arranjo cilíndrico com "flux trap" foi utilizado nos experimentos para estudo dos TLDs e na proposição da metodologia de uso desses TLDs. As irradiações no arranjo retangular foram utilizadas para a validação da metodologia de uso dos TLDs.

Para cada arranjo de núcleo os TLDs foram irradiados em dois diferentes planos axiais ao longo do núcleo. Foi realizada uma irradiação no plano axial na posição central (canal 14-15) do núcleo e em um plano axial na posição lateral (canal 2-3). Essas posições de irradiação estão apresentadas na Figura 17. 


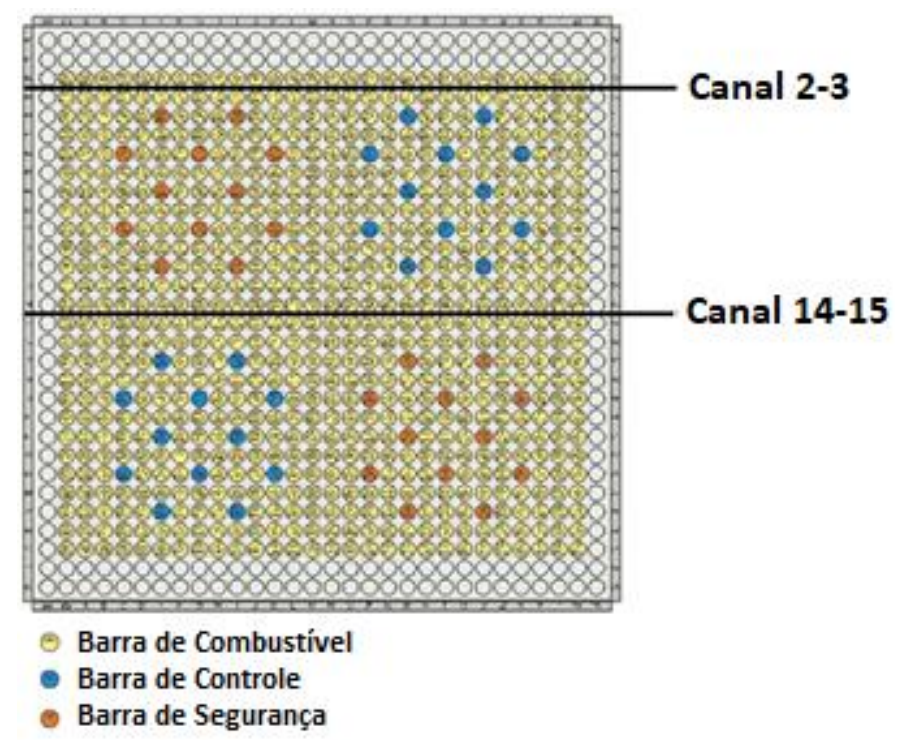

Figura 17 - Canais de irradiação (planos axiais) do reator IPEN/MB-01. Posição Central - Canal 14-15 e posição lateral - Canal 2-3

A altura ativa do núcleo do reator é $546 \mathrm{~mm}$, sendo que, a base do núcleo se encontra na altura de $0 \mathrm{~cm}$ (adaptado como referência neste trabalho). Em cada plano existem seis diferentes posições de irradiação para os TLDs. Estas posições estão ao longo de duas alturas diferentes (uma na altura média do combustível ativo, $273 \mathrm{~mm}$, e outra na altura de $455 \mathrm{~mm}$ ) e em três diferentes posicionamentos horizontais (radiais) nessas alturas (0, -9 e $-18 \mathrm{~cm}$, sendo que o $0 \mathrm{~cm}$ é a posição radial central do núcleo). Essas posições e a placa de posicionamento dos TLDs estão representadas na Figura 18.

a)

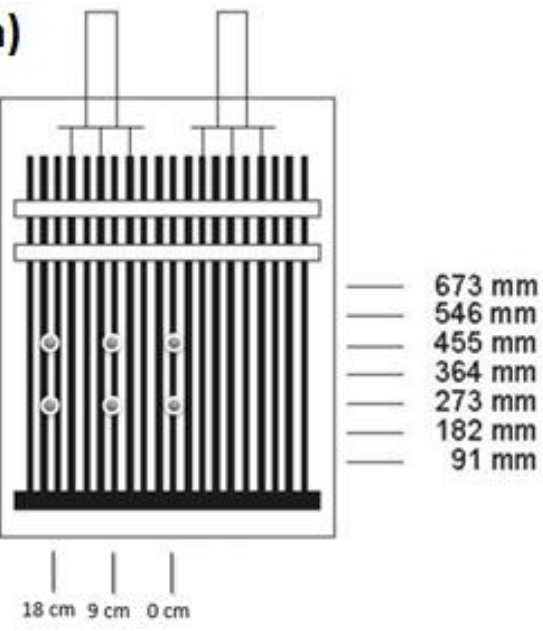

b)

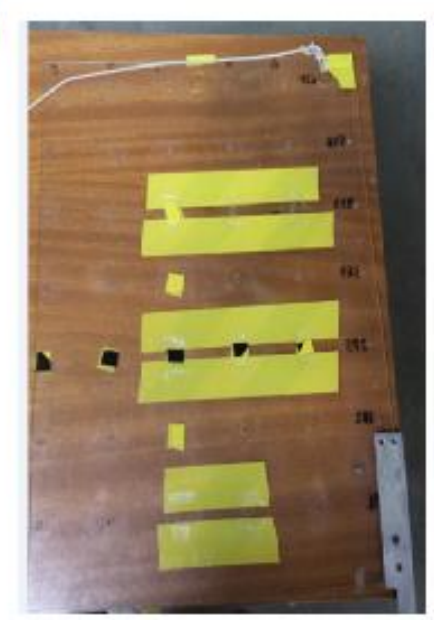

Figura 18 - a) Posições de irradiação dos TLDs no reator IPEN/MB-01 (vista axial do núcleo do reator) (Gonçalves, 2008); b) placa de posicionamento dos TLDs para a irradiação. 
Cada irradiação ocorreu durante uma hora com uma potência de operação térmica de $1 \mathrm{~W}$. Essa configuração de irradiação foi escolhida para possibilitar a remoção dos TLDs logo após o desligamento do reator, e assim reduzir o tempo em que os TLDs ficariam expostos à radiação de fundo.

\subsection{Técnica de Análise por Ativação}

Neste trabalho foram utilizadas folhas de índio para realizar o estudo das intensidades de nêutrons nas irradiações com o irradiador de polietileno, e folhas de ouro para a obtenção dos fluxos no interior do núcleo do reator IPEN/MB-01 - dados obtidos no trabalho de Gonçalves (2008). Como esta metodologia já é bem conhecida pelo grupo de BNCT do IPEN, tanto as folhas de índio como as folhas de ouro foram utilizadas para validar as simulações com o MCNP5.

Foram realizados experimentos tanto com as folhas nuas quanto com folhas com cobertura de Cádmio. Após as irradiações, as folhas foram analisadas através de espectroscopia gama, utilizando um detector de estado sólido de Germânio Hiperpuro (HPGe), o qual fornecia o espectro do material em análise. Pôde-se então obter a taxa de contagem (desintegrações por segundo) da radiação liberada pelos diferentes fotopicos.

Através do número de contagens obtidas no detector, é possível saber a atividade da folha ao término da irradiação, $A_{0}$, e a atividade de saturação, $A^{\infty}$, que é atividade máxima do detector se ele fosse irradiado por um tempo infinito, e esta atividade de saturação é igual à taxa de reação que a folha de ativação estava exposta (Zamboni, 2007). A curva de decaimento da atividade da folha de ativação pode ser vista na Figura 19.

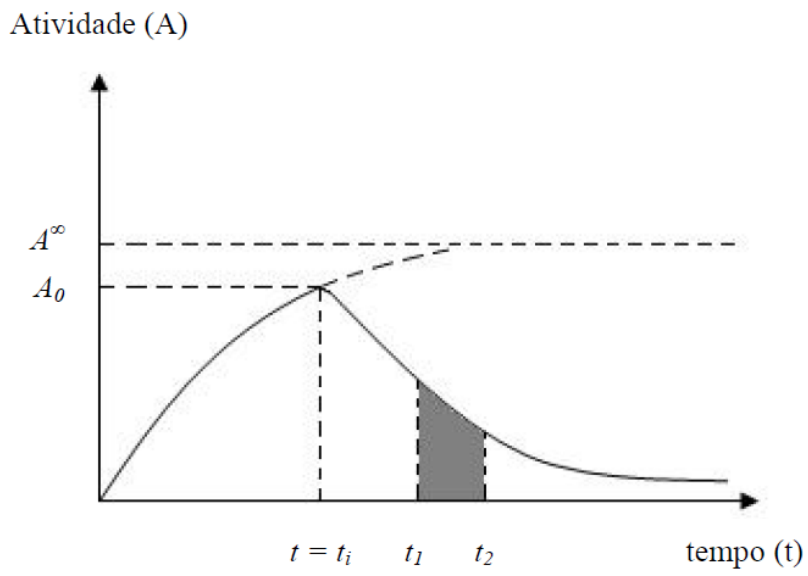

Figura 19 - Atividade da folha de ativação em função do tempo de irradiação $\left(t_{i}\right)$ (Gonçalves, 2008) 
A partir das contagens obtidas no detector pode-se obter a atividade de saturação da folha pela Eq. 4-1 abaixo:

$$
A^{\infty}=\frac{\lambda(C-B G) e^{\lambda t_{2}}}{\varepsilon . I\left(1-e^{-\lambda t_{i}}\right)\left(1-e^{-\lambda\left(t_{2}-t_{1}\right)}\right)}
$$

onde:

$\lambda$ é a constante de decaimento do radioisótopo formado;

$C$ é a contagem do fotopico;

$B G$ ("Background") é a radiação de fundo;

$t_{e}$ é o tempo de espera entre o término da irradiação e a contagem;

$t$ é o tempo de irradiação;

$t_{c}$ é o tempo de contagem;

I é a probabilidade de emissão gama do isótopo formado

$\varepsilon$ é a eficiência total de contagem do fotopico.

Nos experimentos no irradiador de polietileno com as folhas de índio, tanto nuas como com cobertura de cádmio, só a obtenção das atividades de saturação das folhas foi importante para o trabalho.

Para o caso das irradiações no núcleo do reator IPEN/MB-01, tinha-se o interesse de obter o fluxo de nêutrons térmicos e epitérmicos. Para isso, no trabalho de Gonçalves (2008), foi utilizado um par de folhas de ouro (uma nua e outra coberta por cádmio). A atividade de saturação induzida na folha nua é devido aos nêutrons térmicos e epitérmicos. Já na folha com cobertura de cádmio, a atividade é devido aos nêutrons epitérmicos. Porém, como o cádmio não é um filtro ideal, o valor da atividade de saturação das folhas com cádmio deve ser corrigido por um fator que é conhecido como Fator de Cádmio, $F_{C d}$, cujo valor é tabelado na literatura (Zamboni, 2007).

Outro fator importante é a $R a z a ̃ o$ de Cádmio, $R_{C d}$, que é dada pela razão da atividade de saturação da folha nua pela atividade de saturação da folha com cádmio.

A atividade de saturação é dada também por:

$$
A^{\infty}=\Sigma . V \cdot \phi
$$

onde:

$\Sigma$ é a seção de choque macroscópica média de ativação; 
$V$ é o volume do detector;

$\phi$ é o fluxo de nêutrons.

O fluxo de nêutrons térmicos é dado pela Eq. 4-3.

$$
\phi_{t h}=\frac{A_{n u a}^{\infty}\left(1-\frac{F_{C d}}{R_{C d}}\right) \cdot P_{a}}{N_{a} \cdot m \cdot \sigma_{a t v} \cdot K_{t h}}
$$

onde:

$P_{a}$ é o peso atômico do núcleo alvo;

$N_{a}$ é o número de Avogadro;

$m$ é a massa do detector de ativação;

$\sigma_{a t v}$ é a seção de choque microscópica média de ativação.

$K_{t h}$ é o fator de perturbação térmico, para o caso das folhas de ouro infinitamente diluídas seu valor é 1 .

Enquanto o fluxo de nêutrons epitérmicos é dado pela Eq. 4-4.

$$
\phi_{\text {epi }}=\frac{A_{C d}^{\infty}}{N_{T} I_{R}^{\infty}} \cdot \ln \frac{E_{2}}{E_{C d}}
$$

Eq. $4-4$

onde:

$I_{R}^{\infty}$ é conhecida como integral de ressonância e é utilizada na literatura entre os limites $E_{c d}$ e $E_{2}$, que se referem à energia de corte do cádmio e ao limiar da região intermediária e a região rápida do espectro neutrônico;

$N_{T}$ é o número de núcleos alvo.

\subsection{Código de Monte Carlo - MCNP5}

O MCNP é um código de transporte de radiação que utiliza o método de Monte Carlo para estimar as respostas dos sistemas simulados. O método de Monte Carlo baseiase na solução numérica (estocástica) de problemas que modelam as interações das 
radiações com objetos a partir de funções de probabilidades para as diferentes interações possíveis. O código MCNP fornece a solução de sistemas macroscópicos através de simulações das interações microscópicas (Bielajew, 2016).

Neste trabalho foi utilizado o MCNP5 (X-5 Monte Carlo Team, 2005) nas simulações. Este código foi desenvolvido pelo Los Alamos National Laboratory (LANL), e pode ser usado para o transporte de nêutrons, fótons, elétrons individualmente ou de modo acoplado (Kirk, 2010). Quanto à geometria, esse código possui uma vasta flexibilidade de modelagem geométrica, sendo possível a criação de geometrias a partir de superfícies e/ou por estruturas repetidas.

O MCNP5 também foi utilizado para o cálculo de fluxos e doses depositadas devido às diferentes componentes do campo de irradiação. Para a realização desses cálculos, o MCNP5 utiliza estimadores (tallies) que especificam as grandezas a serem obtidas destes cálculos, de acordo com as opções disponíveis ao usuário do código.

\subsubsection{Estimadores utilizados}

Para realizar o cálculo de fluxo ou fluência para nêutrons e/ou gamas, foi utilizado o estimador F4. Este estimador considera uma partícula com peso estatístico $W$ e energia $E$ que realiza um trajeto, $T$ (traço), em um volume específico, $V$. Este segmento realiza uma contribuição de $W T / V$ para a fluência na célula. Tecnicamente, se $\Phi(r, E, \Omega)$ é a fluência em função da posição da energia e da distribuição angular, o uso do estimador F4 irá definir o seguinte cálculo (Shultis e Faw, 2011):

$$
F 4=\frac{1}{V} \int d V \int d E \int d \vec{\Omega} . \phi(\vec{r}, E, \vec{\Omega}) \quad \text { Eq. } 4-5
$$

onde $V$ é o volume da célula, $E$ é a energia da partícula, $\Omega$ é a direção angular e $\phi$ é a fluência.

A resposta desse estimador é dada em partículas por $\mathrm{cm}^{2}$ por partículas geradas na fonte.

Uma variação do estimador F4 é o estimador *F4, que calcula a fluência energética por $\mathrm{cm}^{2}$ por partícula gerada na fonte:

$$
* F 4=\frac{1}{V} \int d V \int d E \int d \vec{\Omega} \cdot E \cdot \phi(\vec{r}, E, \vec{\Omega}) \quad E q .4-6
$$


Foram utilizados outros dois cartões para modificar a resposta dos estimadores anteriores para fornecer a dose depositada devido aos nêutrons e aos gamas nos TLDs.

Para a dose, devido aos nêutrons nas irradiações no reator IPEN/MB-01, foi utilizado o estimador F4 juntamente com a opção FM. Esta opção permite a multiplicação de parâmetros para modificar a resposta do estimador F4, de acordo com as reações de interesse. Essa opção FM é escrita da seguinte maneira:

$$
F M=C m R_{1} R_{2}
$$

Eq. $4-7$

onde $C$ é uma constante multiplicativa que, para o caso de cálculo de dose depositada, recebe o valor da razão entre os valores da densidade atômica $\left(\rho_{a}\right)$ e a densidade por massa $\left(\rho_{g}\right)$ do material; $m$ é o número identificador do material e $R$ são as reações de interesse.

Portanto, para o cálculo de dose depositada devido aos nêutrons, foram utilizadas as reações 1 e -4 (nomenclatura do MCNP para designar as reações) para os valores de $R$, que consistem da secção de choque total e da média de energia transferida por colisão (MeV/colisão), respectivamente. O material utilizado foi a composição dos TLDs 100 e 700 e a constante multiplicativa é a divisão da densidade atômica pela densidade em massa.

Para a dose gama nos LiFs nas irradiações no reator IPEN/MB-01 foi utilizado o estimador *F4 juntamente com os parâmetros $\mathrm{DE} / \mathrm{DF}$, que convertem a energia depositada em dose para determinado material. Para isso, os parâmetros DE/DF considerados são os valores do coeficiente de absorção de energia por massa $\left(\mu_{\text {en }} / \rho\right)$ do material LiF, fornecidos pelo NIST (Nist, 2010).

Como dito anteriormente, o fluxo de nêutrons térmicos (energia inferior a 0,625 eV) e epitérmicos (energia entre $0,625 \mathrm{eV}$ e $100 \mathrm{keV}$ ) são bem conhecidos tanto experimentalmente como por simulação para o reator IPEN/MB-01. Portanto, os primeiros resultados a partir das simulações foram usados para criar os mapas de fluxos no interior do núcleo do reator, e comparar estes dados simulados com os dados experimentais realizados com folhas de ativação de ouro de trabalhos anteriores.

Sabendo então a potência de operação do reator, foi possível encontrar a real fluência em cada região do núcleo do reator durante a operação, e assim corrigir os dados de dose calculada por nêutron gerado na fonte, para a real dose calculada na operação. 


\subsubsection{Simulações do Reator IPEN/MB-01}

Simulações do núcleo do reator IPEN/MB-01 foram realizadas para obter tanto os fluxos de nêutrons e gamas em diferentes regiões no interior do reator, quanto as doses depositadas devido aos nêutrons e gamas em TLDs de LiF posicionados no núcleo.

Nessas simulações, o núcleo do reator, tanto na configuração cilíndrica com "flux trap" quanto na configuração retangular, foi modelado geometricamente no arquivo de entrada com os exatos materiais que compõe o núcleo. A Figura 20 apresenta um desenho esquemático das configurações geométricas para essas simulações. Foram utilizados os estimadores F4 para o cálculo de fluxo de nêutrons e gamas e os estimadores F4 e *F4 com os cartões de modificação FM e DE/DF para o cálculo de dose depositada no LiF.

Os dados de entrada para o código MCNP5, tanto do reator com o núcleo na configuração cilíndrica com "flux trap" quanto para a configuração retangular, estão apresentados no Anexo C.
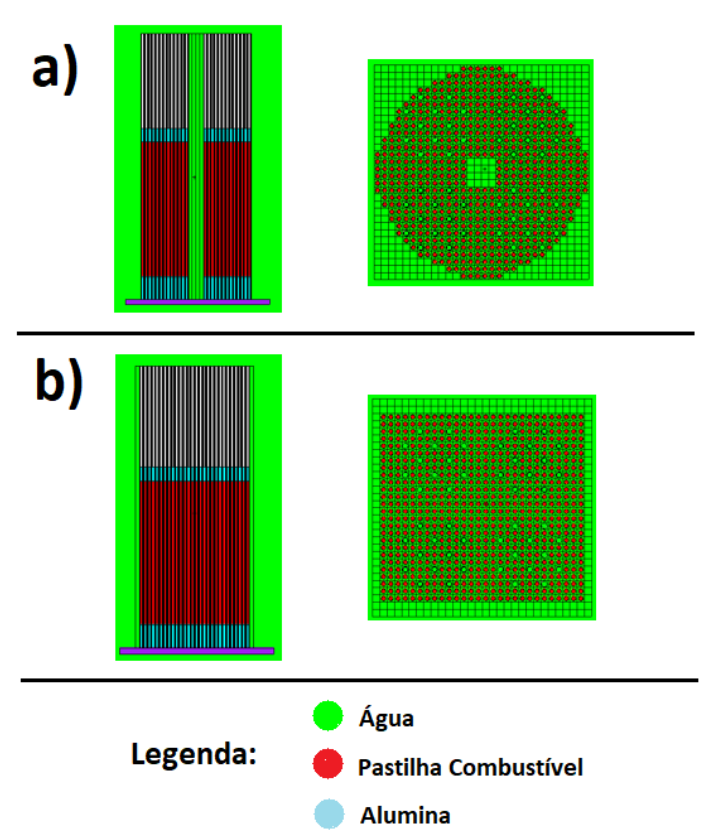

Figura 20 - Figura esquemática dos modelos geométricos para as simulações com o MCNP5 do núcleo do reator IPEN/MB-01 na configuração cilíndrica com "flux trap" (a) e retangular (b) 


\section{RESULTADOS E DISCUSSÕES}

\subsection{Experimentos no Irradiador de Polietileno}

\subsubsection{Caracterização do Irradiador de Polietileno}

Foi realizada uma primeira análise a partir de simulações com o código MCNP5 para avaliar o poder de moderação do irradiador de polietileno. As simulações foram realizadas na lateral do irradiador e na posição central (i.e., a meia altura do cilindro). Estimou-se o aumento da fração de nêutrons térmicos devido à presença do polietileno, em comparação com o mesmo volume de ar no lugar do polietileno. A Tabela 2 apresenta os valores obtidos para os quatro diferentes espectros da fonte de AmBe. As incertezas nas frações apresentadas nessa tabela são menores que $1 \%$.

Tabela 2 - Fração de nêutrons térmicos calculados na lateral do irradiador na posição central com e sem (ar) o material termalizador utilizando os diferentes espectros da fonte de $\mathrm{AmBe}$

\begin{tabular}{|c|c|c|c|c|}
\hline Espectros & Thompson & IAEA & Marsh & ISSO \\
\hline \multirow{2}{*}{$\begin{array}{c}\text { Ar } \\
\text { Irradiador }\end{array}$} & 0.00 & 0.03 & 0.00 & 0.00 \\
\hline & 0.14 & 0.27 & 0.16 & 0.18 \\
\hline
\end{tabular}

A presença do material termalizador (polietileno) faz com que a fração de nêutrons térmicos presente no campo aumente. Mesmo alterando o espectro utilizado nas simulações, o valor encontrado para a fração de nêutrons térmicos é semelhante, com exceção do espectro da IAEA, que apresenta um valor superior ao dos outros espectros.

Foram realizados experimentos e simulações das folhas de ativação de índio nua e com cobertura de cádmio na lateral do irradiador e na posição central, para se obter o fluxo de nêutrons de diferentes energias. Os valores experimentais da média da atividade de saturação da folha de índio nua foi de $3.284 \pm 52 \mathrm{~Bq}$, enquanto o valor obtido para as folhas de índio com a cobertura de cádmio foi de $623 \pm 14 \mathrm{~Bq}$, fornecendo assim uma razão experimental de 5,27 $\pm 0,14$. A Tabela 3 apresenta os dados calculados da razão entre as taxas de reação das folhas de índio nua, pelas folhas de índio com cobertura de cádmio, para os quatro diferentes espectros da fonte de AmBe. 
Tabela 3 - Razão calculada entre a taxa de reação das folhas de Índio nuas pelas folhas de índio com cobertura de cádmio para os diferentes espectros da fonte. As incertezas são inferiores a $1 \%$.

\begin{tabular}{c|cccc}
\multicolumn{1}{c}{ Espectro } & Thompson & IAEA & Marsh & ISO \\
\hline Razão & 5.31 & 5.32 & 5.38 & 5.55
\end{tabular}

Os valores experimentais e simulados são muito próximos e estão dentro da incerteza da resposta da folha de índio, mostrando que a presença do irradiador de polietileno ampliou a fração de nêutrons térmicos.

Este estudo também mostrou que as diferenças nos quatro espectros da fonte de AmBe usados não causam grandes impactos no cálculo da razão da taxa de reação entre as folhas de índio nuas e com cobertura de cádmio, fornecendo valores bastante semelhantes como observado na Tabela 3.

Foi analisado o perfil do fluxo angular na altura média da lateral do irradiador. Esse estudo visou identificar as maiores diferenças de espectro encontradas na lateral do irradiador, devido ao deslocamento da fonte dentro do furo central. Os cálculos computacionais encontraram desvios máximos de $2 \%$ para os fluxos tanto de nêutrons, quanto de radiação gama para o caso da fonte com o deslocamento máximo. A Figura 21 apresenta a atividade de saturação normalizada das folhas de índio nuas obtidas em seis diferentes posições ao redor da lateral do irradiador.

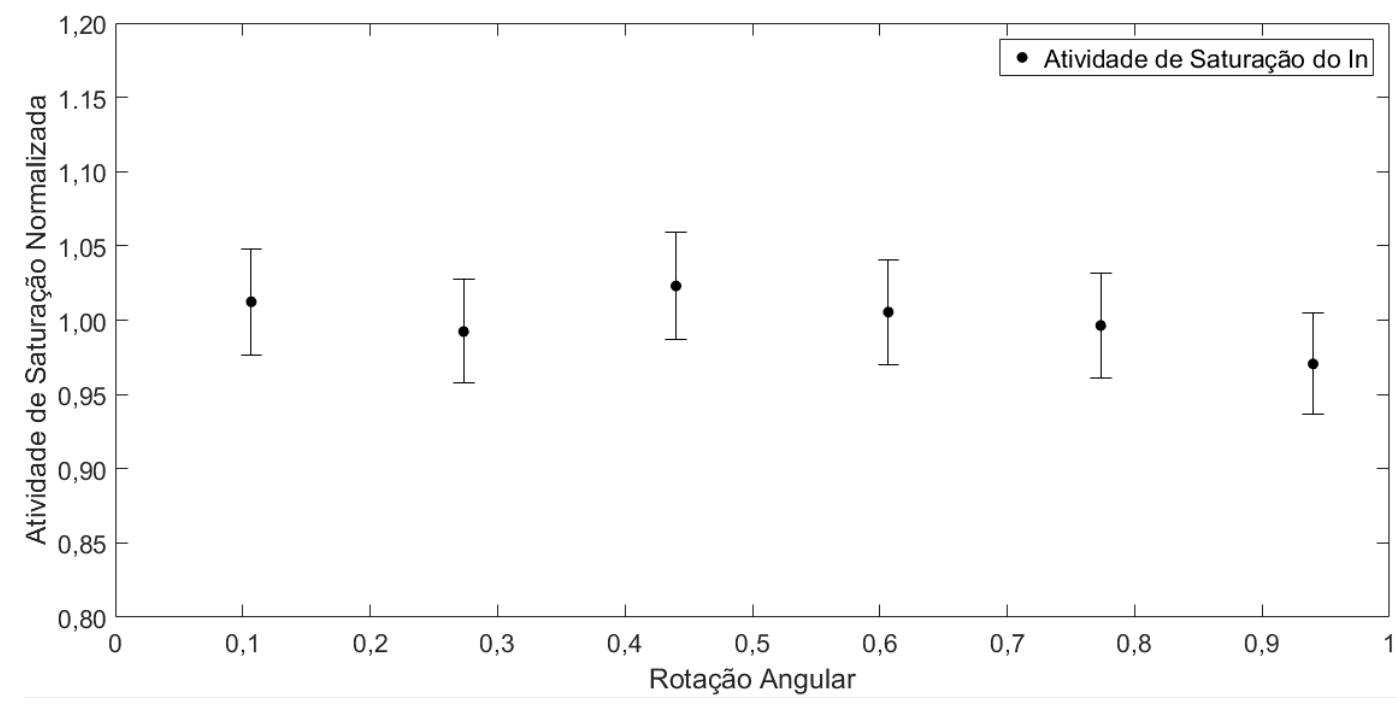

Figura 21 - Atividade de saturação das folhas de Índio nuas irradiadas na posição central na lateral do irradiador

O valor médio encontrado para a atividade de saturação das folhas de índio nuas foi de $3.248 \pm 52 \mathrm{~Bq}$, sendo que cada uma das folhas tem uma incerteza experimental de aproximadamente $4 \%$. 
Os dados obtidos através das simulações mostraram que a maior diferença no fluxo de nêutrons na posição central na lateral do irradiador foi inferior a $2 \%$, para o caso com a fonte no deslocamento máximo. Portanto, os dados, tanto de simulação quanto experimentais (Figura 21), mostram uma boa simetria no campo ao redor do irradiador, o que mostra que o irradiador atende as condições necessárias para ser utilizado no selecionamento e calibração dos TLDs.

O perfil axial vertical foi estudado para estimar as diferenças dos fluxos de nêutrons térmicos na lateral do irradiador ao longo da altura do irradiador. Foram realizados tanto o cálculo computacional como os experimentos com folhas de índio em diferentes alturas na lateral do irradiador. A Figura 22 apresenta o perfil vertical axial simulado normalizado pelo valor máximo, e os valores experimentais normalizados pelo valor máximo de atividade de saturação das folhas de índio nuas nas diferentes alturas.

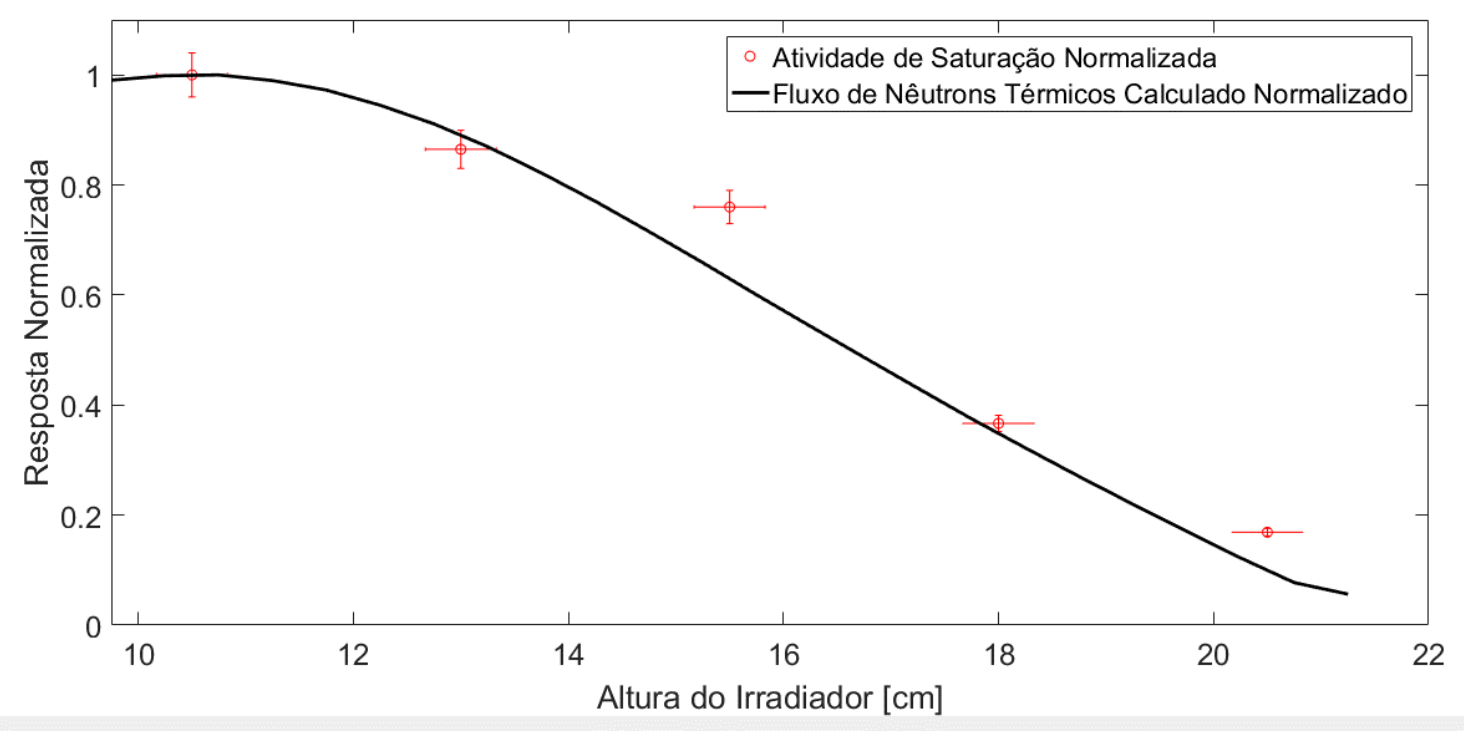

Figura 22 - Perfil vertical axial de nêutrons térmicos na superfície lateral do irradiador de polietileno

No perfil vertical axial, se a altura variar de $1 \mathrm{~cm}$ próximo a altura média do irradiador, terá uma diferença no fluxo térmico de nêutrons de aproximadamente $2 \%$. E com variações de $1,5 \mathrm{~cm}$, a diferença no fluxo térmico de nêutrons é de $5 \%$. Portanto, há a necessidade de um cuidado no posicionamento dos detectores na lateral do irradiador, pois diferenças no posicionamento na altura podem levar a irradiações com diferentes intensidades de nêutrons térmicos. 


\subsubsection{Uso dos TLDs no Irradiador}

Os TLDs já haviam sido selecionados anteriormente em irradiações na fonte de ${ }^{137} \mathrm{Cs}$, sendo que, os dados da reprodutibilidade e selecionamento dos TLDs estão no Apêndice B.

Foi então realizado um novo estudo de reprodutibilidade dos TLDs no campo misto de nêutrons e gamas, provenientes do irradiador de polietileno com a fonte de AmBe. Os dados obtidos estão apresentados na Figura 23:

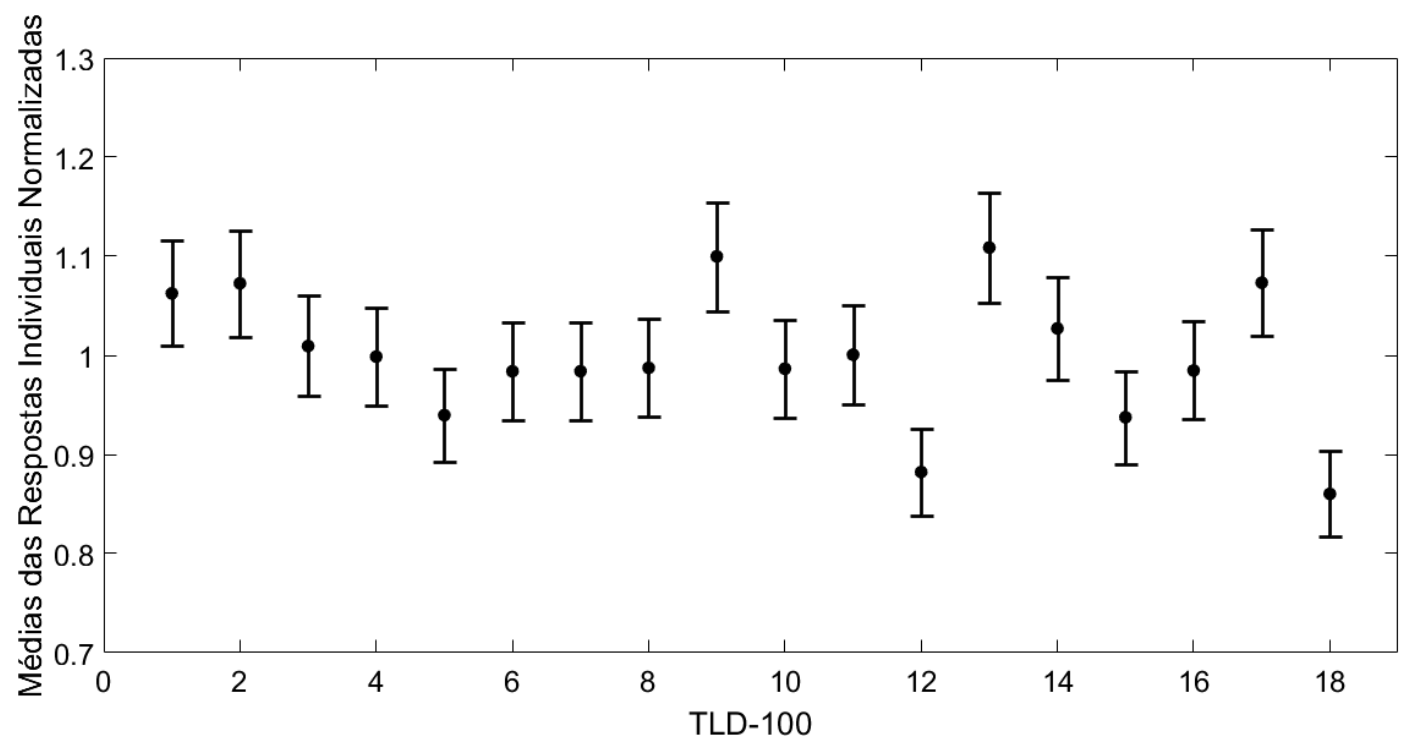

Figura 23 - Reprodutibilidade dos TLDs no irradiador de polietileno com a fonte de AmBe.

Os dados da Figura 23 representam os valores das médias das respostas dos TLDs em 6 diferentes irradiações. O desvio padrão individual dos TLDs é de aproximadamente $6 \%$.

Os valores das respostas obtidos são um pouco superiores aos valores das respostas obtidos nas irradiações na fonte de ${ }^{137} \mathrm{Cs}$, o que já era esperado, uma vez que a presença de nêutrons no campo gera uma maior complexidade na deposição de doses do TLD. Porém, mesmo esses valores, encontram-se dentro dos valores vistos na literatura na utilização dos TLDs.

\subsubsection{Estudo dos TLDs em diferentes posições do irradiador de polietileno}

Conforme visto na Figura 22, o fluxo de nêutrons térmicos apresenta diferentes intensidades ao longo do perfil vertical axial do irradiador. Foi realizado um estudo para 
obter o real perfil de dose em três diferentes alturas do irradiador, e a resposta dos TLDs em cada uma dessas posições. A Figura 24 apresenta os valores simulados de fluxo de nêutron e de gama em função da altura do irradiador:

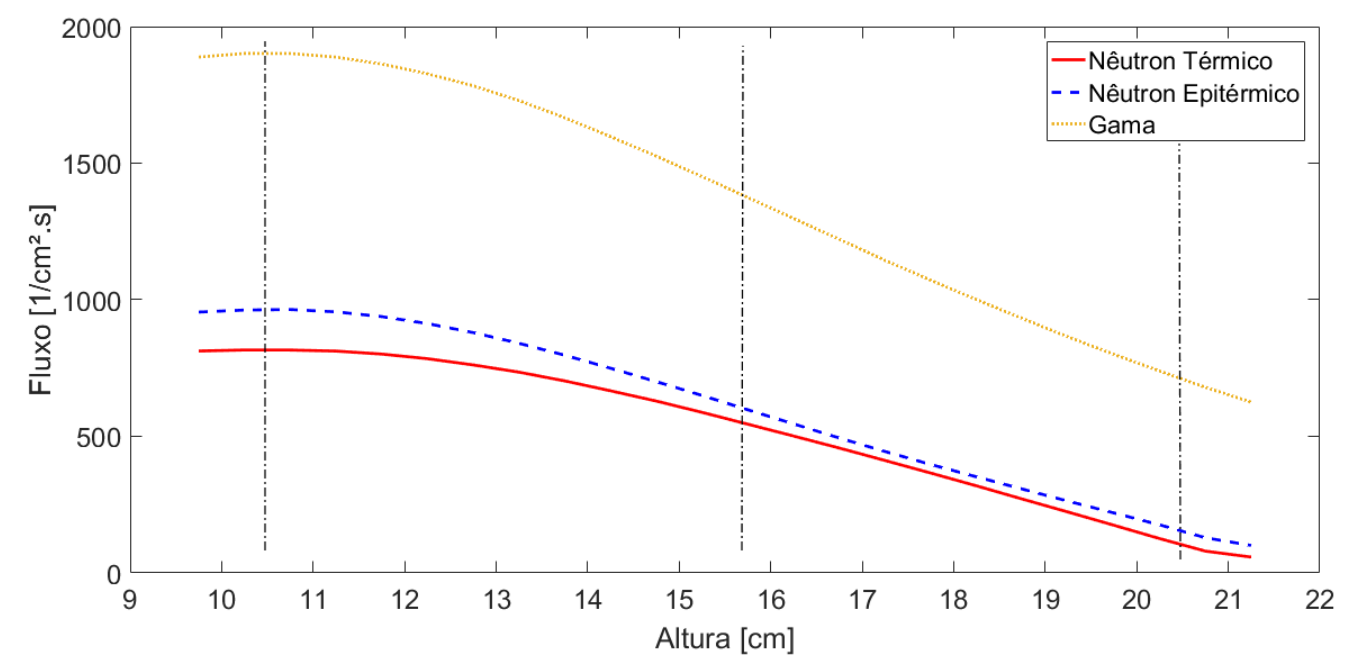

Figura 24 - Perfil axial do fluxo de nêutrons e gamas no irradiador de polietileno. As linhas tracejadas verticais pretas representam as 3 posições dos TLDs nas irradiações ao longo da altura do irradiador. As incertezas são inferiores a $1 \%$.

Foi realizada a irradiação dos TLDs em três diferentes alturas na lateral do irradiador (linhas verticais na Figura 24). Os valores de dose obtidos após a leitura TL, e os valores calculados estão apresentados nas Tabela 4 e Tabela 5 para os TLDs 100 e TLDs 700, respectivamente.

A dose depositada no TLD 100 devido aos nêutrons, calculada nessa irradiação na posição central, foi de aproximadamente 53 mGy e no TLD 700 de $10 \mu \mathrm{Gy}$. Já a dose depositada devido à radiação gama calculada, foi de aproximadamente $1 \mathrm{mGy}$.

Tabela 4 - Doses depositadas calculadas e respostas TL normalizadas dos TLDs 100 nas irradiações axiais no irradiador de polietileno com a fonte de $\mathrm{AmBe}$

\begin{tabular}{|c|c|c|c|c|}
\hline \multirow[t]{2}{*}{$A L T U R A$} & \multicolumn{2}{|c|}{$\begin{array}{c}\text { DOSE CALCULADA } \\
\text { NORMALIZADA }\end{array}$} & \multicolumn{2}{|c|}{$\begin{array}{c}\text { RESPOSTA TL } \\
\text { NORMALIZADA }\end{array}$} \\
\hline & Nêutrons & Gamas & ROI 1 & ROI 2 \\
\hline $10,5 \mathrm{~cm}$ & $1,000 \pm 0,006$ & $1,000 \pm 0,005$ & $1,00 \pm 0,07$ & $1,00 \pm 0,08$ \\
\hline $17,75 \mathrm{~cm}$ & $0,662 \pm 0,007$ & $0,684 \pm 0,005$ & $0,56 \pm 0,06$ & $0,55 \pm 0,06$ \\
\hline $20,5 \mathrm{~cm}$ & $0,112 \pm 0,002$ & $0,333 \pm 0,003$ & $0,16 \pm 0,02$ & $0,11 \pm 0,01$ \\
\hline
\end{tabular}


Tabela 5 - Doses depositadas calculadas e respostas TL normalizadas dos TLDs 700 nas irradiações axiais no irradiador de polietileno com a fonte de $\mathrm{AmBe}$

\begin{tabular}{|c|c|c|c|c|}
\hline \multirow[t]{2}{*}{$A L T U R A$} & \multicolumn{2}{|c|}{$\begin{array}{l}\text { DOSE CALCULADA } \\
\text { NORMALIZADA }\end{array}$} & \multicolumn{2}{|c|}{$\begin{array}{l}\text { RESPOSTA TL } \\
\text { NORMALIZADA }\end{array}$} \\
\hline & Nêutrons & Gamas & ROI 1 & ROI 2 \\
\hline $10,5 \mathrm{~cm}$ & $1,000 \pm 0,006$ & $1,000 \pm 0,005$ & $1,00 \pm 0,06$ & $1,00 \pm 0,09$ \\
\hline $17,75 \mathrm{~cm}$ & $0,652 \pm 0,007$ & $0,684 \pm 0,005$ & $0,58 \pm 0,06$ & $0,49 \pm 0,05$ \\
\hline $20,5 \mathrm{~cm}$ & $0,116 \pm 0,002$ & $0,333 \pm 0,003$ & $0,17 \pm 0,02$ & $0,09 \pm 0,01$ \\
\hline
\end{tabular}

As razões das quedas das doses depositadas nos TLDs devido aos nêutrons e aos gamas, são iguais quando comparadas entre as alturas de $10,5 \mathrm{~cm}$ e $17,75 \mathrm{~cm}$ (uma diminuição de aproximadamente $35 \%$ para nêutrons e $32 \%$ para gamas). Na comparação das razões das quedas de doses entre as alturas de 17,75 e $20,5 \mathrm{~cm}$, há uma queda mais acentuada da dose depositada devido aos nêutrons, em comparação com a razão da queda na dose depositada devido à radiação gama (uma diminuição de aproximadamente $83 \%$ para nêutrons e $51 \%$ para gamas).

As quedas de respostas TL de ambos os TLDs são bastante semelhantes, porém o ROI 2 apresenta uma queda proporcional com a queda de dose depositada devido aos nêutrons, o que é esperado, pois esta região é associada mais fortemente à dose depositada por nêutrons. Já o ROI 1 não apresenta queda proporcional à dose depositada com nenhuma das componentes do campo, corroborando o fato de que esta região apresenta uma resposta tanto para nêutrons como para gamas, em ambos os TLDs.

As Tabelas Tabela 6 e Tabela 7 apresentam respectivamente, para os dosímetros TLD 100 e 700, uma comparação entre as razões das respostas TL das regiões de interesse (ROI 1 e ROI 2) e as razões de doses calculadas devido a nêutrons e gamas.

Tabela 6 - Comparação da relação entre as respostas dos ROIs do TLD 100 e a razão de doses calculadas devido a nêutron e gama no TLD 100

\begin{tabular}{|c|c|c|c|c|}
\hline $\begin{array}{c}\text { ALTURA } \\
{[\mathrm{cm}]}\end{array}$ & $\begin{array}{c}\text { ROI } 1 \\
{[\mathrm{nC}]}\end{array}$ & $\begin{array}{c}\text { ROI } 2 \\
{[\mathrm{nC}]}\end{array}$ & ROI 2 / ROI 1 & $\begin{array}{c}\text { RAZÃO DE } \\
\text { DOSE } \\
\text { NÊUTRONS / } \\
\text { DOSE GAMA }\end{array}$ \\
\hline 10,5 & $24,8 \pm 1,2$ & $10,2 \pm 0,5$ & $0,41 \pm 0,03$ & $992 \pm 7$ \\
\hline 17,75 & $13,9 \pm 0,7$ & $5,6 \pm 0,3$ & $0,40 \pm 0,03$ & $965 \pm 9$ \\
\hline 20,5 & $3,8 \pm 0,2$ & $1,07 \pm 0,05$ & $0,28 \pm 0,02$ & $323 \pm 7$ \\
\hline
\end{tabular}


Tabela 7 - Comparação da relação entre as respostas dos ROIs do TLD 700 e a razão de doses calculadas devido a nêutron e gama no TLD 700

\begin{tabular}{|c|c|c|c|c|}
\hline $\begin{array}{c}A L T U R A \\
{[\mathrm{~cm}]}\end{array}$ & $\begin{array}{c}\text { ROI } 1 \\
{[\mathrm{nC}]}\end{array}$ & $\begin{array}{c}\text { ROI } 2 \\
{[\mathrm{nC}]}\end{array}$ & ROI 2 / ROI 1 & $\begin{array}{c}\text { RAZÃO DE } \\
\text { DOSE } \\
\text { NÊUTRONS / } \\
\text { DOSE GAMA }\end{array}$ \\
\hline 10,5 & $15,9 \pm 0,8$ & $4,2 \pm 0,2$ & $0,26 \pm 0,03$ & $0,203 \pm 0,02$ \\
\hline 17,75 & $9,2 \pm 0,5$ & $2,1 \pm 0,1$ & $0,23 \pm 0,02$ & $0,195 \pm 0,02$ \\
\hline 20,5 & $2,6 \pm 0,1$ & $0,35 \pm 0,02$ & $0,14 \pm 0,01$ & $0,067 \pm 0,02$ \\
\hline
\end{tabular}

Na comparação realizada entre as respostas termoluminescentes das regiões de interesse dos TLDs com relação às doses depositadas nos TLDs devido aos nêutrons e gamas, é observada uma tendência de diminuição das diferenças entre as duas regiões de interesse conforme a dose depositada de nêutrons aumenta. Sendo uma forte evidência para o fato que o ROI 1 apresenta resposta tanto para nêutrons quanto para gamas, e que o ROI 2 responde com maior intensidade para os nêutrons em ambos os TLDs.

Porém, uma análise mais profunda da dependência de cada região de interesse para cada componente de campo não é possível pois, como dito anteriormente, as relações entre nêutrons e gamas não têm uma alteração significativa quando se altera a altura de irradiação no irradiador.

\subsubsection{Linearidade das respostas dos TLDs}

Um outro estudo realizado a partir de irradiações de TLDs no irradiador de polietileno, foi verificar a linearidade desses TLDs em função da dose depositada. Para isso, grupos de TLDs foram irradiados na posição central do irradiador durante períodos diferentes. Os TLDs foram irradiados durante cinco, quatorze e dezenove dias.

A Figura 25 e a Figura 26 apresentam o estudo de linearidade das respostas do TLD 100 e TLD 700, respectivamente. 


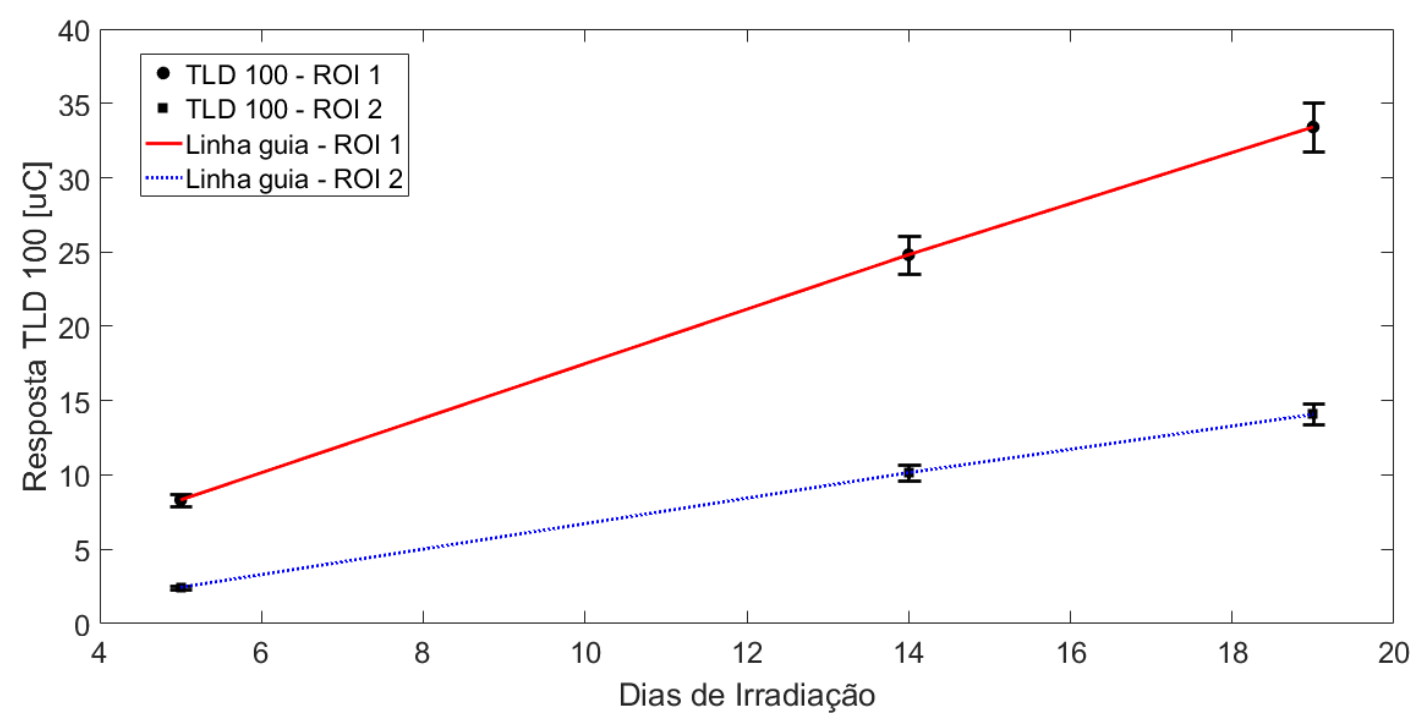

Figura 25 - Linearidade da resposta do TLD 100 em irradiações no irradiador de polietileno com a fonte de $\mathrm{AmBe}$

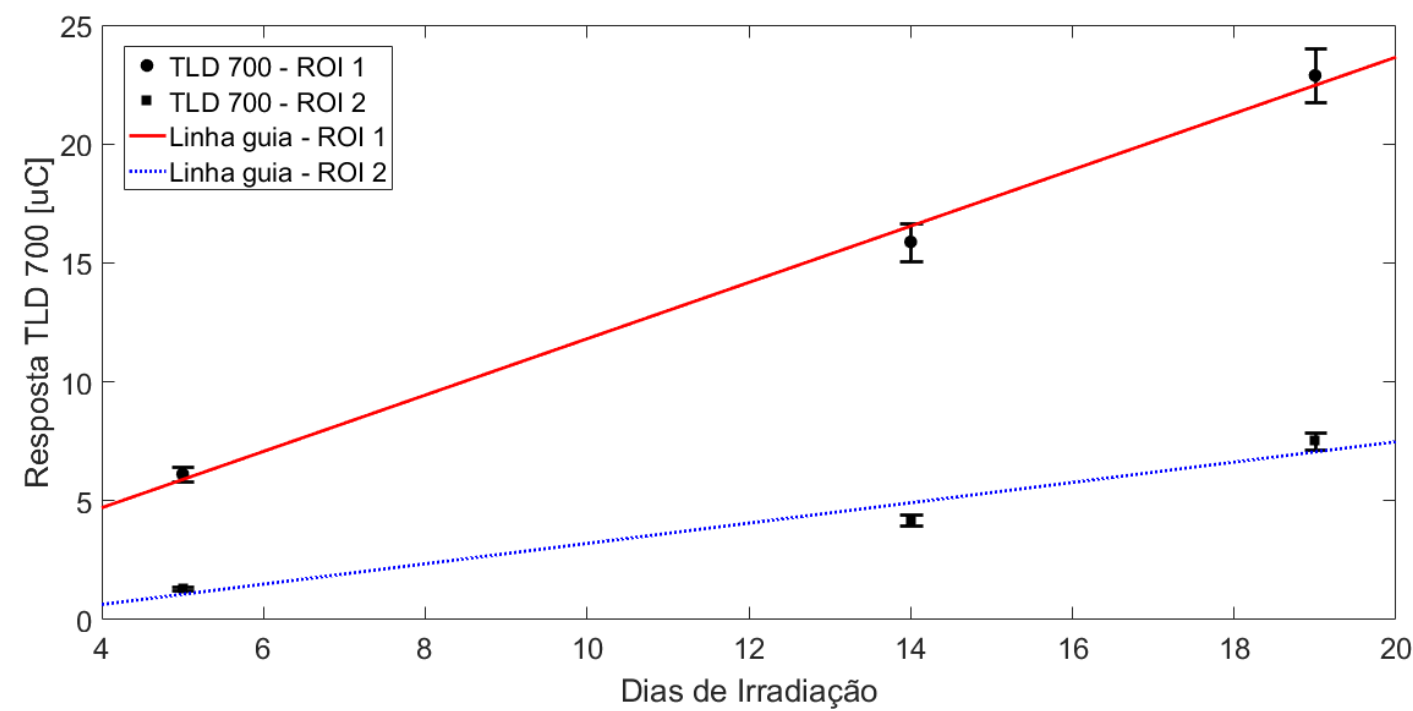

Figura 26 - Linearidade da resposta do TLD 700 em irradiações no irradiador de polietileno com a fonte de AmBe

As respostas dos TLDs 100, tanto do ROI 1 quanto do ROI 2, apresentam boa linearidade com a dose depositada pela fonte de AmBe no irradiador de polietileno, com ajustes de retas com valores de $\mathrm{R}^{2}$ superiores a 0,99 .

A linearidade dos TLDs 700 também é observável, porém com menor precisão do que os TLDs 100, principalmente para o ROI 2 do TLD 700 que apresenta valor de $\mathrm{R}^{2} \mathrm{de}$ aproximadamente 0,95 . 
Este estudo mostrou uma boa linearidade das respostas dos TLDs quando irradiados em um campo misto de nêutrons e gamas.

\subsection{Simulações do Reator IPEN/MB-01}

As simulações do núcleo do reator IPEN/MB-01 foram realizadas para obter os fluxos de nêutrons e gamas em diferentes regiões no interior do reator, e obter as doses depositadas devido aos nêutrons e aos gamas em TLDs de LiF posicionados no núcleo. Os dados de entrada, tanto do reator com o núcleo na configuração cilíndrica com "flux trap" quanto para a configuração retangular, estão apresentados no Anexo C.

Como um exemplo de resultados de cálculos dos mapas de fluxos gerados através das simulações, a Figura 27 apresenta o mapa de fluxo de nêutron térmico no canal 1415, e a Figura 28 apresenta o mapa de fluxo de gamas no mesmo canal para o núcleo no arranjo cilíndrico com "flux trap".

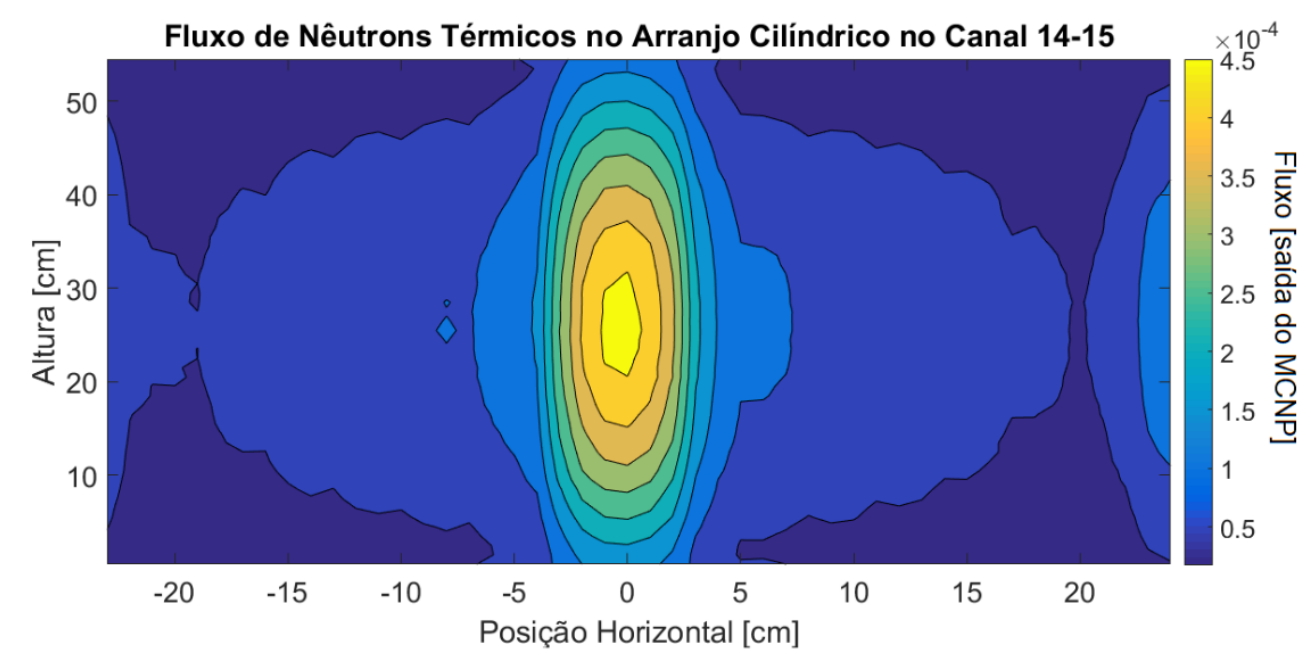

Figura 27 - Mapa de fluxo de nêutrons térmicos simulado, obtido no canal 14-15 com núcleo cilíndrico. As incertezas estatísticas máximas são de $1 \%$. 


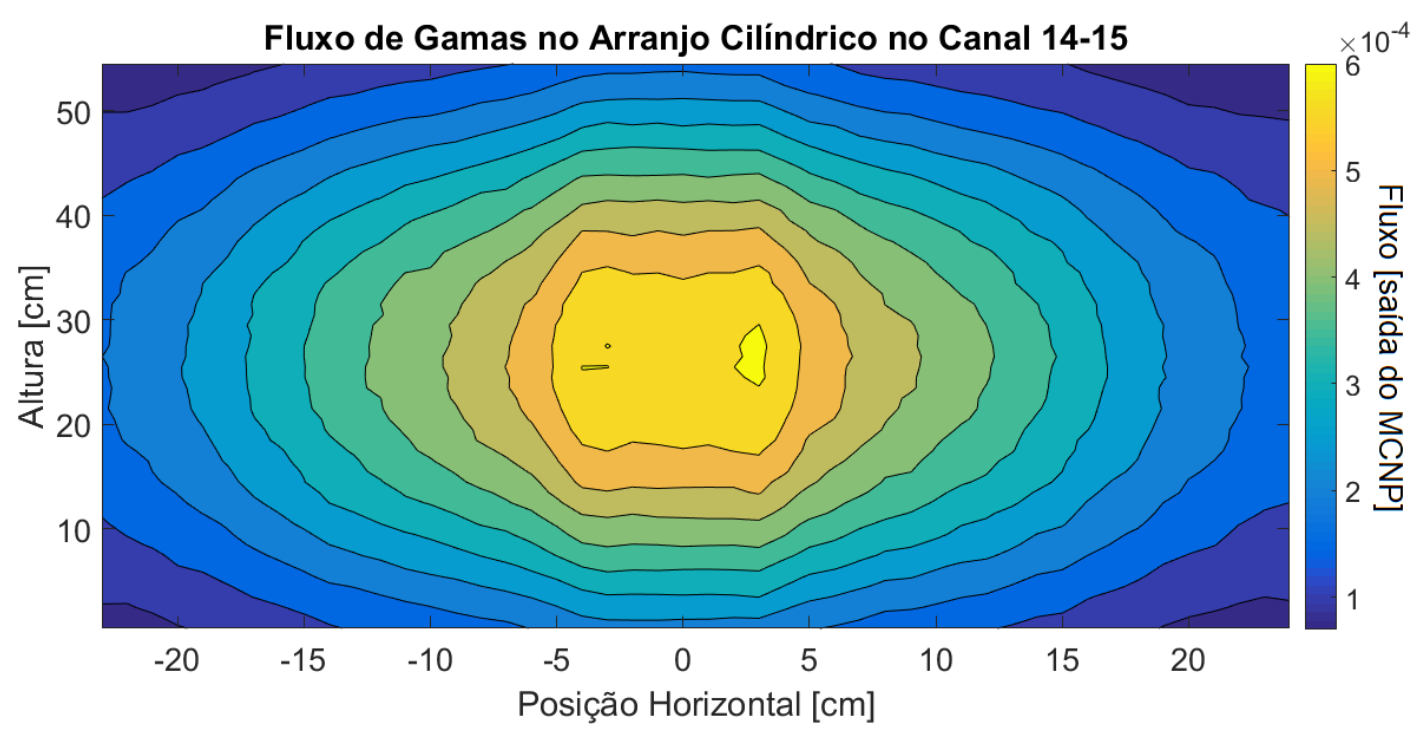

Figura 28 - Mapa do fluxo de gamas simulado, obtido no canal 14-15 com núcleo cilíndrico. As incertezas estatísticas máximas são de $1 \%$.

Essas simulações mostraram que, variando as posições de irradiação dentro do núcleo, se tem uma grande alteração na composição de nêutrons térmicos e de gamas no campo. Portanto, foram escolhidas as posições com espectros diferentes para possibilitar um melhor estudo das respostas dos TLDs.

\subsubsection{Validação das Simulações}

Para realizar a validação das simulações com o código MCNP5, foram comparados os dados de fluxo de nêutrons térmicos e epitérmicos simulados com o código MCNP5, e experimentais, utilizando folhas de ativação de ouro para vários planos no reator na configuração retangular. Os dados de folhas de ativação de ouro para a configuração retangular do reator IPEN/MB-01 foram obtidos através do trabalho de Gonçalves (2008). As Figura 29 e Figura 30 apresentam os dados das folhas de ouro e fluxos calculados para dois diferentes planos no interior do reator. As incertezas máximas nos fluxos calculados são inferiores a $1 \%$. 


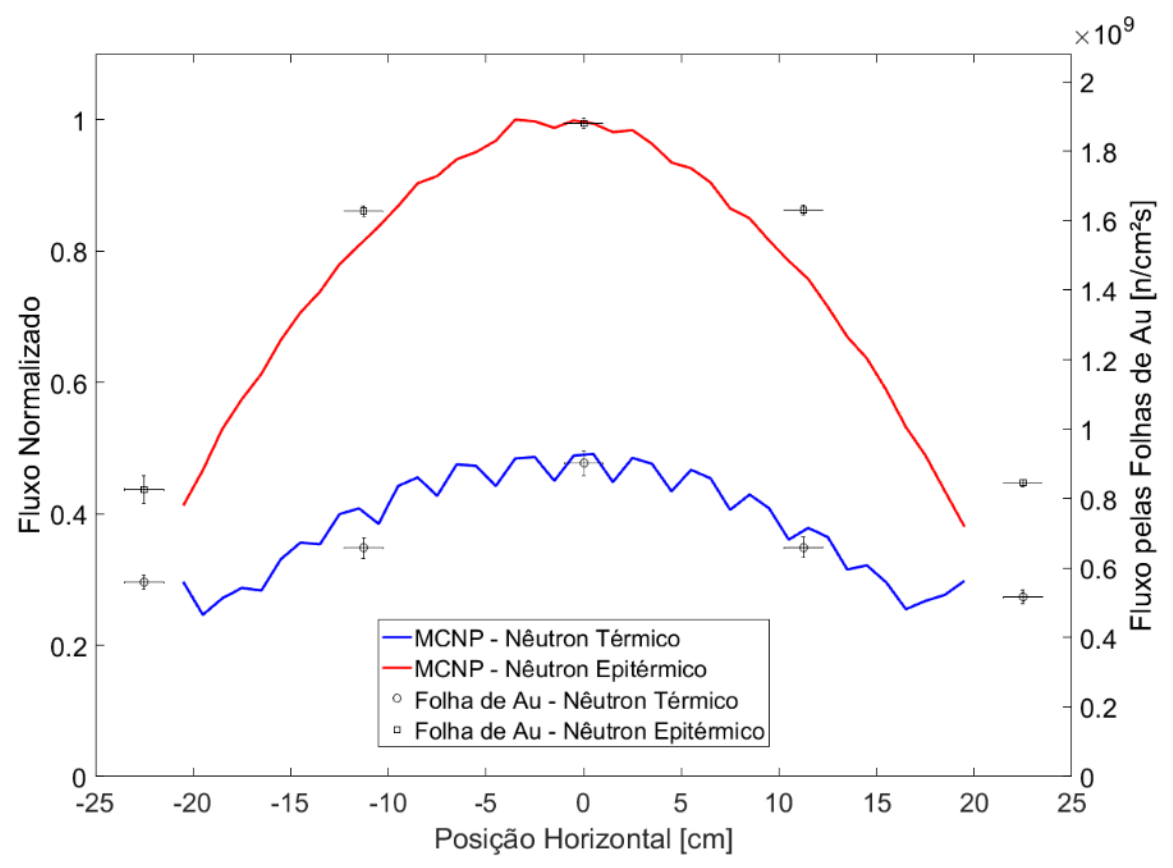

Figura 29 - Comparação entre as distribuições de fluxos de nêutrons térmicos e epitérmicos simulados e experimentais com folhas de ativação de ouro de trabalhos anteriores (Gonçalves, 2008) no arranjo retangular do núcleo na direção radial no canal 14-15 na altura de $273 \mathrm{~mm}$.

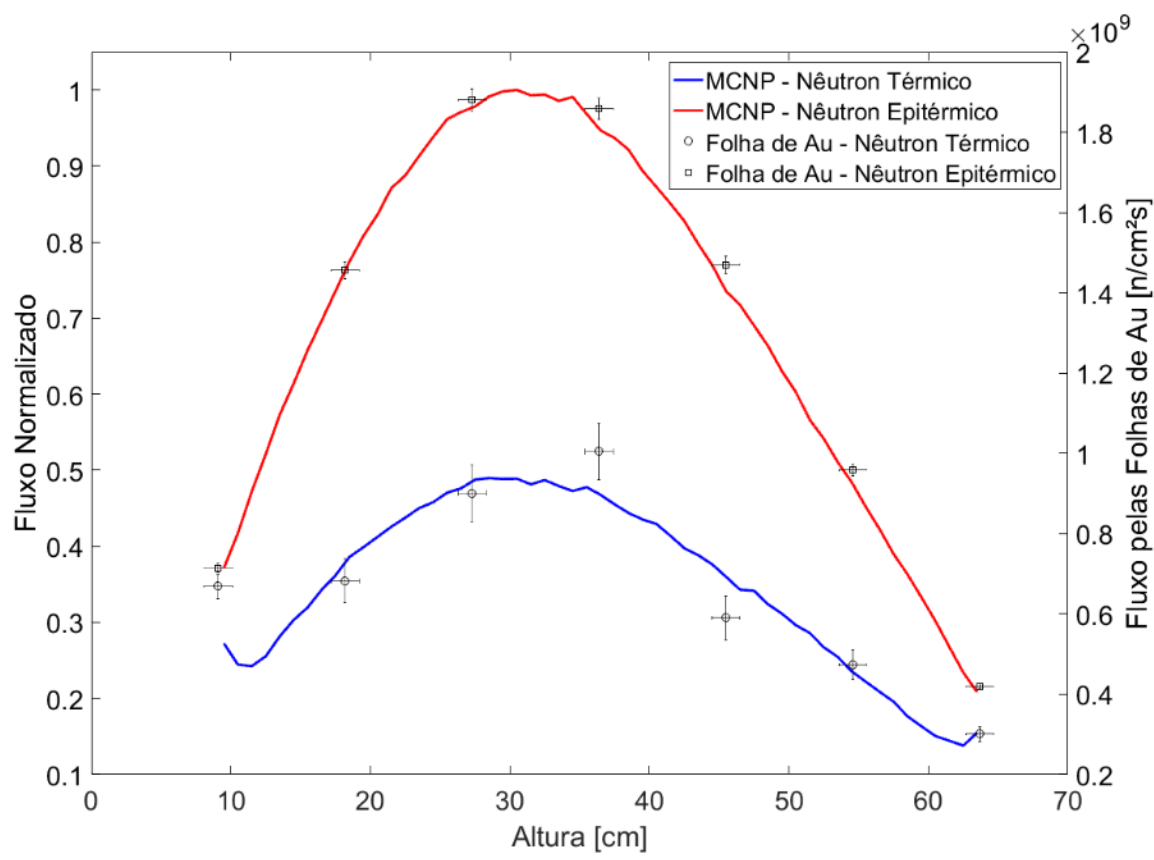

Figura 30 - Comparação entre as distribuições de fluxos de nêutrons térmicos e epitérmicos simulados e experimentais com folhas de ativação de ouro de trabalhos anteriores (Gonçalves, 2008) no arranjo retangular do núcleo na direção axial do canal $14-15$ e posição horizontal $0 \mathrm{~cm}$ 
Os dados calculados experimentalmente com as folhas de ouro, e os obtidos através das simulações, apresentam perfis semelhantes, mostrando que as simulações representam bem a realidade no núcleo do reator IPEN/MB-01. As divergências entre os dados simulados e os dados experimentais das folhas de ativação de ouro, são de no máximo 9\% na comparação do fluxo horizontal e de $14 \%$ no fluxo pela altura.

O correto posicionamento das folhas no interior do reator não é simples, uma vez que o posicionamento é feito sem muito controle do real posicionamento da placa de irradiação. Além disso, as incertezas experimentais das folhas chegam a 7\%. Tendo em vista estas dificuldades experimentais, conclui-se que a simulação representa adequadamente o real fluxo no interior do reator.

Outro ponto importante destes dados é que as regiões mais distantes da altura média (273 $\mathrm{mm}$ de altura) apresentam um alto gradiente de fluxo axial, onde as incertezas de posicionamento tornam-se ainda mais relevantes. Para o canal 14-15 na altura $445 \mathrm{~mm}$, há um gradiente de fluxo de quase $8 \%$ por centímetro na direção axial, tanto de nêutrons térmicos quanto de gamas.

\subsection{Experimentos com TLDs no reator IPEN/MB-01}

Os TLDs foram irradiados nos dois arranjos de núcleo nos canais 14-15 e 2-3 (Figura 17) e posicionados em uma matriz $2 \times 3$ nesses canais (Figura 18). Para cada posição de irradiação, foram usados 3 TLDs de cada tipo.

As seções a seguir apresentam as respostas dos TLDs quando irradiados no núcleo do reator IPEN/MB-01 na configuração cilíndrica com "flux trap".

Diferentemente do modo como foi apresentado até agora, os valores de fluxos calculados pelo MCNP5 a seguir são apresentados em valores absolutos, e não mais valores normalizados. Esta mudança foi realizada a partir dos fluxos calculados no trabalho de Gonçalves (2008), em que a potência térmica de operação do reator era de 100W. Como os experimentos no núcleo do reator realizados neste trabalho foram realizados à $1 \mathrm{~W}$ de potência térmica, tem-se que o fluxo é duas ordens de grandeza inferior aos fluxos obtidos por Gonçalves. A partir desses dados e dos dados obtidos por simulações com o código MCNP5, sabendo-se a potência de operação do reator, foi possível calcular o fluxo em cada posição do núcleo do reator em termos absolutos.

\subsubsection{TLD 100}

A Figura 31 apresenta a comparação entre as respostas das duas regiões de interesse do TLD 100 com os fluxos simulados com o MCNP5. 


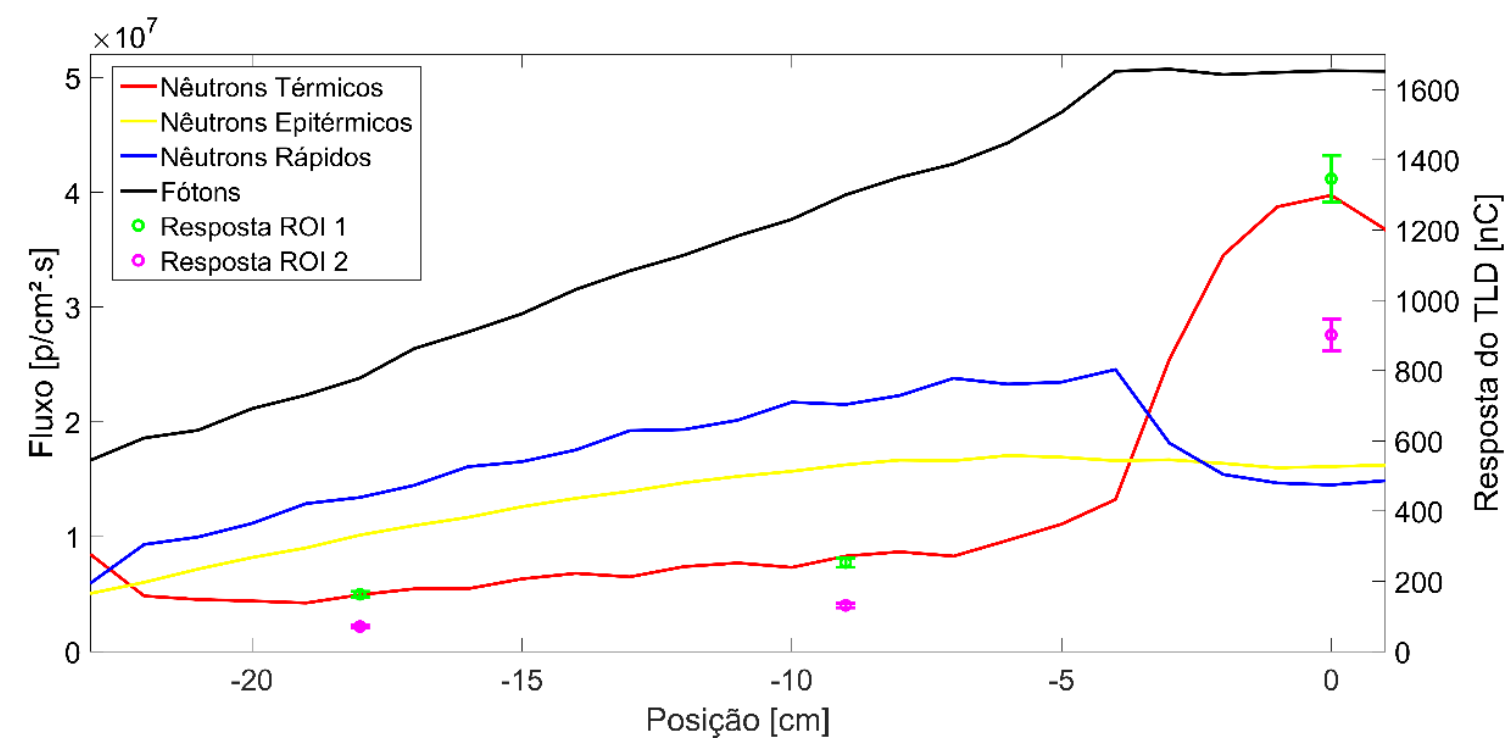

Figura 31 - Fluxos de nêutrons e fótons calculados pelo MCNP5 (onde o $p$ da unidade significa partículas, nêutrons ou gamas) e as respostas dos TLDs 100 nos ROIs 1 e 2, para o canal 14-15 na posição $273 \mathrm{~mm}$ com o núcleo no arranjo cilíndrico com "flux trap”. As incertezas máximas nos fluxos calculados são inferiores a $1 \%$.

É possível notar uma forte dependência das duas regiões de interesse do TLD 100 com o fluxo de nêutron térmico, o que era esperado, dado que esse TLD apresenta sensibilidade aos nêutrons térmicos. Segundo a literatura, o ROI 1 apresenta uma sensibilidade tanto para nêutrons térmicos quanto para os gamas, já o ROI 2 apresenta sensibilidade apenas para os nêutrons térmicos.

A Tabela 8 apresenta a variação nos fluxos de nêutrons térmicos e gamas nas posições -9 e $-18 \mathrm{~cm}$ em relação à posição central (posição $0 \mathrm{~cm}$ ) e às respectivas variações de respostas dos dois ROIs do TLD 100 em relação à mesma posição. Os valores estão normalizados pelos fluxos na posição central.

Tabela 8 - Comparação entre os fluxos de nêutrons e gamas e as respostas dos dois ROIs (1 e 2) do TLD 100 irradiados no arranjo cilíndrico com "flux trap" no canal 14-15 na posição $273 \mathrm{~mm}$.

\begin{tabular}{|c|c|c|c|c|}
\hline Posição $[\mathrm{cm}]$ & $\begin{array}{l}\text { Fluxo de } \\
\text { nêutrons } \\
\text { térmicos } \\
\text { (Calculado) }\end{array}$ & $\begin{array}{c}\text { Fluxo de } \\
\text { gamas } \\
\text { (Calculado) }\end{array}$ & $\begin{array}{c}\text { Resposta } \\
\text { TLD 100 ROI } \\
1\end{array}$ & $\begin{array}{c}\text { Resposta } \\
\text { TLD } 100 \text { ROI } \\
2\end{array}$ \\
\hline 0 & $1,000 \pm 0,006$ & $1,000 \pm 0,006$ & $1,00 \pm 0,07$ & $1,00 \pm 0,07$ \\
\hline-9 & $0,212 \pm 0,002$ & $0,781 \pm 0,006$ & $0,19 \pm 0,02$ & $0,15 \pm 0,02$ \\
\hline-18 & $0,130 \pm 0,001$ & $0,483 \pm 0,003$ & $0,12 \pm 0,02$ & $0,08 \pm 0,01$ \\
\hline
\end{tabular}


Pode-se notar que a variação nas respostas dos TLDs 100 (tanto do ROI 1 como do ROI 2) seguem, aproximadamente, a variação no fluxo de nêutrons térmicos.

A partir de simulações com o MCNP5, foram calculadas também as doses depositadas nos diferentes TLDs devido aos nêutrons e à radiação gama.

A Figura 32 apresenta uma comparação da dose depositada calculada devido a nêutron no TLD 100 no canal 14-15 com a resposta TL no ROI 1, no arranjo do núcleo cilíndrico com "flux trap". Nessa figura não é apresentada a dose devido à radiação gama, pois o valor é inferior a $2 \%$ do valor da dose devido aos nêutrons, não sendo possível uma boa visualização.

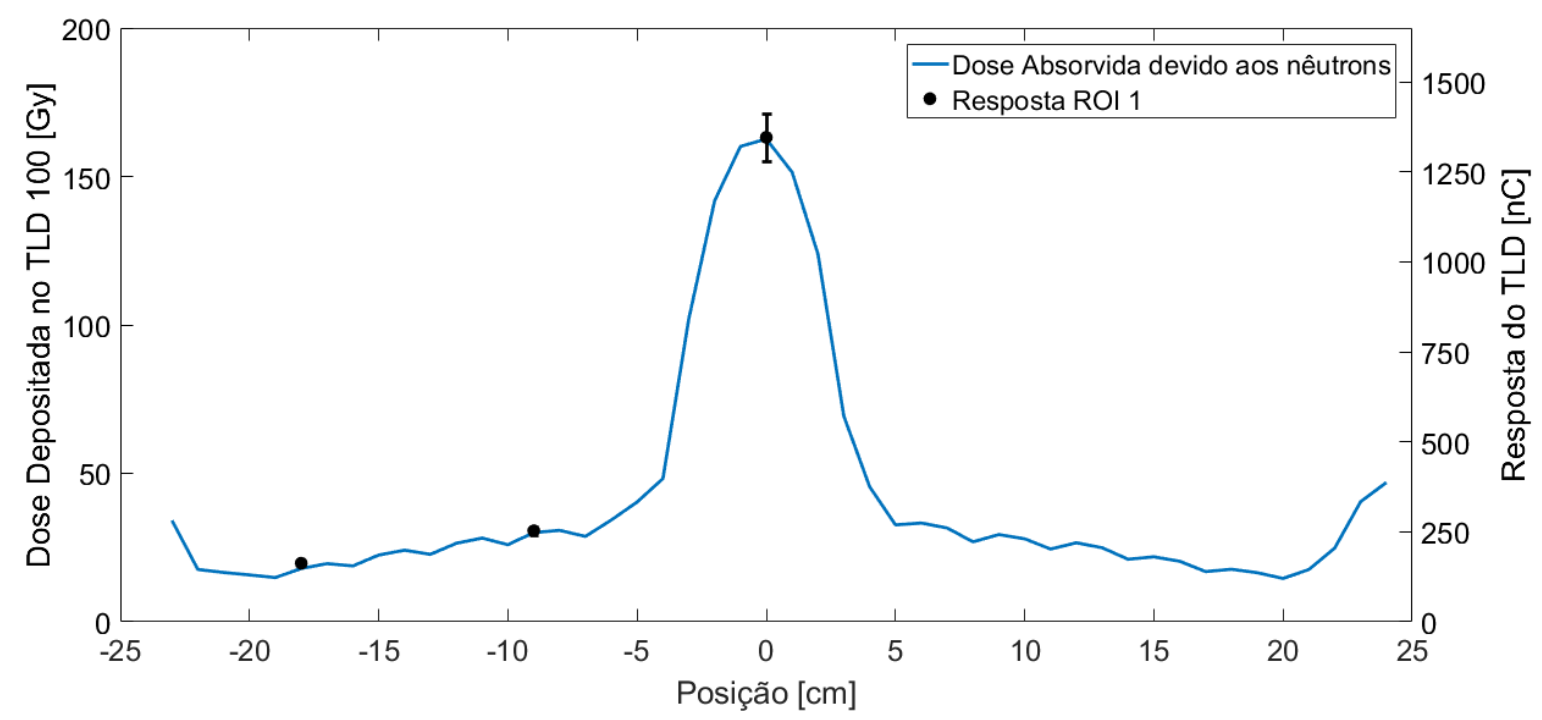

Figura 32 - Comparação da dose depositada calculada devido aos nêutrons no TLD 100 e a resposta TL do ROI 1, no canal 14-15 na posição $273 \mathrm{~mm}$ do reator com o núcleo na configuração cilíndrica com 'flux trap. A incerteza máxima na dose calculada é inferior a $1 \%$.'

A dose depositada calculada no TLD 100 pelo código MCNP5 nas três diferentes posições radiais de irradiação dos TLDs está apresentada na Tabela 9. 
Tabela 9 - Dose depositada calculada pelo MCNP5 no TLD 100

\begin{tabular}{|c|c|c|}
\hline Posição $[\mathrm{cm}]$ & $\begin{array}{c}\text { Dose } \\
\text { depositada de } \\
\text { nêutrons nos } \\
\text { TLDs 100 } \\
\text { [Gy] }\end{array}$ & $\begin{array}{c}\text { Dose } \\
\text { depositada de } \\
\text { gama nos } \\
\text { TLDs 100 } \\
\text { [Gy] }\end{array}$ \\
\hline 0 & $163 \pm 11$ & $0,89 \pm 0,06$ \\
\hline-9 & $30 \pm 2$ & $0,75 \pm 0,05$ \\
\hline-18 & $18 \pm 1$ & $0,46 \pm 0,03$ \\
\hline
\end{tabular}

É possível observar da Figura 31, da Figura 32 e da Tabela 9, que mesmo o fluxo da radiação gama sendo superior ao fluxo de nêutrons térmicos na posição central, a dose depositada no TLD 100 devido aos nêutrons é aproximadamente 190 vezes maior do que a dose depositada devido à radiação gama na posição $0 \mathrm{~cm}$.

Os resultados mostrados na Tabela 10, permitem uma análise dos resultados nas diferentes posições de irradiação no canal 14-15 e no canal 2-3 na altura de 273 mm para o TLD 100 (posições horizontais $0,-9$ e $-18 \mathrm{~cm}$ ) em comparação com a variação de dose depositada em relação à posição central e à variação de resposta dos TLDs 100 para essas mesmas posições. 
Tabela 10 - Comparação dos resultados de dose depositados simulados e resposta TL dos TLDs 100 no arranjo cilíndrico com "flux trap" normalizados pelos resultados da posição $0 \mathrm{~cm}$.

\begin{tabular}{|c|c|c|c|c|c|c|c|}
\hline \multirow{3}{*}{ Canal } & \multirow{3}{*}{ Posição } & \multicolumn{6}{|c|}{ RAZÕES CALCULADAS } \\
\hline & & \multicolumn{4}{|c|}{ Valores Simulados } & \multicolumn{2}{|c|}{ Valores Experimentais } \\
\hline & & Fluxo de Nêutrons & Fluxo de Gamas & Dose de Nêutrons & Dose de Gama & TLD 100 ROI 1 & TLD 100 ROI 2 \\
\hline $14-15$ & $0 \mathrm{~cm}$ & 1,000 & 1,000 & 1,000 & 1,000 & 1,00 & 1,00 \\
\hline $14-15$ & $-9 \mathrm{~cm}$ & $0,212 \pm 0,002$ & $0,781 \pm 0,008$ & $0,184 \pm 0,001$ & $0,820 \pm 0,009$ & $0,19 \pm 0,02$ & $0,15 \pm 0,01$ \\
\hline $14-15$ & $-18 \mathrm{~cm}$ & $0,130 \pm 0,001$ & $0,483 \pm 0,004$ & $0,115 \pm 0,001$ & $0,547 \pm 0,005$ & $0,12 \pm 0,01$ & $0,09 \pm 0,01$ \\
\hline $2-3$ & $0 \mathrm{~cm}$ & $0,137 \pm 0,001$ & $0,460 \pm 0,003$ & $0,116 \pm 0,001$ & $0,494 \pm 0,004$ & $0,13 \pm 0,01$ & $0,10 \pm 0,01$ \\
\hline $2-3$ & $-9 \mathrm{~cm}$ & $0,152 \pm 0,001$ & $0,430 \pm 0,003$ & $0,132 \pm 0,001$ & $0,461 \pm 0,003$ & $0,11 \pm 0,01$ & $0,06 \pm 0,01$ \\
\hline $2-3$ & $-18 \mathrm{~cm}$ & $0,315 \pm 0,002$ & $0,310 \pm 0,002$ & $0,296 \pm 0,002$ & $0,247 \pm 0,002$ & $0,27 \pm 0,03$ & $0,21 \pm 0,02$ \\
\hline
\end{tabular}


É possível observar que as respostas dos TLDs 100, tanto do ROI 1 quanto do ROI 2 , seguem a variação de dose depositada devido aos nêutrons, mostrando que em regiões onde a dose é predominantemente devido a nêutrons, a resposta TL do TLD 100 segue o mesmo padrão do comportamento da dose devido aos nêutrons.

Esse comportamento das respostas dos TLDs 100 é encontrado também nas irradiações na altura $455 \mathrm{~mm}$ dos dois canais no arranjo cilíndrico com "flux trap".

Por conta das características da dose no TLD 100 presentes no interior do reator, ou seja, a predominância da dose devido a nêutrons, é possível criar uma curva de calibração da resposta do TLDs 100 para a dose depositada no TLD 100 nestas condições. Para a realização das calibrações, foram utilizados os valores de doses depositadas calculadas pelo MCNP5, e as respostas dos TLDs quando irradiados no núcleo do reator IPEN/MB-01 na configuração cilíndrica com "flux trap" nos canais 14-15 e 2-3, e na posição $273 \mathrm{~mm}$ e $455 \mathrm{~mm}$. Os dados de fluxo de nêutrons referentes a essas diferentes posições estão apresentados no Apêndice D.

Para a curva de calibração, foi utilizado um ajuste de uma função polinomial de primeira ordem, Eq. 5-1, no qual $D$ representa a dose depositada no TLD e $R$ representa a resposta termoluminescente.

$$
D=m \cdot R+n
$$

A Figura 33 apresenta a relação de dose depositada calculada com as respostas do ROI 1 do TLD 100 juntamente com a curva ajustada, e a Figura 34 apresenta o gráfico de resíduo para esse ajuste.

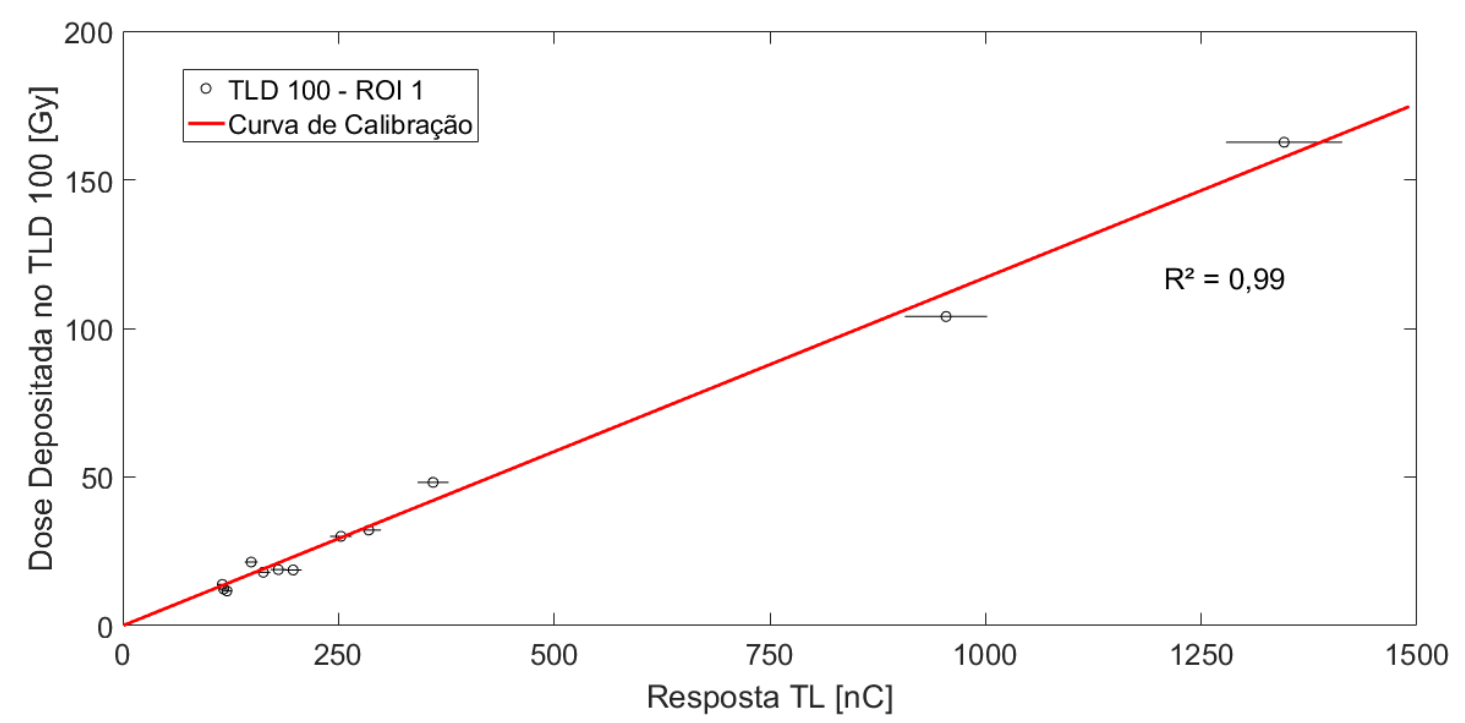

Figura 33 - Curva de calibração da dose devido à nêutrons térmicos no TLD 100 - ROI 


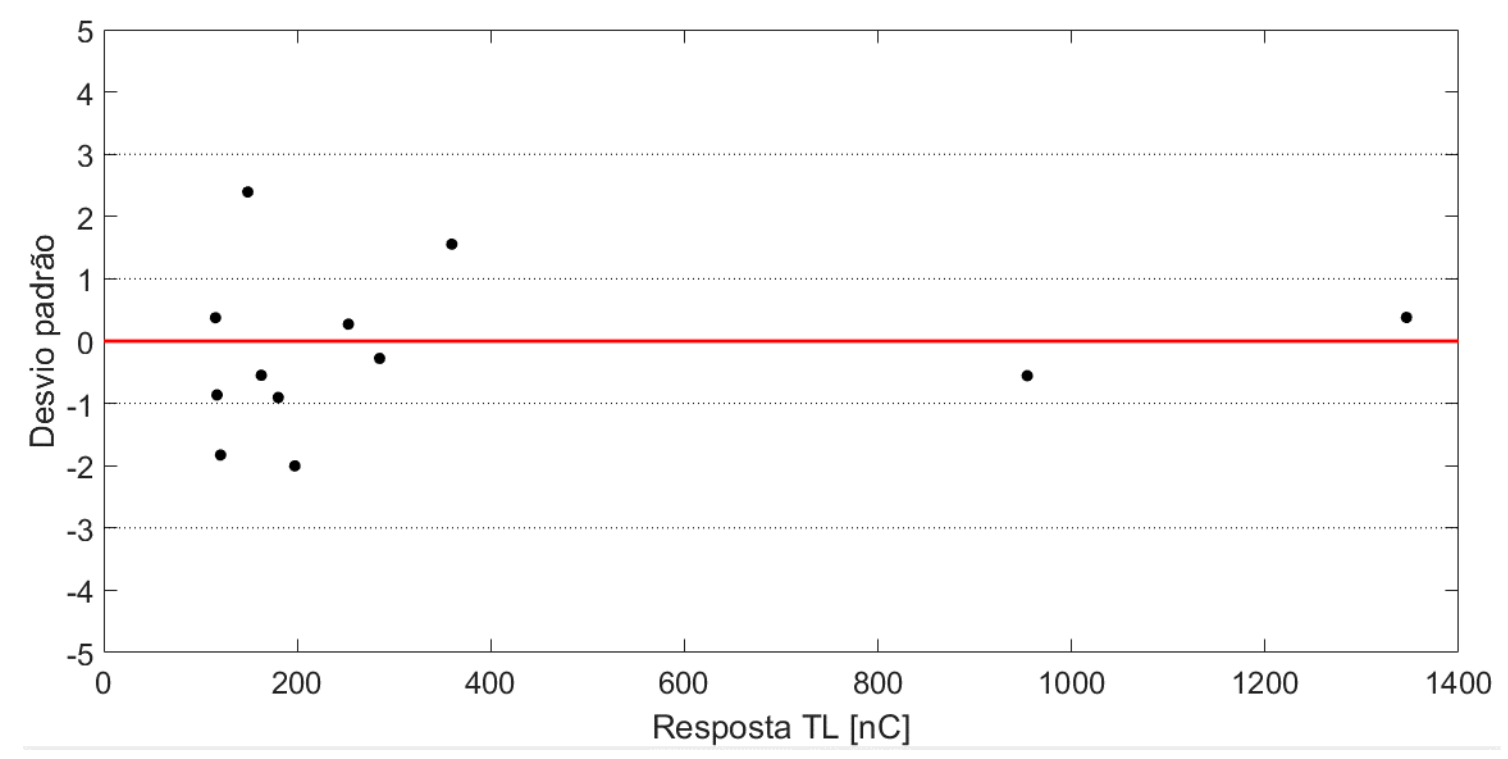

Figura 34 - Gráfico de resíduo das respostas TL do ROI 1 do TLD 100 pela curva ajustada pela equação polinomial de primeira ordem.

No caso do ROI 1 do TLD 100, foi optado por forçar o coeficiente linear da função polinomial de primeira ordem a ser nulo. Isso porque o seu valor, quando ajustado, era zero com uma incerteza 4 Gy. Portanto, para não propagar essa incerteza, foi optado por deixar apenas um grau de liberdade (coeficiente angular) para melhorar o ajuste. A curva ajustada para o caso apresentado na Figura 33 é:

$$
\text { Dose }_{\text {nêutron } \rightarrow T L D 100}=R_{T L D 100-R O I 1} \cdot(0,116 \pm 0,005) \quad E q .5-2
$$

A Figura 35 apresenta os dados das respostas do ROI 2 do TLD 100 e a curva ajustada em função da dose depositada devido à nêutrons no TLD 100, e a Figura 36 apresenta o gráfico de resíduo para esse ajuste. 


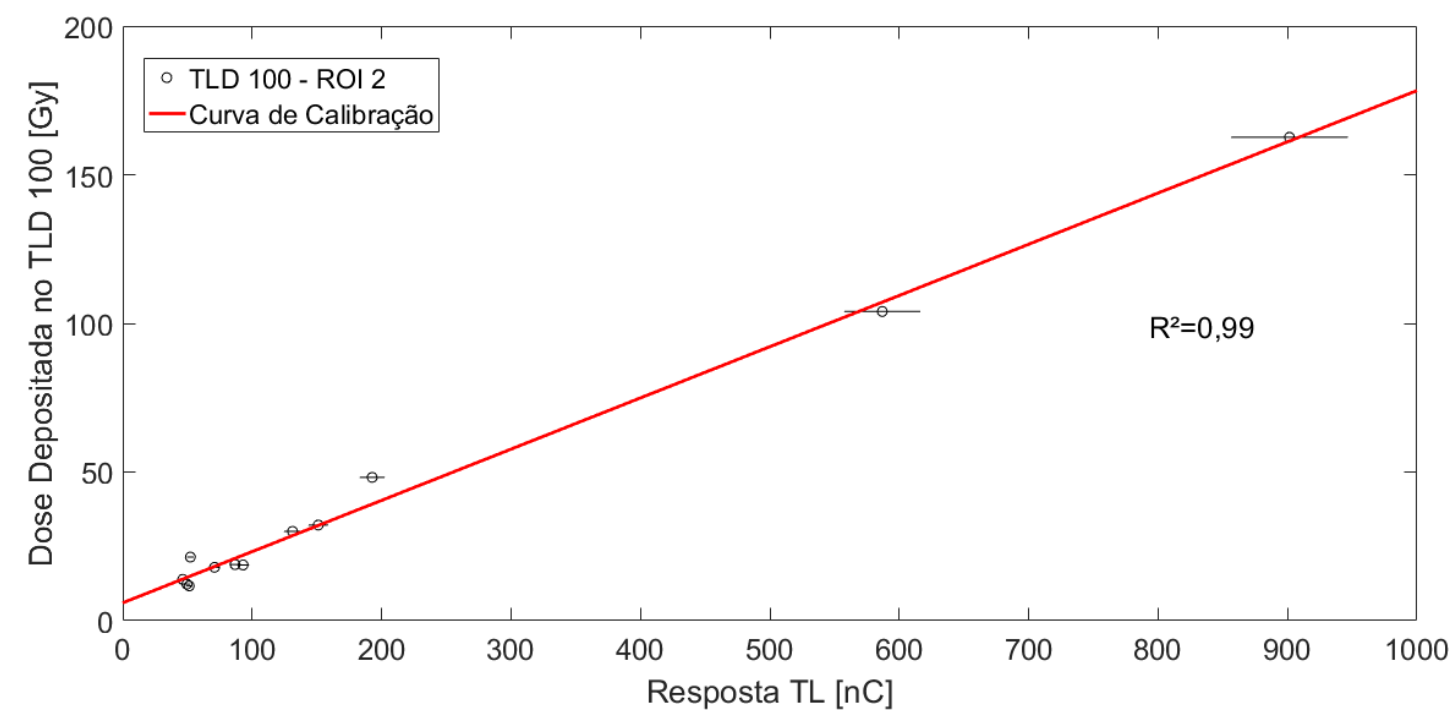

Figura 35 - Curva de calibração da dose devido à nêutrons térmicos no TLD 100 - ROI 2

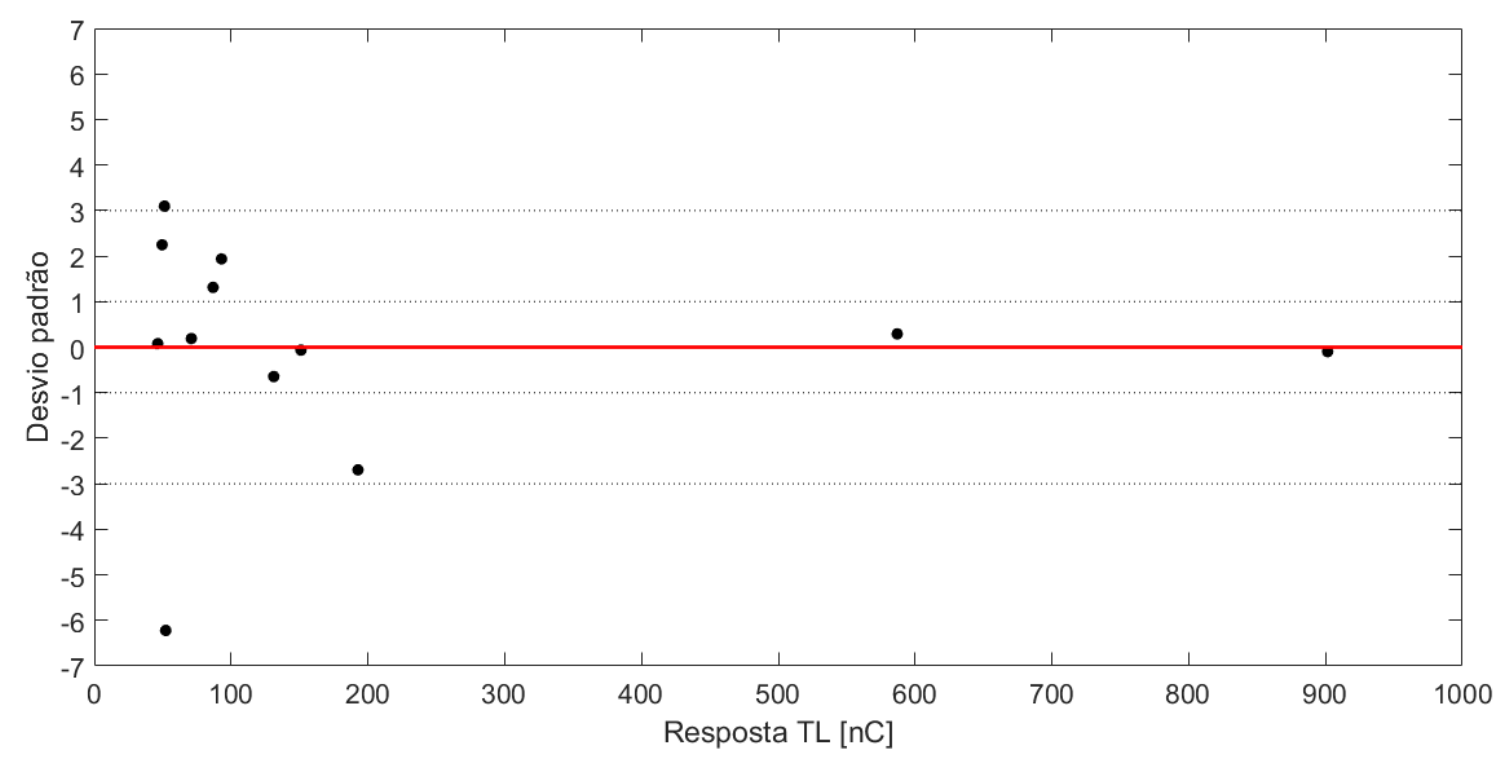

Figura 36 - Gráfico de resíduo das respostas TL do ROI 2 do TLD 100 pela curva ajustada pela equação polinomial de primeira ordem.

A curva ajustada para o caso apresentado na Figura 35 é:

$$
\text { Dose }_{\text {nêutron } \rightarrow T L D 100}=R_{T L D 100-R O I 2} \cdot(0,172 \pm 0,001)+(6 \pm 3) \quad \text { Eq. } 5-3
$$

Analisando o gráfico de resíduos do ajuste para o ROI 2 do TLD 100 (Figura 36) é observado que o ajuste não é tão bom quanto ao ajuste realizado para o ROI do TLD 
100. Portanto, este trabalho propõe o uso do ROI do TLD 100 quando for realizar a dosimetria de nêutrons térmicos em campos que apresentem o fluxo de nêutrons térmicos e de gamas com a mesma ordem de grandeza.

\subsubsection{TLD 700}

Foi realizado um estudo similar para o TLD 700. A Figura 37 apresenta a comparação dos fluxos simulados, e as respostas do ROI 1 do TLD 700 para o canal 1415 com o arranjo do núcleo cilíndrico com "flux trap".

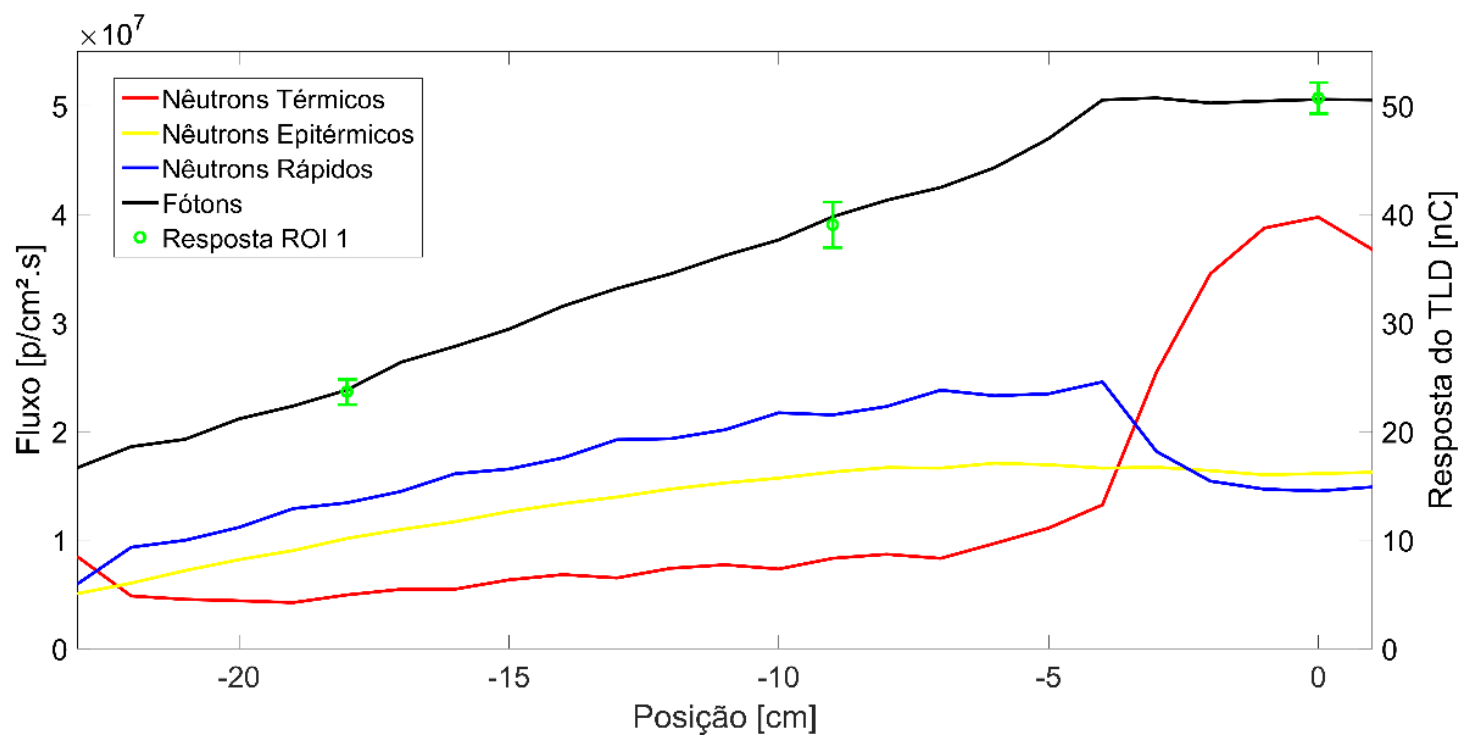

Figura 37 - Comparação entre os fluxos calculados pelo MCNP5 e a resposta TL no ROI 1 dos TLDs 700 para o canal 14-15 com o núcleo no arranjo cilíndrico com "flux trap". As incertezas máximas nos fluxos calculados são inferiores a $1 \%$.

Para o ROI 1 do TLD 700, é observado que sua resposta tem alta dependência com a variação do fluxo de gamas, o que era esperado pelo fato deste TLD ter menor sensibilidade aos nêutrons em comparação ao TLD 100. O mesmo estudo foi realizado para a resposta do ROI 2 do TLD 700. A Tabela 11 apresenta os dados da variação nos fluxos de nêutrons térmicos e gamas nas posições de -9 e $-18 \mathrm{~cm}$ em relação à posição central (posição $0 \mathrm{~cm}$ ), e as respectivas variações de respostas do ROI 1 e do ROI 2 do TLD 700 em relação à mesma posição. 
Tabela 11 - Comparação entre os fluxos de nêutrons e gamas calculados e as respostas dos ROI 1 e 2 do TLD 700

\begin{tabular}{|c|c|c|c|c|}
\hline Posição [cm] & $\begin{array}{l}\text { Fluxo de } \\
\text { nêutron } \\
\text { térmico } \\
\text { (Calculado) }\end{array}$ & $\begin{array}{c}\text { Fluxo de } \\
\text { gamas } \\
\text { (Calculado) }\end{array}$ & $\begin{array}{c}\text { Resposta TLD } \\
700 \text { ROI } 1\end{array}$ & $\begin{array}{l}\text { Resposta TLD } \\
700 \text { ROI } 2\end{array}$ \\
\hline 0 & $1,000 \pm 0,006$ & $1,000 \pm 0,006$ & $1,00 \pm 0,07$ & $1,00 \pm 0,07$ \\
\hline-9 & $0,212 \pm 0,002$ & $0,781 \pm 0,006$ & $0,77 \pm 0,06$ & $0,54 \pm 0,04$ \\
\hline-18 & $0,130 \pm 0,001$ & $0,483 \pm 0,003$ & $0,47 \pm 0,03$ & $0,26 \pm 0,02$ \\
\hline
\end{tabular}

Pode-se observar que a resposta do ROI 1 do TLD 700 apresenta forte dependência com o fluxo de gamas, enquanto a queda da resposta do ROI 2 fica em uma posição intermediária entre a variação do fluxo de nêutrons e a variação no fluxo de gamas. O resultado do cálculo de dose depositada e a resposta TL do ROI 1 no TLD 700, estão apresentados na Figura 38.

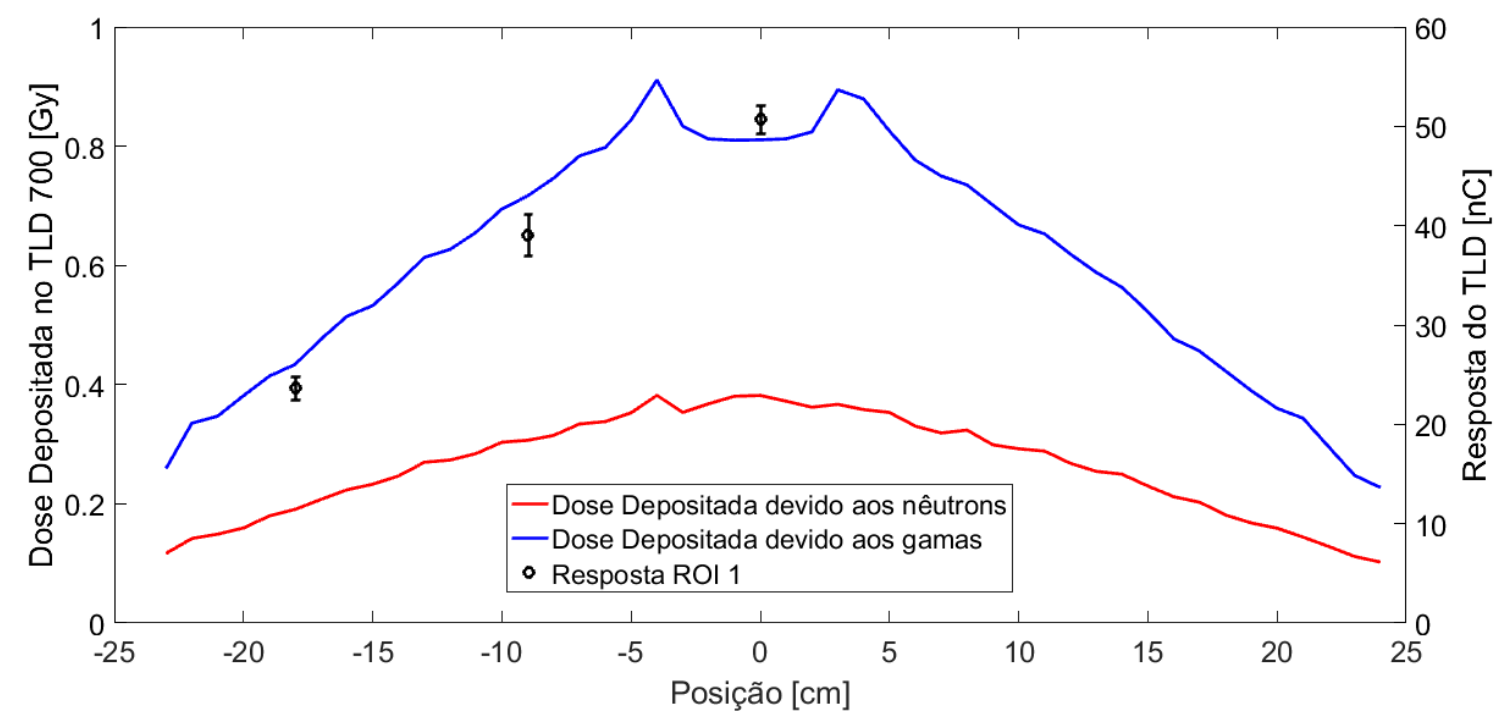

Figura 38 - Comparação das doses calculadas devido aos nêutrons e devido à radiação gama no TLD 700 no canal 14-15 na posição $273 \mathrm{~mm}$ do reator com o núcleo na configuração cilíndrica com "flux trap" e a resposta TL do ROI 1 do TLD 700. As incertezas máximas nas doses calculadas são inferiores a $1 \%$.

O mesmo estudo foi realizado para a resposta do ROI 2, e a análise da dose depositada e da resposta do TLD 700 nas diferentes posições de irradiação do canal 14- 
15. A Tabela 12 apresenta os resultados de doses e respostas TL do ROI 1 e 2 para o TLD 700 nas posições $0 \mathrm{~cm}$ (central), $-9 \mathrm{~cm} \mathrm{e}-18 \mathrm{~cm}$.

Tabela 12 - Comparação dos resultados de dose calculados e respostas TL dos TLDs 700 normalizados pelos dados da posição $0 \mathrm{~cm}$ (central).

\begin{tabular}{|c|c|c|c|c|}
\hline Posição [cm] & $\begin{array}{c}\text { Dose } \\
\text { depositada de } \\
\text { nêutrons } \\
\text { (Calculado) }\end{array}$ & $\begin{array}{c}\text { Dose } \\
\text { depositada de } \\
\text { gama } \\
\text { (Calculado) } \\
\end{array}$ & $\begin{array}{l}\text { Resposta do } \\
\text { ROI } 1\end{array}$ & $\begin{array}{c}\text { Resposta do } \\
\text { ROI } 2\end{array}$ \\
\hline 0 & $1,000 \pm 0,006$ & $1,000 \pm 0,006$ & $1,00 \pm 0,07$ & $1,00 \pm 0,07$ \\
\hline-9 & $0,822 \pm 0,007$ & $0,821 \pm 0,007$ & $0,77 \pm 0,06$ & $0,54 \pm 0,04$ \\
\hline-18 & $0,517 \pm 0,004$ & $0,545 \pm 0,004$ & $0,47 \pm 0,03$ & $0,26 \pm 0,02$ \\
\hline
\end{tabular}

Apesar da dose depositada devido à radiação gama ser superior à dose depositada devido aos nêutrons (veja Figura 38), as variações dessas doses nas diferentes posições de irradiação são muito semelhantes. As variações nas respostas TL (ROI 1 e ROI 2) do TLD 700 não são proporcionais às variações encontradas para as doses depositadas.

Para contribuir na análise da resposta do TLD 700, estes foram irradiados no canal 2-3 e na posição de $273 \mathrm{~mm}$. A Figura 39 e a Figura 40 apresentam, respectivamente, as comparações das respostas dos TLDs 700 pelos fluxos e pelas doses nas diferentes posições do núcleo do reator. 


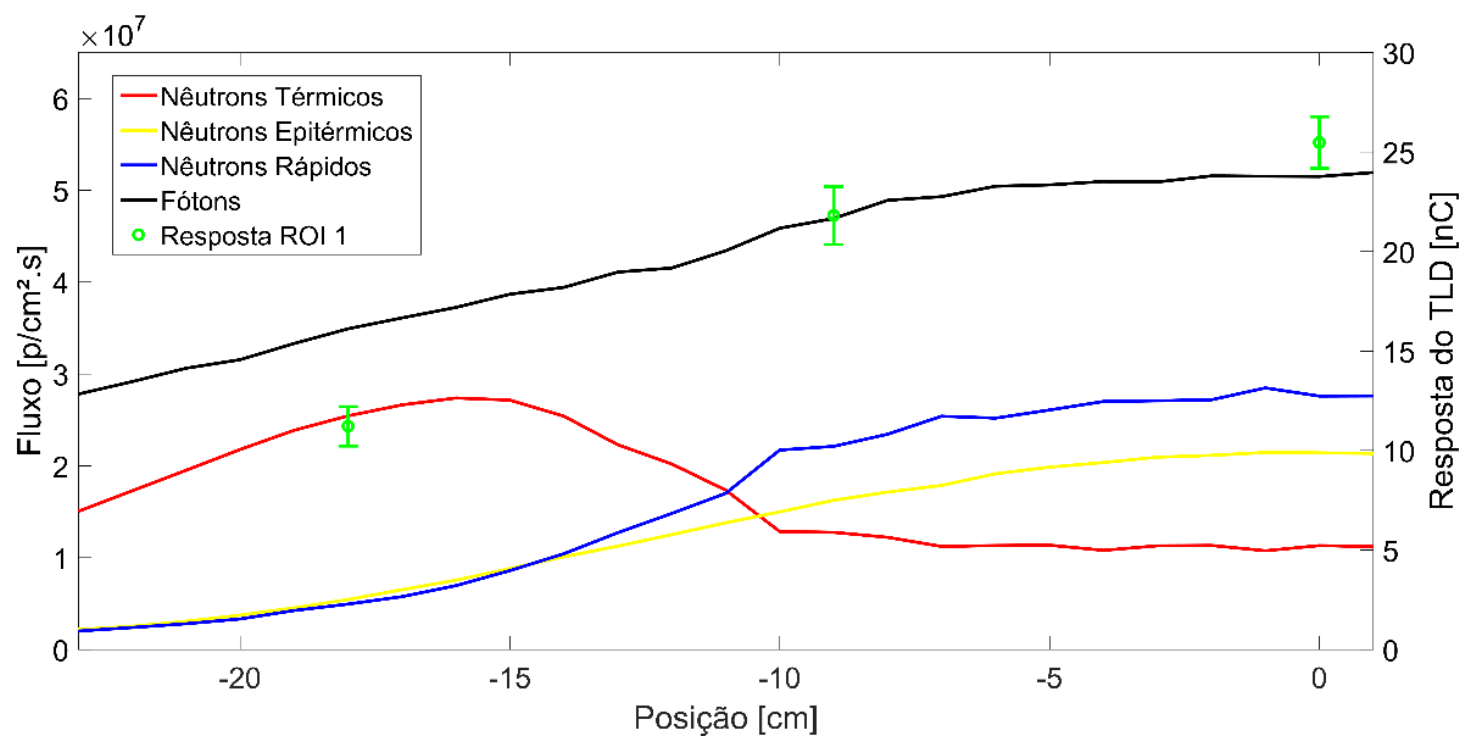

Figura 39 - Comparação entre os fluxos calculados pelo MCNP5 e a resposta TL do ROI 1 dos TLDs 700 para o canal 2-3 com o núcleo no arranjo cilíndrico com "flux trap”. As incertezas máximas nos fluxos calculados são inferiores a $1 \%$.

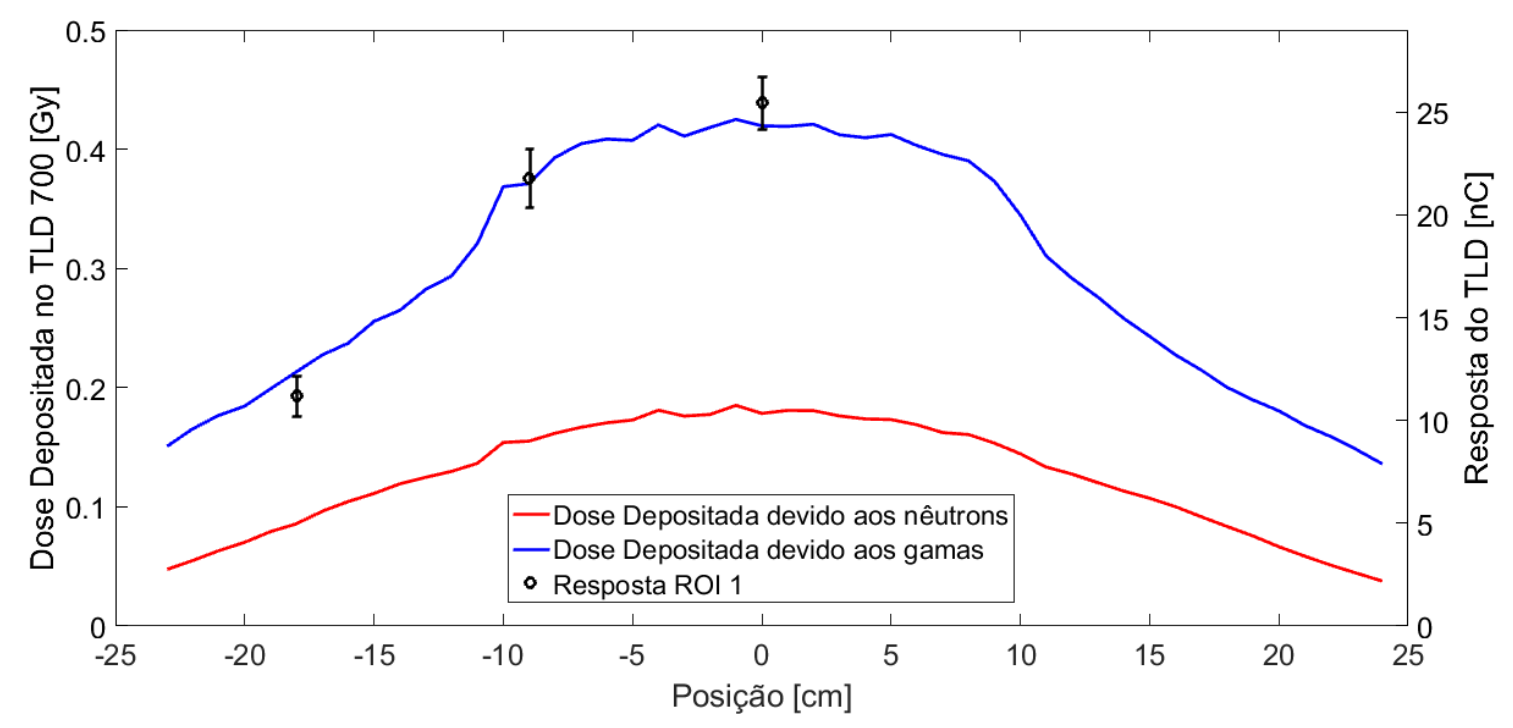

Figura 40 - Comparação das doses calculadas devido aos nêutrons e devido à radiação gama no TLD 700 no canal 2-3 da posição $273 \mathrm{~mm}$ do reator com o núcleo na configuração cilíndrica com "flux trap" e a resposta TL do ROI 1 do TLD 700. As incertezas máximas nas doses calculadas são inferiores a $1 \%$.

Na comparação entre a Figura 39 e a Figura 40, pode-se notar que a dose depositada de nêutrons no TLD 700 não segue o perfil do fluxo de nêutrons térmicos, e sim, um perfil mais próximo dos fluxos de nêutrons epitérmicos e rápidos, mostrando que este TLD, nessas configurações de irradiação, apresenta uma sensibilidade maior aos nêutrons de maior energia. 
Apesar dessa constatação, não foi possível separar da resposta TL do TLD a contribuição, devido à cada faixa energética dos nêutrons.

Os dados das variações das respostas dos TLDs 700 em comparação aos fluxos e às doses depositadas nas irradiações no canal 14-15 e no canal 2-3 na posição 273 mm, estão apresentados na Tabela 13. 
Tabela 13 - Comparação dos dados de fluxo e dose depositados simulados e resposta TL dos TLDs 700 normalizados pelos dados da posição 0 cm

\begin{tabular}{|c|c|c|c|c|c|c|}
\hline \multirow{3}{*}{ Canal } & \multirow{3}{*}{ Posição } & \multicolumn{5}{|c|}{ RAZÕES CALCULADAS } \\
\hline & & \multicolumn{4}{|c|}{ Valores Simulados } & \multirow{2}{*}{$\begin{array}{c}\begin{array}{c}\text { Valores } \\
\text { Experimentais }\end{array} \\
\text { TLD } 700 \text { ROI } 1\end{array}$} \\
\hline & & Fluxo de Nêutrons & Fluxo de Gamas & Dose de Nêutrons & Dose de Gama & \\
\hline $14-15$ & $-9 \mathrm{~cm}$ & $0,212 \pm 0,002$ & $0,781 \pm 0,008$ & $0,810 \pm 0,008$ & $0,820 \pm 0,009$ & $0,77 \pm 0,08$ \\
\hline $14-15$ & $-18 \mathrm{~cm}$ & $0,130 \pm 0,001$ & $0,483 \pm 0,004$ & $0,500 \pm 0,005$ & $0,547 \pm 0,005$ & $0,47 \pm 0,05$ \\
\hline $2-3$ & $-9 \mathrm{~cm}$ & $0,152 \pm 0,001$ & $0,430 \pm 0,003$ & $0,405 \pm 0,004$ & $0,461 \pm 0,003$ & $0,43 \pm 0,05$ \\
\hline $2-3$ & $-18 \mathrm{~cm}$ & $0,315 \pm 0,002$ & $0,310 \pm 0,002$ & $0,238 \pm 0,002$ & $0,247 \pm 0,002$ & $0,22 \pm 0,02$ \\
\hline
\end{tabular}


Nas posições nas quais os TLDs foram irradiados, a variação de fluxo de nêutrons térmicos e gamas eram bem diferentes, porém, as variações dos fluxos de gamas e de nêutrons de mais alta energia eram semelhantes. Portanto, as variações nas doses depositadas devido a estas duas componentes foram semelhantes, impossibilitando uma melhor análise da contribuição de cada componente para a resposta TL do TLD 700.

Para um estudo profundo sobre o TLD 700 em campos mistos, há a necessidade de comparar suas respostas nestes casos e em irradiações em campos puros de gamas e de nêutrons. Como citado por Gambarini (2014), o estudo da resposta a nêutrons do TLD 700 não é uma tarefa simples, devido à dificuldade de se obter um campo puro de nêutrons.

\subsection{Metodologia para uso dos TLDs em Reatores}

Com os dados obtidos nos estudos das respostas termoluminescentes dos TLDs quando irradiados no interior do núcleo do reator IPEN/MB-01, foi proposta uma metodologia para o cálculo da dose de nêutrons no TLD 100. Isso foi possível, pois o TLD 100, devido à diferença de dose depositada entre nêutrons e gamas, apresentou sensibilidade observável apenas para os nêutrons térmicos.

Aconselha-se o uso apenas do ROI 1 do TLD 100, pois mesmo o ROI 2 apresentando linearidade com a dose depositada, os desvios nas respostas do ROI 2 são muito superiores ao da resposta do ROI 1, e os dados obtidos com a curva de calibração pelo ROI 2 apresentam algumas discrepâncias com as reais doses depositadas nos TLDs.

\subsubsection{Teste da utilização da metodologia proposta para o TLD 100}

Para testar a metodologia proposta, foram realizadas algumas irradiações dos TLDs, com o núcleo do reator na configuração retangular. Na configuração retangular, os espectros do campo são muito diferentes dos espectros de campo na configuração cilíndrica com "flux trap" (os espectros estão apresentados nos Apêndices D e E), portanto, o TLD 100 estava sendo testado em campos diferentes daquele em que a metodologia havia sido criada.

A partir das respostas do ROI 1 dos TLDs 100 e utilizando a equação de calibração (Eq. 5-2), foi possível obter as doses depositadas devido a nêutrons no TLD 100. Estes valores foram comparados com os valores calculados através do código MCNP5 e estão apresentados em um gráfico na Figura 41. Neste gráfico, a linha verde representa a posição correta que os pontos deveriam estar, ou seja, o caso em que a metodologia com o ROI 1 do TLD 100 e os cálculos através das simulações, fornecem o mesmo valor de dose depositada devido aos nêutrons no TLD 100. A Figura 42 apresenta o gráfico de resíduos dos dados de dose depositada devido a nêutrons no TLD 100 calculado pelos próprios TLDs, frente aos valores encontrados a partir das simulações. 


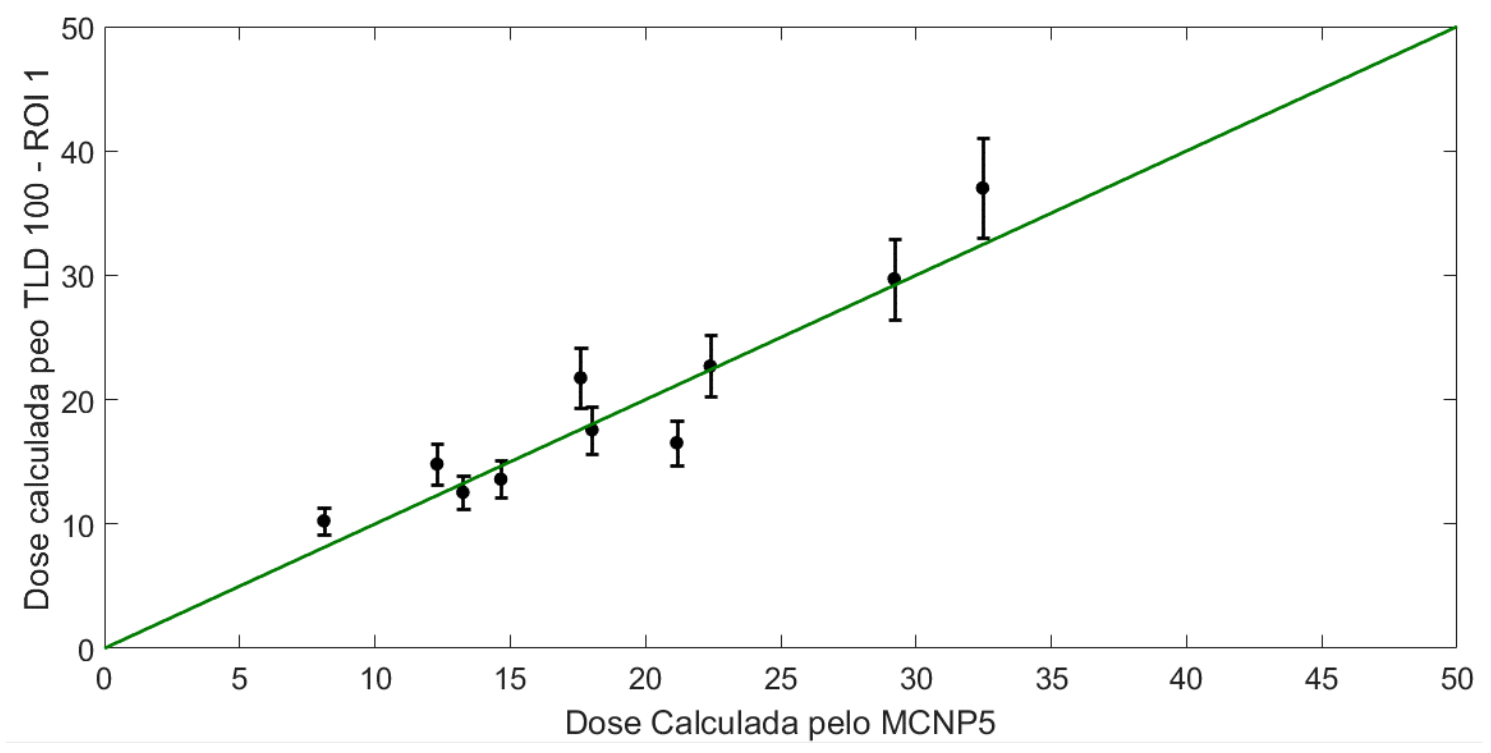

Figura 41 - Gráfico comparando o valor de dose depositada devido aos nêutrons no TLD 100 a partir da resposta do ROI 1 do TLD 100 e a partir das simulações com o MCNP.

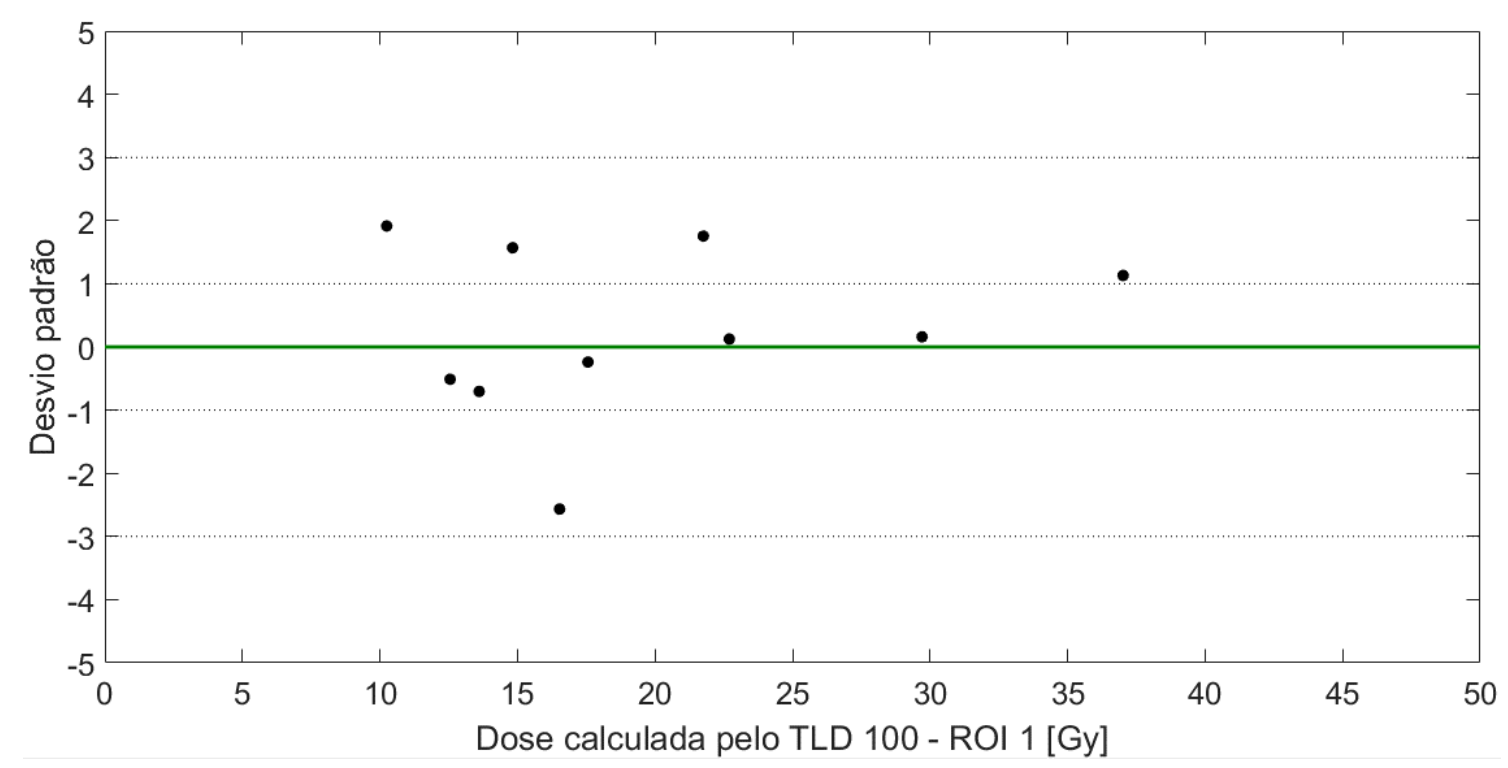

Figura 42 - Gráfico de resíduos da dose depositada de nêutrons térmicos no TLD 100 calculada pela curva de calibração do ROI 1 do TLD 100. 
Os dados de dose obtidos a partir da aplicação das fórmulas de calibração nas respostas dos TLDs aproximam-se dos valores esperados pelos cálculos com o código MCNP5. Portanto, em campos onde o fluxo de nêutrons térmicos e o fluxo de gamas estejam na mesma ordem de grandeza, a metodologia proposta para cálculo de dose de nêutrons no TLD 100, a partir da resposta TL do ROI 1 do TLD 100, é válida e pode ser utilizada para a dosimetria de nêutrons. 


\section{CONCLUSÃO}

O presente trabalho apresenta resultados dosimétricos com uso de TLDs em campo misto de nêutrons e gamas em duas faixas diferentes de fluxo de nêutrons.

O irradiador de polietileno com fonte de $\mathrm{AmBe}$ desenvolvido nesse trabalho, forneceu um fluxo de nêutrons na faixa de $10^{3}$ nêutrons $/ \mathrm{cm}^{2}$.s na posição de irradiação. Nestas condições, foi observado que o TLD 100 e o TLD 700 apresentam uma boa linearidade de sua resposta com a dose. A configuração geométrica e a homogeneidade de dose em sua superfície, fazem com que esse irradiador se torne um ótimo instrumento para selecionamento, estudo de reprodutibilidade e correspondência de resposta com dose depositada para um campo misto de baixo fluxo. Um estudo mais profundo das relações entre as regiões de interesse e as doses depositadas devido às diferentes componentes de campo não foi possível, uma vez que não foram observadas grandes variações de fluxo e dose com mudanças na posição axial do irradiador.

Experimentos no reator IPEN/MB-01 foram importantes para aumentar o conhecimento do grupo quanto ao uso dos TLDs de LiF em um campo proveniente de um reator, onde o fluxo de nêutrons está na faixa de $10^{7}$ nêutrons $/ \mathrm{cm}^{2} . \mathrm{s}$, i.e., quatro ordens de grandeza maior do que o fluxo de nêutrons gerado no irradiador de AmBe. As irradiações no núcleo do reator IPEN/MB-01 ofereceram uma variedade de espectros de campo, propiciando um estudo mais detalhado das respostas dos TLDs que puderam ser irradiados em campos com as mais variadas composições entre nêutrons térmicos e gamas. Esta característica das irradiações no núcleo do reator IPEN/MB-01 não é encontrada em outros trabalhos da literatura, nos quais os TLDs são sempre irradiados em um único espectro de campo misto, como no caso dos trabalhos de Gambarini et. al. (2015), Ekendahl et. al. (2017), Torkzadeh e Manouchehri (2006) e Tsai et. al. (2018), que foram todos realizados em um único espectro de campo. Deste modo, o reator IPEN/MB-01 mostra-se como uma ferramenta única no mundo quanto a possibilidade de variação de espectro de campo misto onde o TLD pode ser irradiado. Entretanto, a maior dificuldade encontrada nessas irradiações, foi a de assegurar o correto posicionamento dos TLDs.

Nesse estudo, na maioria das posições, o fluxo de gamas era superior ao fluxo de nêutrons, mas sempre estando na mesma ordem de grandeza. O TLD 100 apresentou uma dose depositada devido a nêutrons muito superior à dose depositada devido a gamas. Isso é explicado pela concentração superior de ${ }^{6} \mathrm{Li}$ presente nesse TLD. Já para o TLD 700, a diferença de dose depositada entre as componentes de campo não foi alta, estando na mesma ordem de grandeza. Em consequência dessa maior sensibilidade do TLD 100 para nêutrons, sua resposta chega a ser 260 vezes superior a resposta do TLD 700. Nas condições de irradiação usadas neste trabalho (fluxos de nêutrons térmicos e gamas com a mesma ordem de grandeza), foi observado que os dosímetros TLD 100 respondem quase unicamente para nêutrons, sendo sua sensibilidade à gama desprezível. Em virtude disto, este TLD se mostrou adequado para medidas de dose devido a nêutrons e, consequentemente, foi proposto o uso destes para a obtenção da dose depositada de 
nêutrons, diferentemente do que se é proposto na literatura, em que é aconselhado subtrair a dose devido à gamas no TLD 100 para obter a real dose devido aos nêutrons.

A metodologia criada para o cálculo da dose depositada no TLD 100 a partir da resposta do ROI 1 do próprio TLD, foi obtida através de irradiações em diferentes posições no interior do núcleo do reator IPEN/MB-01 no arranjo cilíndrico com "flux trap", na qual os TLDs estavam expostos a campos em que as composições nêutron/gama eram bastante variadas. O teste dessa metodologia foi realizado em irradiações em diferentes posições no núcleo do reator IPEN/MB-01 na configuração retangular, o que fornecia espectros de campo bem diferentes dos espectros utilizados na criação da metodologia. Foi demostrado então que a metodologia proposta funcionou mesmo quando testada em campos com espectros diferentes daquele na qual ela foi criada, mostrando que esta metodologia pode ser empregada quando se tem um campo de irradiação que apresente o fluxo de nêutrons térmicos e de gamas na mesma ordem de grandeza.

O TLD 700 foi, por algum tempo, considerado sensível apenas à radiação gama, e sua resposta devido apenas a essa componente do campo. Alguns trabalhos recentes apontam para um entendimento diferente sobre a sensibilidade do TLD 700 (Gambarini et al., 2014); este trabalho mostrou que este TLD não tem uma resposta unicamente devido à radiação gama. Sua resposta está associada a uma relação entre as doses depositadas provenientes de nêutrons e de gamas. No particular caso dos espectros utilizados nesse trabalho, foi observado que no TLD 700, a dose depositada devido a nêutrons mais energéticos era maior do que a dose depositada devido a nêutrons térmicos, diferentemente do que se é observado na literatura (Gambarini et al., 2014). Entretanto, esta dependência com a energia dos nêutrons no TLD 700 aparenta estar associada à composição das diferentes componentes de campo, sendo possível observar diferentes dependências, dependendo do espectro do campo.

No presente trabalho não foi possível propor um método para obter a dose de gamas ou de nêutrons a partir dos TLDs 700, contudo, demonstrou-se que a utilização do TLD 700 como sendo sensível unicamente à radiação gama é um equívoco para campos com a mesma ordem de grandeza de fluxo das diferentes componentes de campo, e que as doses devido a nêutrons mais energéticos já são mensuradas por esse TLD, o que pode gerar equívocos na dosimetria utilizando este TLD. 


\section{APÊNDICE A - Dependência Energética dos TLDs devido à Radiação}

\section{Gama}

Vários trabalhos anteriores (Davis et al., 2003; Nunn et al., 2008; Massillon-Jl et $a l ., 2014)$ se preocuparam em estudar a dependência energética dos TLDs de LiF para radiação gama, e como parte deste trabalho de Doutorado, reproduziu-se através de simulações os dados obtidos da dependência energética desses TLDs.

Para realizar esta comparação, foi utilizada a grandeza física 'Resposta Termoluminescente por unidade de Kerma no ar' $\left(\mathrm{R}_{\mathrm{MC}}\right)$ calculado de forma puramente computacional. A definição desta grandeza física é a mesma realizada nos trabalhos anteriores de dependência energética e a Eq.A-1 apresenta sua forma de cálculo.

$$
R_{M C}=\frac{\frac{D_{L i F, Q}}{K_{a i r, Q}}}{\frac{D_{L i F, Q o}}{K_{a i r, Q o}}}
$$

Para uma verificação de como estavam os valores obtidos, foi calculado o $\mathrm{R}_{\mathrm{MC}}$ (Eq. A.1), em que são apenas os resultados obtidos normalizados pelo resultado do ${ }^{60} \mathrm{Co}$, e comparados com os dados de Davis (Davis et al., 2003). Nessa comparação, foram simulados a dose depositada e o kerma no ar para as fontes de ${ }^{60} \mathrm{Co},{ }^{137} \mathrm{Cs}$ e ${ }^{192} \mathrm{I}$, além das qualidades de raio-X utilizadas por Davis e algumas outras qualidades de raio-X presentes no IPEN. A Figura 43 apresenta esta comparação: 


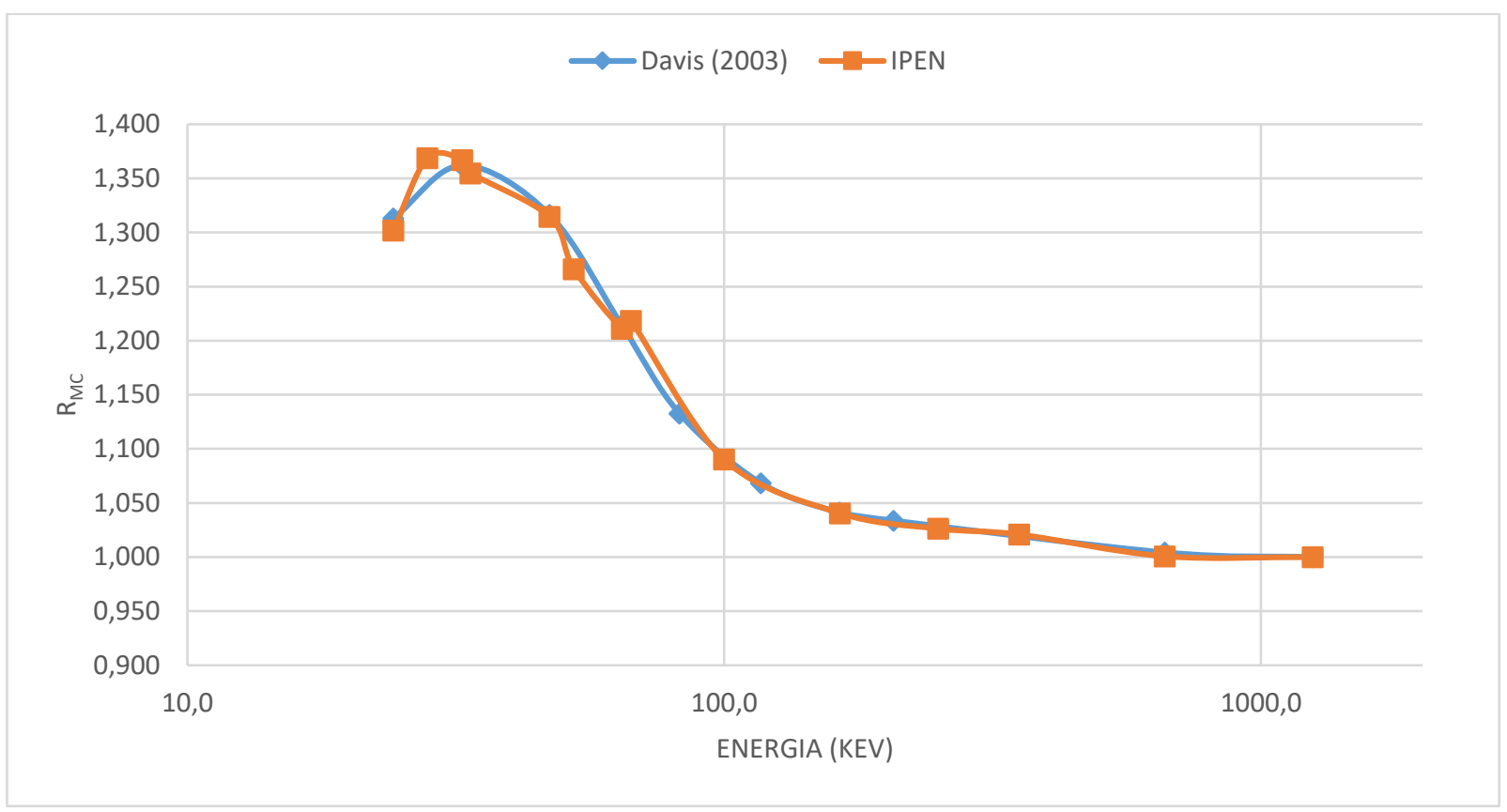

Figura 43 - Comparação dos resultados de $\mathrm{R}_{\mathrm{MC}}$ obtidos neste trabalho e no trabalho de Davis (Davis et al., 2003)

É possível observar uma boa concordância entre os dois trabalhos, apesar de Davis utilizar uma tampa nos suportes de acrílico de $6,2 \mathrm{~mm}$ quando utilizadas as fontes de ${ }^{60} \mathrm{Co}$ $\mathrm{e}^{137} \mathrm{Cs}$, diferente da nossa de $5 \mathrm{~mm}$. Segundo Davis, em seu trabalho, seria necessária uma espessura de 6,2mm de acrílico para gerar equilíbrio eletrônico na posição dos TLDs, porém, outros trabalhos utilizam espessuras diferentes para o mesmo propósito. Foram realizadas algumas simulações com o código MCNP5 para analisar a mínima espessura necessária para garantir o equilíbrio eletrônico, e os dados obtidos mostraram que uma espessura de $5 \mathrm{~mm}$ de acrílico já seria suficiente.

Esse estudo mostrou que as simulações com os TLDs de LiF representam bem a real dependência energética destes TLDs para radiação gama. Portanto, simulações posteriores em campos de gama fornecerão corretamente as doses depositadas nestes TLDs, levando sempre em conta a dependência energética para gama. 


\section{APÊNDICE B - Reprodutibilidade dos TLDs}

Antes de utilizar os TLDs nos campos de interesse, primeiramente foi realizado um estudo quanto à reprodutibilidade dos diferentes tipos de TLD em fonte gama. Esse estudo visava obter as respostas individuas de cada TLD, e as diferenças entre as respostas individuais e a média das respostas dos TLDs.

Foram utilizados dois lotes de TLD, um lote de TLD 100 e outro lote de TLD 700, com 50 TLDs em cada lote. Esses TLDs foram posicionados em um suporte de acrílico com uma matriz de $8 \times 8$ e irradiados em uma fonte de ${ }^{137} \mathrm{Cs}$, Figura 44. Nas irradiações foram fornecidos uma dose de $100 \mathrm{mGy}$ de kerma no ar.
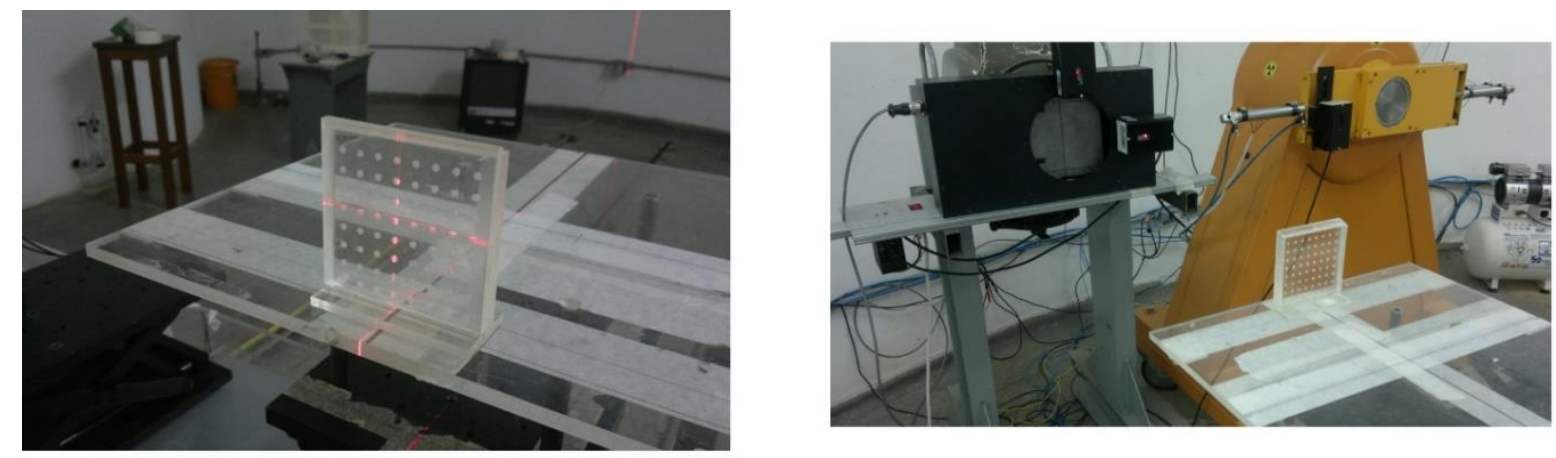

Figura 44 - Irradiação dos TLDs na fonte de ${ }^{137}$ Cs para o estudo da reprodutibilidade

A princípio, o objetivo era a criação de um fator de normalização individual de cada TLD para que todo o lote fosse utilizado, conforme realizado em trabalhos anteriores (Cavalieri, 2013). Porém, esta abordagem não foi possível, pois o uso de um fator de calibração individual requer que os dosímetros sempre respondam da mesma forma em relação à média de todos os dosímetros, ou seja, que os desvios fossem sistemáticos. Esta característica não foi observada nos dosímetros tipo disco, conforme ilustra a Figura 45, que apresenta os possíveis diferentes valores de fator de normalização individual de cada TLD, em 3 diferentes irradiações na fonte de ${ }^{137} \mathrm{Cs}$. 


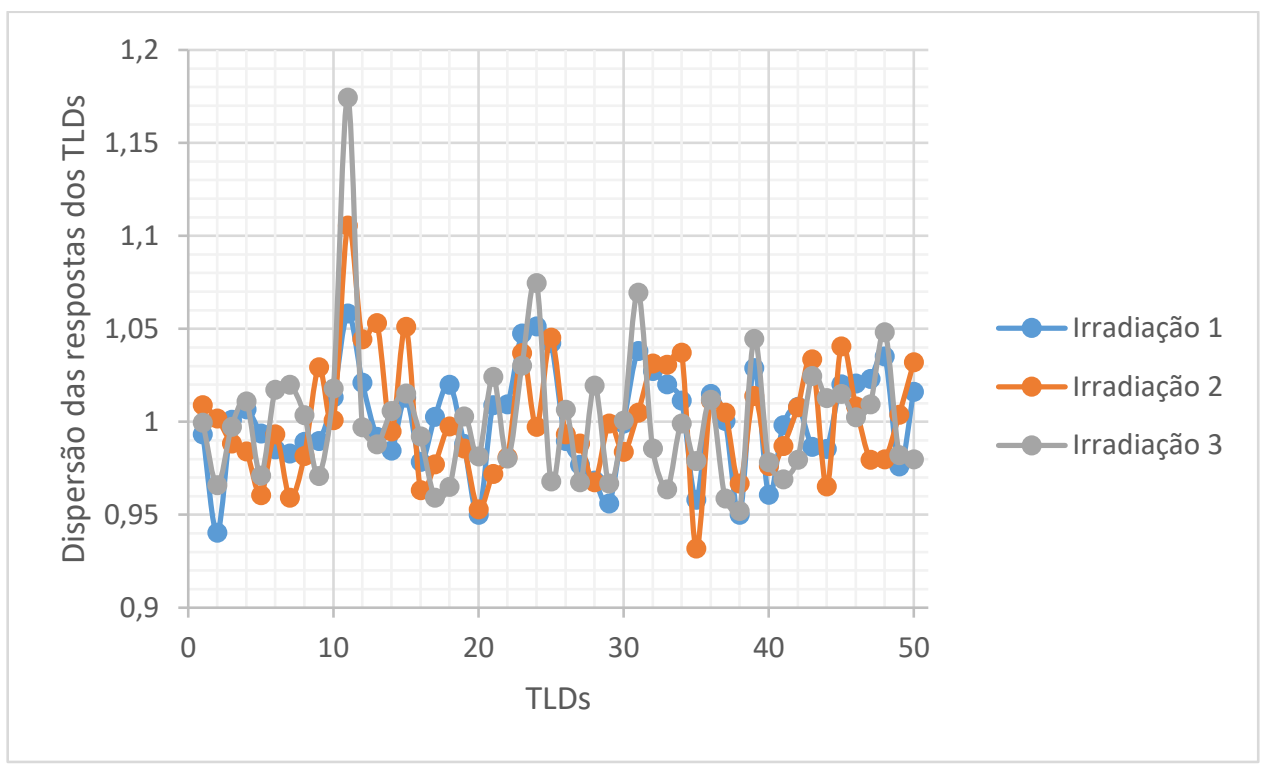

Figura 45 - Dispersão das respostas dos TLDs 100 em relação à média em 3 diferentes irradiações na fonte de ${ }^{137} \mathrm{Cs}$.

Portanto, foi adotada a metodologia de selecionar os TLDs com respostas mais próximas da média e que apresentassem menor dispersão em relação à média nas diferentes irradiações. Como exemplo, a Figura 46 mostra o histograma com as respostas dos TLDs 100 em certa irradiação.

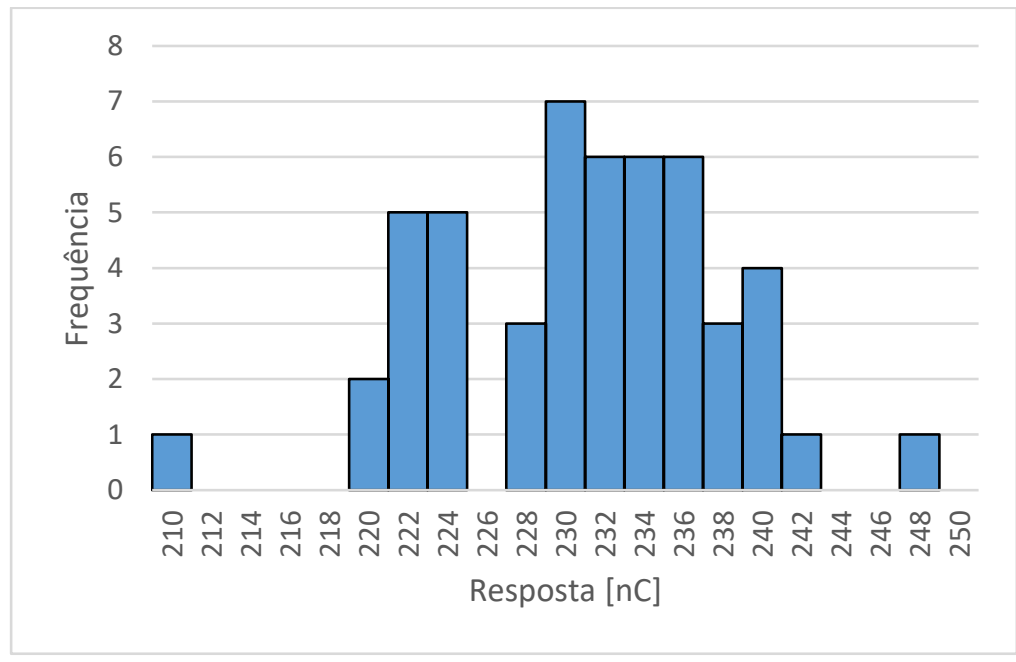

Figura 46 - Histograma com as respostas dos TLDs 100 em uma determinada irradiação na fonte de ${ }^{137} \mathrm{Cs}$

Foram então selecionados os TLDs que apresentavam uma variação máxima de $3 \%$ em relação à média de todos os TLDs, totalizando 18 TLDs de cada tipo para serem utilizados em trabalhos futuros 


\section{APÊNDICE C - Inputs do Reator IPEN/MB-01}

Input do reator na configuração cilíndrica com "flux trap":

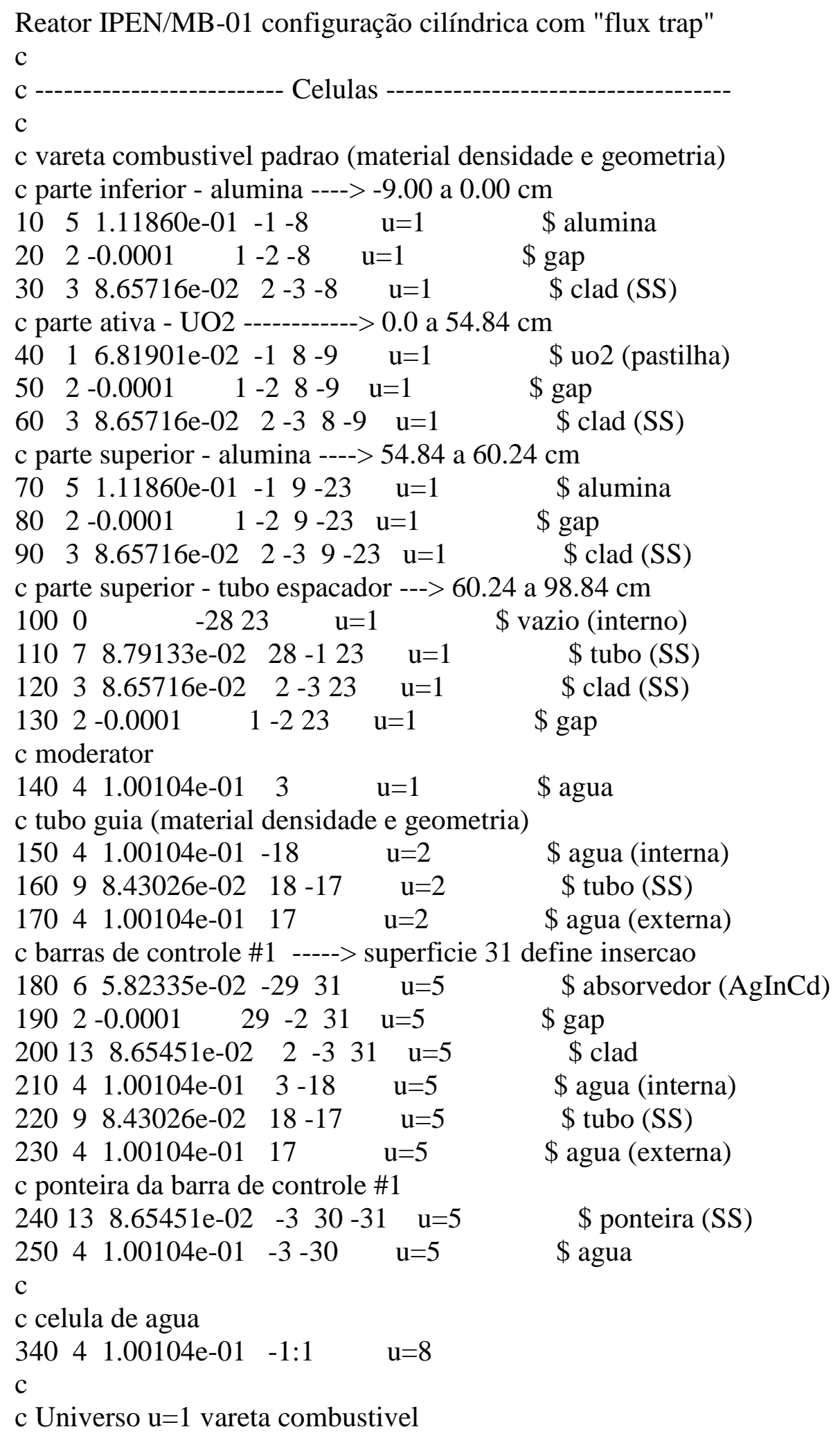




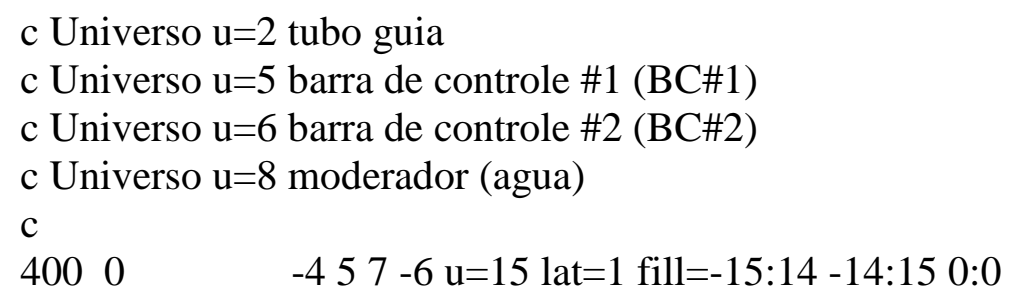

888888888888111111888888888888

888888888811111111118888888888 888888881111111111111188888888 888888111111111111111111888888 888881211121111111151115188888 888811111111111111111111118888 888121112111211115111511151888 888111111111111111111111111888 881111211121111111151115111188 881111111111111111111111111188 811121112111211115111511151118 811111111111111111111111111118 111111211121111111151115111111 111111111111188881111111111111 111111111111188881111111111111 111111111111188881111111111111 111111111111188881111111111111 111111511151111111121112111111 811111111111111111111111111118 811151115111511112111211121118 881111111111111111111111111188 881111511151111111121112111188 888111111111111111111111111888 888151115111511112111211121888 888811111111111111111111118888 888881511151111111121112188888 888888111111111111111111888888 888888881111111111111188888888 888888888811111111118888888888 888888888888111111888888888888 c limite do arranjo

$$
\begin{aligned}
& 410 \quad 0 \quad-13 \quad 14-151625-24 \text { fill=15 } \\
& \text { c } \\
& \text { c placa matriz }(2.20 \mathrm{~cm}) \\
& 42010 \quad 8.67030 \mathrm{e}-02 \quad-3435-3637 \text {-25 } 32 \\
& \text { c } \\
& \text { c agua do tanque moderador } \\
& 4304 \text { 1.00104e-01 }-1233-50 \\
& (13:-14: 15:-16:-25: 24) \\
& \text { (34:-35: 36:-37:25:-32) }
\end{aligned}
$$




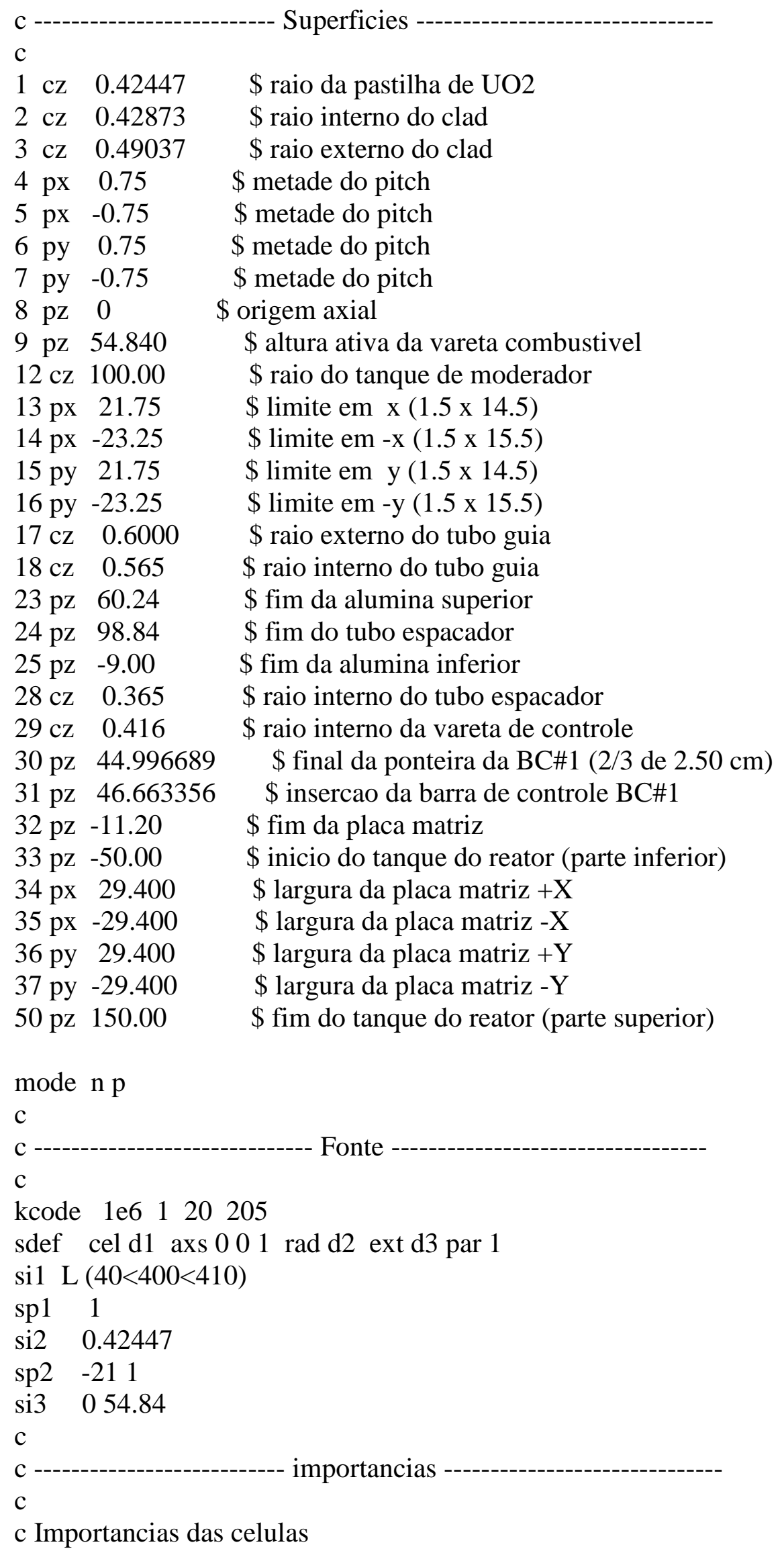




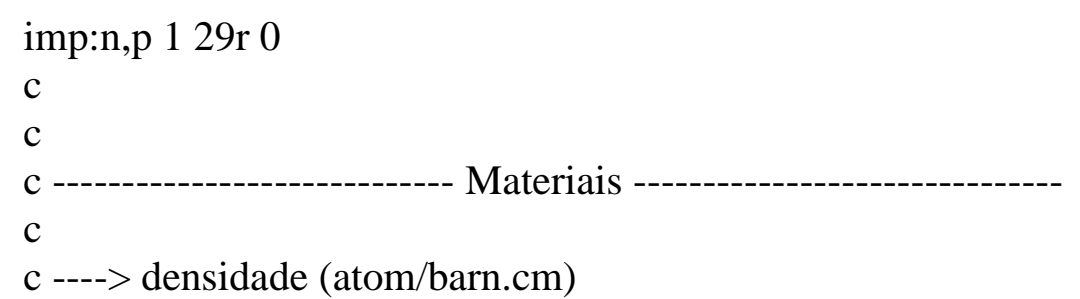

c pastilha - uo2 (atom/barn.cm)

c pastilha - uo2

m1 92235.70c 9.99240e-04 92238.70c 2.1694e-02 8016.70c $4.54890 \mathrm{e}-02$ 92234.70c 7.84620e-06

c vazio (gap)

$\mathrm{m} 2 \quad 8016.70 \mathrm{c} 1$

c encamisamento da vareta combustivel - SS304 - (clad)

m3 26054.70c 3.57366e-03 26056.70c 5.40491e-02 26057.70c 1.22693e-03 $26058.70 \mathrm{c} 1.59256 \mathrm{e}-04$

24050.70c 7.61902e-04 24052.70c $1.41123 \mathrm{e}-02$ 24053.70c $1.56980 \mathrm{e}-03$

$24054.70 \mathrm{c} 3.82755 \mathrm{e}-04$

28058.70c 5.62942e-03 28060.70c 2.09590e-03 28061.70c 8.96301e-05

28062.70 c $2.80805 \mathrm{e}-0428064.70 \mathrm{c} 6.96915 \mathrm{e}-05$

14028.70 c $6.28990 \mathrm{e}-04$ 14029.70c $3.07498 \mathrm{e}-05$ 14030.70c $1.97329 \mathrm{e}-05$

16032.70 c $1.48849 \mathrm{e}-0516033.70 \mathrm{c} \quad 1.13926 \mathrm{e}-07$ 16034.70c $6.20747 \mathrm{e}-07$

16036.70 c $2.78500 \mathrm{e}-09$

42092.70c $1.30932 \mathrm{e}-05$ 42094.70c $7.98754 \mathrm{e}-06$ 42095.70c $1.36022 \mathrm{e}-05$

42096.70c $1.41032 \mathrm{e}-05$ 42097.70c $7.99122 \mathrm{e}-06$ 42098.70c $1.99853 \mathrm{e}-05$

42100.70c $7.81608 \mathrm{e}-06$

25055.70c $1.46450 \mathrm{e}-03$ 15031.70c $4.00400 \mathrm{e}-05$ 6000.70c $1.12390 \mathrm{e}-04$

27059.70c $1.74020 \mathrm{e}-04$

c agua

$\mathrm{m} 4$ 1001.70c $6.67360 \mathrm{e}-02$ 8016.70c $3.33680 \mathrm{e}-02$

mt4 lwtr.10t

c alumina - al2o3

m5 8016.70c 6.71160e-02 13027.70c 4.47440e-02

c barra de controle - AG-IN-CD

m6 47107.70c 2.31847e-02 47109.70c 2.11443e-02

49113.70c 3.42556e-03 49115.70c 7.50941e-03

48106.70c 3.43547e-05 48108.70c 2.40077e-05 48110.70c 3.30790e-04

48111.70c 3.35939e-04 48112.70c $6.27647 \mathrm{e}-04$ 48113.70c $3.15035 \mathrm{e}-04$

48114.70c 7.34172e-04 48116.70c 1.88096e-04

16032.70 c $1.79100 \mathrm{e}-0416033.70$ c $1.37080 \mathrm{e}-06$ 16034.70c $7.46906 \mathrm{e}-06$

$16036.70 \mathrm{c} 3.35102 \mathrm{e}-08$

6000.70c $1.50520 \mathrm{e}-03$ 8016.70c $1.77030 \mathrm{e}-03$

c tubo espacador - SS

m7 26054.70c 3.74872e-03 26056.70c 5.66967e-02 26057.70c $1.28703 \mathrm{e}-03$

$26058.70 \mathrm{c} 1.67057 \mathrm{e}-04$

24050.70 c $7.59839 \mathrm{e}-0424052.70 \mathrm{c} \quad 1.40741 \mathrm{e}-0224053.70 \mathrm{c} 1.56555 \mathrm{e}-03$

$24054.70 \mathrm{c} 3.81719 \mathrm{e}-04$

28058.70 c $4.53128 \mathrm{e}-0328060.70 \mathrm{c} \quad 1.68705 \mathrm{e}-0328061.70 \mathrm{c} \quad 7.21458 \mathrm{e}-05$

28062.70c 2.26028e-04 28064.70c 5.60967e-05

25055.70c $1.15810 \mathrm{e}-03$

14028.70c 1.03286e-03 14029.70c 5.04940e-05 14030.70c 3.24033e-05 
15031.70c 3.11240e-05 6000.70c 2.40780e-04 27059.70c $1.14500 \mathrm{e}-04$ c tubo guia - SS

m9 26054.70c 3.44894e-03 26056.70c 5.21628e-02 26057.70c $1.18411 \mathrm{e}-03$

26058.70c $1.53698 \mathrm{e}-04$

24050.70c $7.38069 \mathrm{e}-0424052.70$ c $1.36708 \mathrm{e}-02$ 24053.70c $1.52070 \mathrm{e}-03$

24054.70c 3.70782e-04

28058.70 c $6.27853 \mathrm{e}-03$ 28060.70c $2.33757 \mathrm{e}-03$ 28061.70c $9.99650 \mathrm{e}-05$

28062.70c 3.13183e-04 28064.70c 7.77273e-05

$25055.70 \mathrm{c} 1.15010 \mathrm{e}-03$

14028.70 c $6.12655 \mathrm{e}-04 \quad 14029.70$ c $2.99512 \mathrm{e}-05$ 14030.70c $1.92205 \mathrm{e}-05$

15031.70c 4.50000e-05 6000.70c 8.89680e-05

c placa matriz - SS

m10 26054.70c 3.63630e-03 26056.70c 5.49964e-02 26057.70c $1.24843 \mathrm{e}-03$

26058.70c $1.62047 \mathrm{e}-04$

24050.70c $7.56501 \mathrm{e}-0424052.70 \mathrm{c} \quad 1.40122 \mathrm{e}-0224053.70 \mathrm{c} \quad 1.55868 \mathrm{e}-03$

24054.70c 3.80042e-04

28058.70c 5.28566e-03 28060.70c $1.96791 \mathrm{e}-03$ 28061.70c $8.41568 \mathrm{e}-05$

28062.70c 2.63658e-04 28064.70c $6.54358 \mathrm{e}-05$

$14028.70 \mathrm{c} \quad 8.01962 \mathrm{e}-04 \quad 14029.70 \mathrm{c} 3.92060 \mathrm{e}-05$ 14030.70c $2.51595 \mathrm{e}-05$

16032.70 c $4.25282 \mathrm{e}-06 \quad 16033.70$ c $3.25504 \mathrm{e}-08$ 16034.70c $1.77356 \mathrm{e}-07$

$16036.70 \mathrm{c} 7.95715 \mathrm{e}-10$

42092.70c 4.62114e-06 42094.70c 2.81913e-06 42095.70c 4.80079e-06

42096.70c $4.97759 \mathrm{e}-06$ 42097.70c 2.82043e-06 42098.70c $7.05364 \mathrm{e}-06$

42100.70c 2.75861e-06

25055.70c 1.25030e-03 15031.70c 5.54400e-05 6000.70c 7.94260e-05

c encamisamento das barras de controle e de seguranca - SS304

m13 26054.70c 3.50278e-03 26056.70c 5.29770e-02 26057.70c $1.20259 \mathrm{e}-03$

26058.70c $1.56097 \mathrm{e}-04$

24050.70c $7.62733 \mathrm{e}-0424052.70$ c $1.41277 \mathrm{e}-02$ 24053.70c $1.57152 \mathrm{e}-03$

$24054.70 \mathrm{c} 3.83172 \mathrm{e}-04$

28058.70c $6.54682 \mathrm{e}-03$ 28060.70c $2.43746 \mathrm{e}-03$ 28061.70c $1.04236 \mathrm{e}-04$

28062.70 c 3.26566e-04 28064.70c $8.10488 \mathrm{e}-05$

14028.70 c $7.07614 \mathrm{e}-04$ 14029.70c 3.45935e-05 14030.70c $2.21996 \mathrm{e}-05$

16032.70c $4.25282 \mathrm{e}-06$ 16033.70c 3.25504e-08 16034.70c $1.77356 \mathrm{e}-07$

16036.70 c $7.95715 \mathrm{e}-10$

42092.70c $2.31057 \mathrm{e}-06$ 42094.70c $1.40957 \mathrm{e}-06$ 42095.70c $2.40040 \mathrm{e}-06$

42096.70c 2.48879e-06 42097.70c $1.41022 \mathrm{e}-06$ 42098.70c $3.52682 \mathrm{e}-06$

42100.70c $1.37931 \mathrm{e}-06$

29063.70c 9.43728e-05 29065.70c 4.07687e-05

50112.70c 3.30769e-08 50114.70c $2.17761 \mathrm{e}-08$ 50115.70c $1.12914 \mathrm{e}-08$

50116.70c $4.78714 \mathrm{e}-0750117.70$ c $2.50690 \mathrm{e}-07$ 50118.70c $7.83891 \mathrm{e}-07$

50119.70c $2.75677 \mathrm{e}-0750120.70 \mathrm{c} \quad 1.03719 \mathrm{e}-0650122.70 \mathrm{c} \quad 1.44933 \mathrm{e}-07$

50124.70c $1.78316 \mathrm{e}-07$

15031.70c $4.15796 \mathrm{e}-05$ 6000.70c $8.33972 \mathrm{e}-05$ 27059.70c $1.37594 \mathrm{e}-04$

25055.70c $1.18080 \mathrm{e}-03$

c TLD 100

m100 9019.70c $0.5 \quad 3006.70 \mathrm{c} 0.0375 \quad 3007.70 \mathrm{c} \quad 0.4625$

c TLD 700

m700 9019.70c $0.5 \quad 3006.70$ c 0.00005 3007.70c 0.49995 
Input do reator na configuração retangular:

Reator IPEN/MB-01 configuração retangular

$\mathrm{c}$

c ------------------------- Celulas

c vareta combustivel padrao (material densidade e geometria)

c parte inferior - alumina ----> -9.00 a $0.00 \mathrm{~cm}$

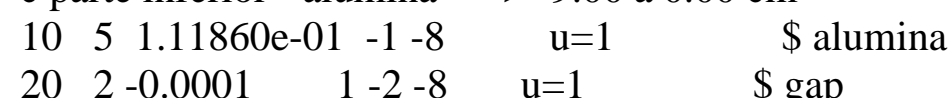

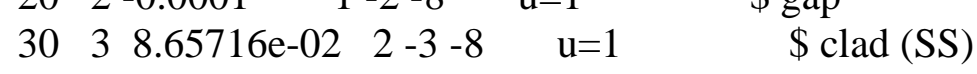

c parte ativa - UO2 ----------> 0.0 a $54.84 \mathrm{~cm}$

$\begin{array}{lllllll}40 & 1 & 6.81901 \mathrm{e}-02 & -1 & 8 & -9 & \mathrm{u}=1\end{array}$

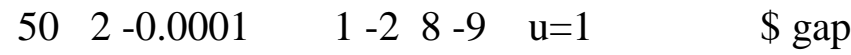

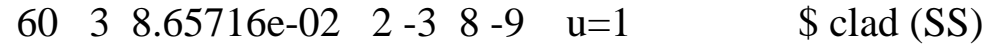

c parte superior - alumina ----> 54.84 a $60.24 \mathrm{~cm}$

$\begin{array}{lllllll}70 & 5 & 1.11860 \mathrm{e}-01 & -1 & 9 & -23 & \mathrm{u}=1\end{array}$

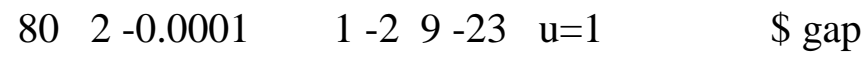

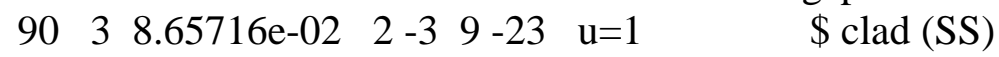

c parte superior - tubo espacador ---> 60.24 a $98.84 \mathrm{~cm}$

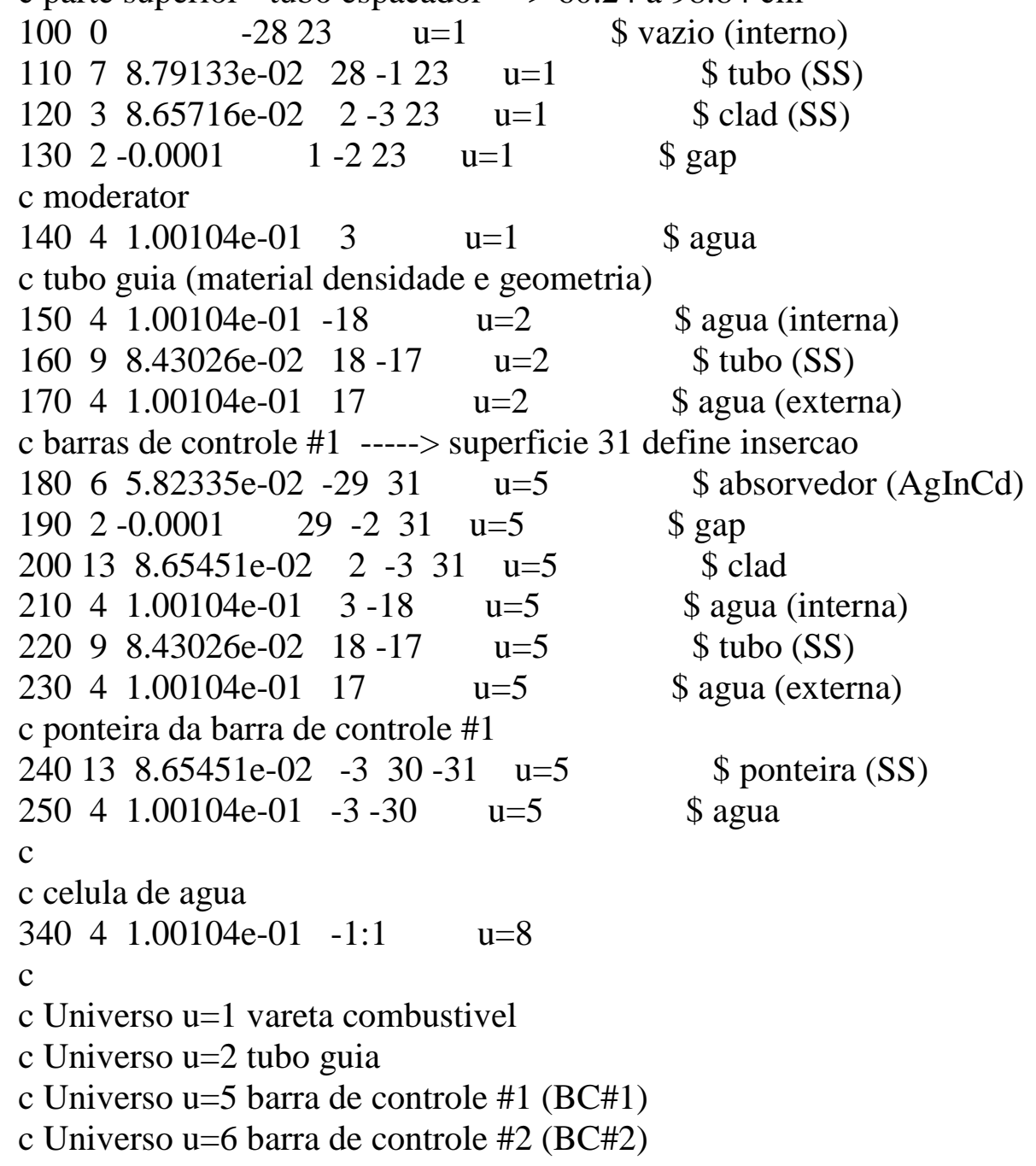




\begin{abstract}
c Universo $\mathrm{u}=8$ moderador (agua)
c

$4000 \quad-457-6 \mathrm{u}=15$ lat=1 fill=-15:14 $-14: 150: 0$

888888888888888888888888888888 888888888888888888888888888888 811111111111111111111111111118 811111111111111111111111111118 811111211121111111151115111118 811111111111111111111111111118 811121112111211115111511151118 811111111111111111111111111118 811111211121111111151115111118 811111111111111111111111111118 811121112111211115111511151118 811111111111111111111111111118 811111211121111111151115111118 811111111111111111111111111118 811111111111111111111111111118 811111111111111111111111111118 811111111111111111111111111118 811111511151111111121112111118 811111111111111111111111111118 811151115111511112111211121118 811111111111111111111111111118 811111511151111111121112111118 811111111111111111111111111118 811151115111511112111211121118 811111111111111111111111111118 811111511151111111121112111118 811111111111111111111111111118 811111111111111111111111111118 888888888888888888888888888888 888888888888888888888888888888 c limite do arranjo
\end{abstract}

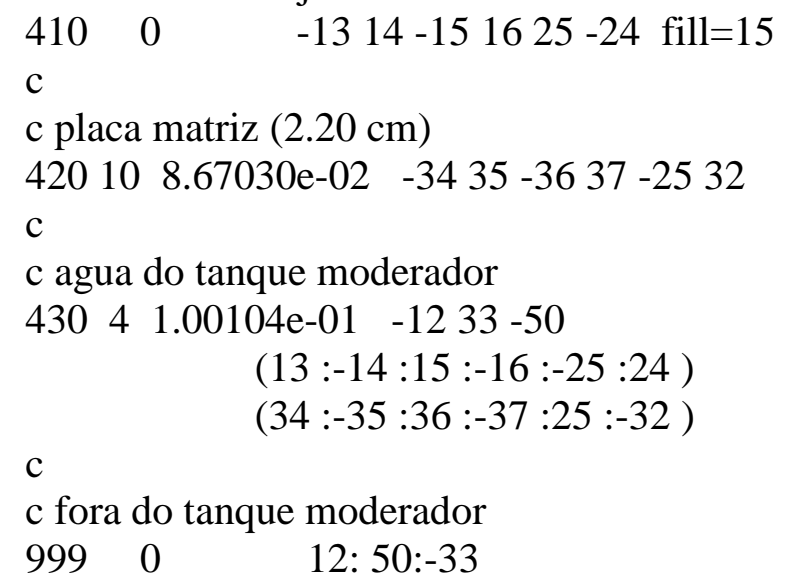


$1 \mathrm{cz} \quad 0.42447$ \$ raio da pastilha de UO2

$2 \mathrm{cz} \quad 0.42873 \quad$ \$ raio interno do clad

$3 \mathrm{cz} \quad 0.49037 \quad$ \$ raio externo do clad

4 px $0.75 \quad$ \$ metade do pitch

5 px $-0.75 \quad$ \$ metade do pitch

6 py $0.75 \quad \$$ metade do pitch

7 py $-0.75 \quad \$$ metade do pitch

$8 \mathrm{pz} 0 \quad$ \$ origem axial

$9 \mathrm{pz} 54.840 \quad$ \$ altura ativa da vareta combustivel

$12 \mathrm{cz} 100.00 \quad$ \$ raio do tanque de moderador

13 px $21.75 \quad$ \$ limite em x $(1.5 \times 14.5)$

$14 \mathrm{px}-23.25 \quad \$$ limite em $-\mathrm{x}(1.5 \times 15.5)$

15 py $21.75 \quad$ \$limite em y $(1.5 \times 14.5)$

16 py $-23.25 \quad \$$ limite em -y $(1.5$ x 15.5$)$

$\begin{array}{lll}17 \mathrm{cz} & 0.6000 & \$ \text { raio externo do tubo guia }\end{array}$

$18 \mathrm{cz} \quad 0.565 \quad$ \$ raio interno do tubo guia

$23 \mathrm{pz} \quad 60.24 \quad$ \$ fim da alumina superior

$24 \mathrm{pz} \quad 98.84 \quad$ \$ fim do tubo espacador

$25 \mathrm{pz}-9.00 \quad$ \$ fim da alumina inferior

$28 \mathrm{cz} \quad 0.365$ \$ raio interno do tubo espacador

$29 \mathrm{cz} \quad 0.416 \quad$ \$ raio interno da vareta de controle

$30 \mathrm{pz} 29.346689$ \$ final da ponteira da BC\#1 $(2 / 3$ de $2.50 \mathrm{~cm})$

$31 \mathrm{pz} \quad 31.013356$ \$ insercao da barra de controle BC\#1

$32 \mathrm{pz}-11.20 \quad$ \$ fim da placa matriz

$33 \mathrm{pz}-50.00 \quad$ \$ inicio do tanque do reator (parte inferior)

34 px $29.400 \quad$ \$ largura da placa matriz $+X$

35 px $-29.400 \quad$ \$ largura da placa matriz $-X$

36 py $29.400 \quad$ \$ largura da placa matriz $+Y$

37 py $-29.400 \quad$ \$ largura da placa matriz $-Y$

$50 \mathrm{pz} 150.00 \quad \$$ fim do tanque do reator (parte superior)

mode $\mathrm{n} \mathrm{p}$

$\mathrm{c}$

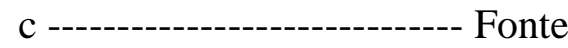

$\mathrm{c}$

kcode 1 e6 120205

sdef cel d1 axs $001 \operatorname{rad} 2$ ext $\mathrm{d} 3 \operatorname{par} 1$

si1 L $(40<400<410)$

sp1 1

si2 0.42447

sp2 -211

si3 054.84

$\mathrm{c}$

c ---------------------------- importancias

$\mathrm{c}$

c Importancias das celulas

imp:n,p 1 29r 0

c

c 


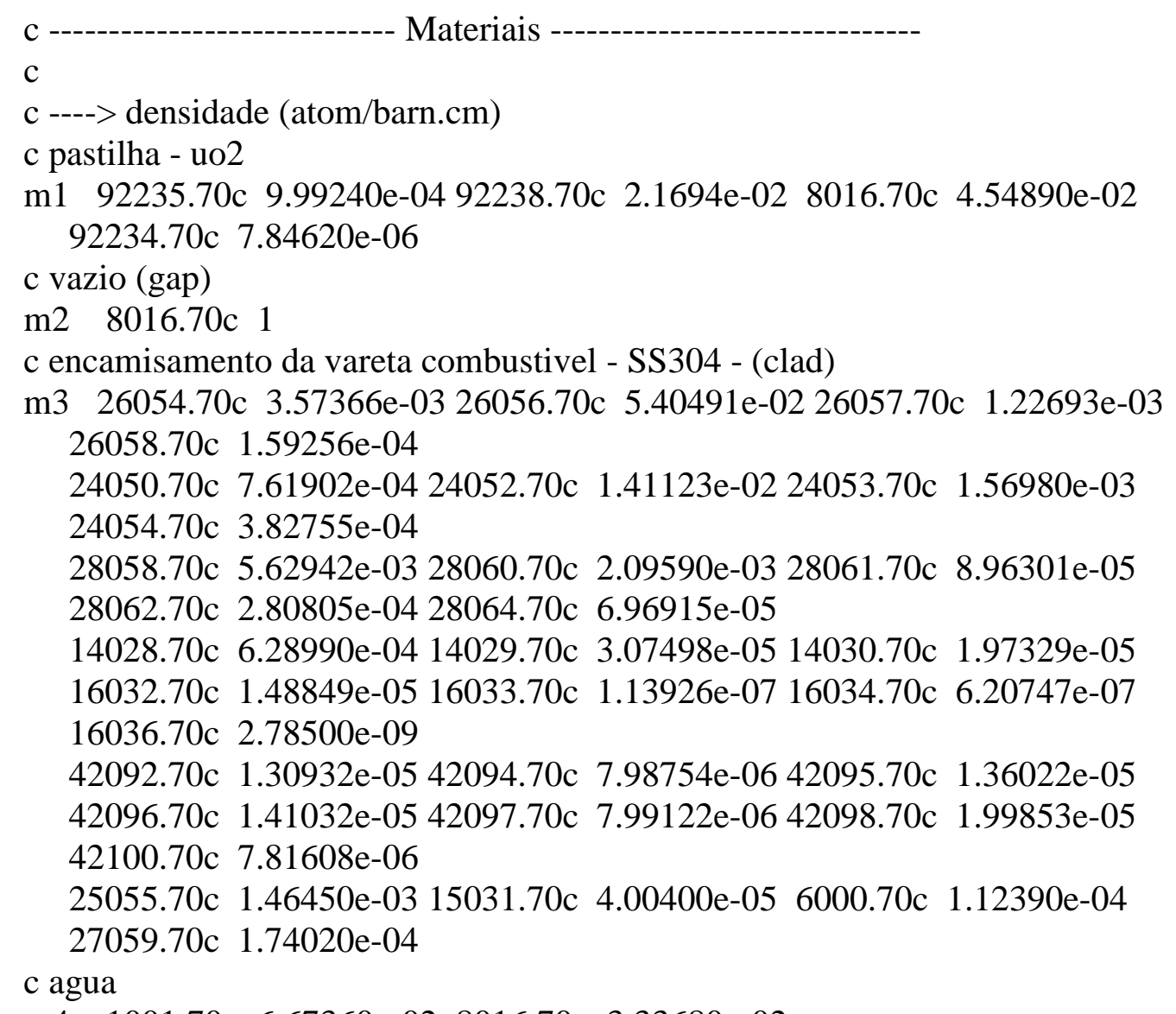

m4 1001.70c 6.67360e-02 8016.70c 3.33680e-02

mt4 lwtr.10t

c alumina - al2o3

m5 8016.70c 6.71160e-02 13027.70c 4.47440e-02

c barra de controle - AG-IN-CD

m6 47107.70c 2.31847e-02 47109.70c 2.11443e-02

49113.70c 3.42556e-03 49115.70c 7.50941e-03

48106.70c 3.43547e-05 48108.70c 2.40077e-05 48110.70c 3.30790e-04

48111.70c 3.35939e-04 48112.70c $6.27647 \mathrm{e}-04$ 48113.70c $3.15035 \mathrm{e}-04$

48114.70c 7.34172e-04 48116.70c $1.88096 \mathrm{e}-04$

16032.70 c $1.79100 \mathrm{e}-0416033.70 \mathrm{c} \quad 1.37080 \mathrm{e}-06$ 16034.70c $7.46906 \mathrm{e}-06$

16036.70 c $3.35102 \mathrm{e}-08$

6000.70c $1.50520 \mathrm{e}-03$ 8016.70c $1.77030 \mathrm{e}-03$

c tubo espacador - SS

m7 26054.70c 3.74872e-03 26056.70c 5.66967e-02 26057.70c $1.28703 \mathrm{e}-03$

26058.70c $1.67057 \mathrm{e}-04$

24050.70c $7.59839 \mathrm{e}-0424052.70 \mathrm{c} \quad 1.40741 \mathrm{e}-0224053.70 \mathrm{c} 1.56555 \mathrm{e}-03$

$24054.70 \mathrm{c} 3.81719 \mathrm{e}-04$

28058.70c $4.53128 \mathrm{e}-0328060.70 \mathrm{c} 1.68705 \mathrm{e}-03$ 28061.70c $7.21458 \mathrm{e}-05$

28062.70c 2.26028e-04 28064.70c 5.60967e-05

25055.70c $1.15810 \mathrm{e}-03$

14028.70 c $1.03286 \mathrm{e}-03$ 14029.70c $5.04940 \mathrm{e}-05$ 14030.70c $3.24033 \mathrm{e}-05$

15031.70 c 3.11240e-05 6000.70c 2.40780e-04 27059.70c $1.14500 \mathrm{e}-04$

c tubo guia - SS

m9 26054.70c $3.44894 \mathrm{e}-03$ 26056.70c $5.21628 \mathrm{e}-02$ 26057.70c $1.18411 \mathrm{e}-03$ 
$26058.70 \mathrm{c} 1.53698 \mathrm{e}-04$

24050.70c 7.38069e-04 24052.70c $1.36708 \mathrm{e}-02$ 24053.70c $1.52070 \mathrm{e}-03$ $24054.70 \mathrm{c} 3.70782 \mathrm{e}-04$

28058.70c 6.27853e-03 28060.70c 2.33757e-03 28061.70c 9.99650e-05 28062.70c 3.13183e-04 28064.70c 7.77273e-05

25055.70c $1.15010 \mathrm{e}-03$

14028.70 c $6.12655 \mathrm{e}-04$ 14029.70c $2.99512 \mathrm{e}-05$ 14030.70c $1.92205 \mathrm{e}-05$

15031.70c 4.50000e-05 6000.70c 8.89680e-05

c placa matriz - SS

m10 26054.70c 3.63630e-03 26056.70c $5.49964 \mathrm{e}-02$ 26057.70c $1.24843 \mathrm{e}-03$

$26058.70 \mathrm{c} 1.62047 \mathrm{e}-04$

24050.70c $7.56501 \mathrm{e}-0424052.70 \mathrm{c} 1.40122 \mathrm{e}-02$ 24053.70c $1.55868 \mathrm{e}-03$

24054.70c 3.80042e-04

28058.70c 5.28566e-03 28060.70c $1.96791 \mathrm{e}-03$ 28061.70c $8.41568 \mathrm{e}-05$

28062.70c 2.63658e-04 28064.70c 6.54358e-05

14028.70c 8.01962e-04 14029.70c 3.92060e-05 14030.70c $2.51595 \mathrm{e}-05$

16032.70 c $4.25282 \mathrm{e}-0616033.70 \mathrm{c} 3.25504 \mathrm{e}-08$ 16034.70c $1.77356 \mathrm{e}-07$

$16036.70 \mathrm{c} 7.95715 \mathrm{e}-10$

42092.70c 4.62114e-06 42094.70c 2.81913e-06 42095.70c $4.80079 \mathrm{e}-06$

42096.70c $4.97759 \mathrm{e}-06$ 42097.70c $2.82043 \mathrm{e}-06$ 42098.70c $7.05364 \mathrm{e}-06$

42100.70c 2.75861e-06

25055.70c 1.25030e-03 15031.70c 5.54400e-05 6000.70c 7.94260e-05

c encamisamento das barras de controle e de seguranca - SS304

m13 26054.70c 3.50278e-03 26056.70c 5.29770e-02 26057.70c $1.20259 \mathrm{e}-03$

$26058.70 \mathrm{c} 1.56097 \mathrm{e}-04$

24050.70c $7.62733 \mathrm{e}-0424052.70 \mathrm{c} \quad 1.41277 \mathrm{e}-0224053.70 \mathrm{c} \quad 1.57152 \mathrm{e}-03$

$24054.70 \mathrm{c} 3.83172 \mathrm{e}-04$

28058.70c $6.54682 \mathrm{e}-03$ 28060.70c $2.43746 \mathrm{e}-03$ 28061.70c $1.04236 \mathrm{e}-04$

28062.70c 3.26566e-04 28064.70c 8.10488e-05

14028.70c 7.07614e-04 14029.70c 3.45935e-05 14030.70c $2.21996 \mathrm{e}-05$

16032.70c 4.25282e-06 16033.70c 3.25504e-08 16034.70c $1.77356 \mathrm{e}-07$

$16036.70 \mathrm{c} 7.95715 \mathrm{e}-10$

42092.70c 2.31057e-06 42094.70c $1.40957 \mathrm{e}-06$ 42095.70c $2.40040 \mathrm{e}-06$

42096.70c 2.48879e-06 42097.70c $1.41022 \mathrm{e}-06$ 42098.70c $3.52682 \mathrm{e}-06$

42100.70c $1.37931 \mathrm{e}-06$

29063.70c $9.43728 \mathrm{e}-05$ 29065.70c $4.07687 \mathrm{e}-05$

50112.70c $3.30769 \mathrm{e}-0850114.70$ c $2.17761 \mathrm{e}-08$ 50115.70c $1.12914 \mathrm{e}-08$

50116.70c $4.78714 \mathrm{e}-0750117.70$ c $2.50690 \mathrm{e}-07$ 50118.70c $7.83891 \mathrm{e}-07$

50119.70c $2.75677 \mathrm{e}-07$ 50120.70c $1.03719 \mathrm{e}-0650122.70 \mathrm{c} \quad 1.44933 \mathrm{e}-07$

$50124.70 \mathrm{c} 1.78316 \mathrm{e}-07$

15031.70c $4.15796 \mathrm{e}-05$ 6000.70c $8.33972 \mathrm{e}-05$ 27059.70c $1.37594 \mathrm{e}-04$

25055.70c $1.18080 \mathrm{e}-03$

c TLD 100

m100 9019.70c $0.5 \quad 3006.70 \mathrm{c} 0.0375$ 3007.70c 0.4625

c TLD 700

m700 9019.70c $0.5 \quad 3006.70 \mathrm{c} 0.00005 \quad 3007.70 \mathrm{c} 0.49995$ 


\section{APÊNDICE D - Características do Campo do Reator IPEN/MB-01 na}

\section{Configuração Cilíndrica com "Flux Trap"}

- Canal 14-15 ; Posição 273 mm:

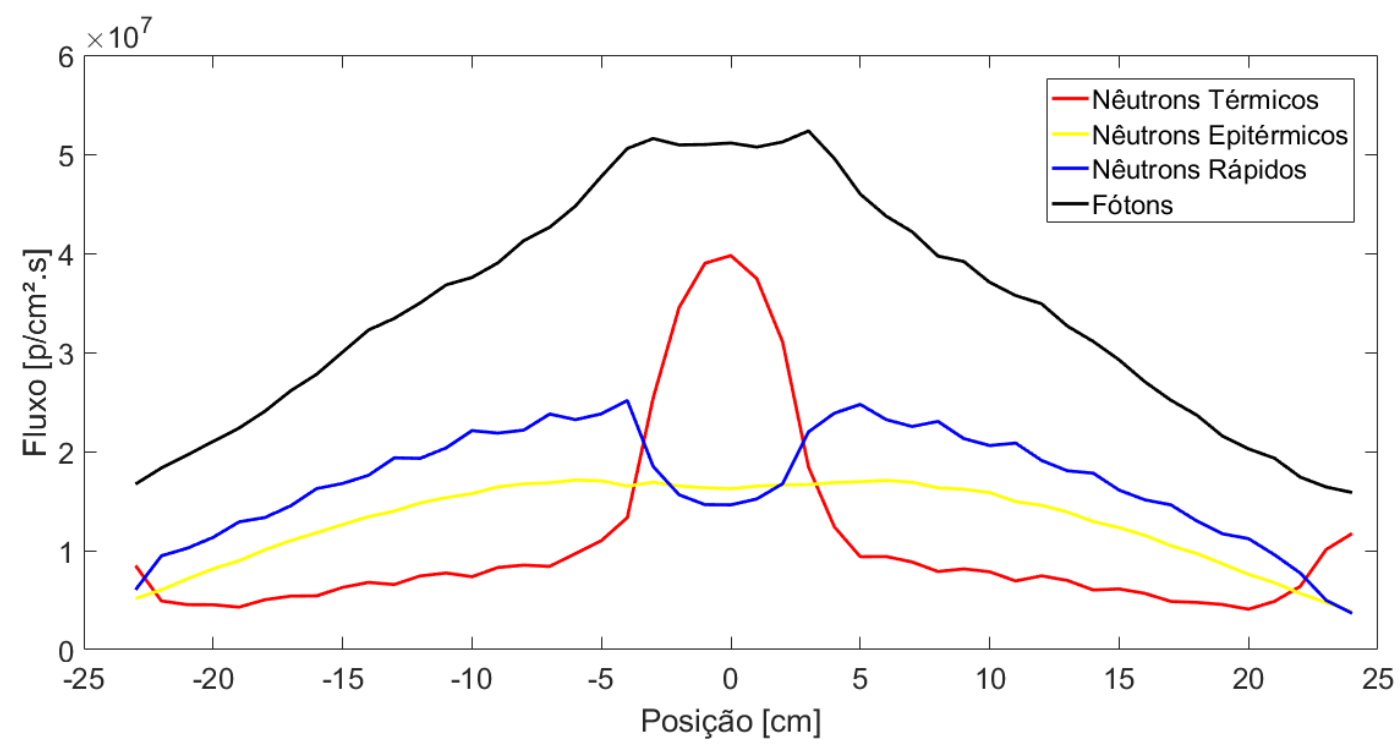

Figura 47 - Fluxos no interior do núcleo do reator IPEN/MB-01 na configuração cilíndrica com “flux trap' no canal 14-15 na posição $273 \mathrm{~mm}$

- Canal 14-15 ; Posição 445 mm:

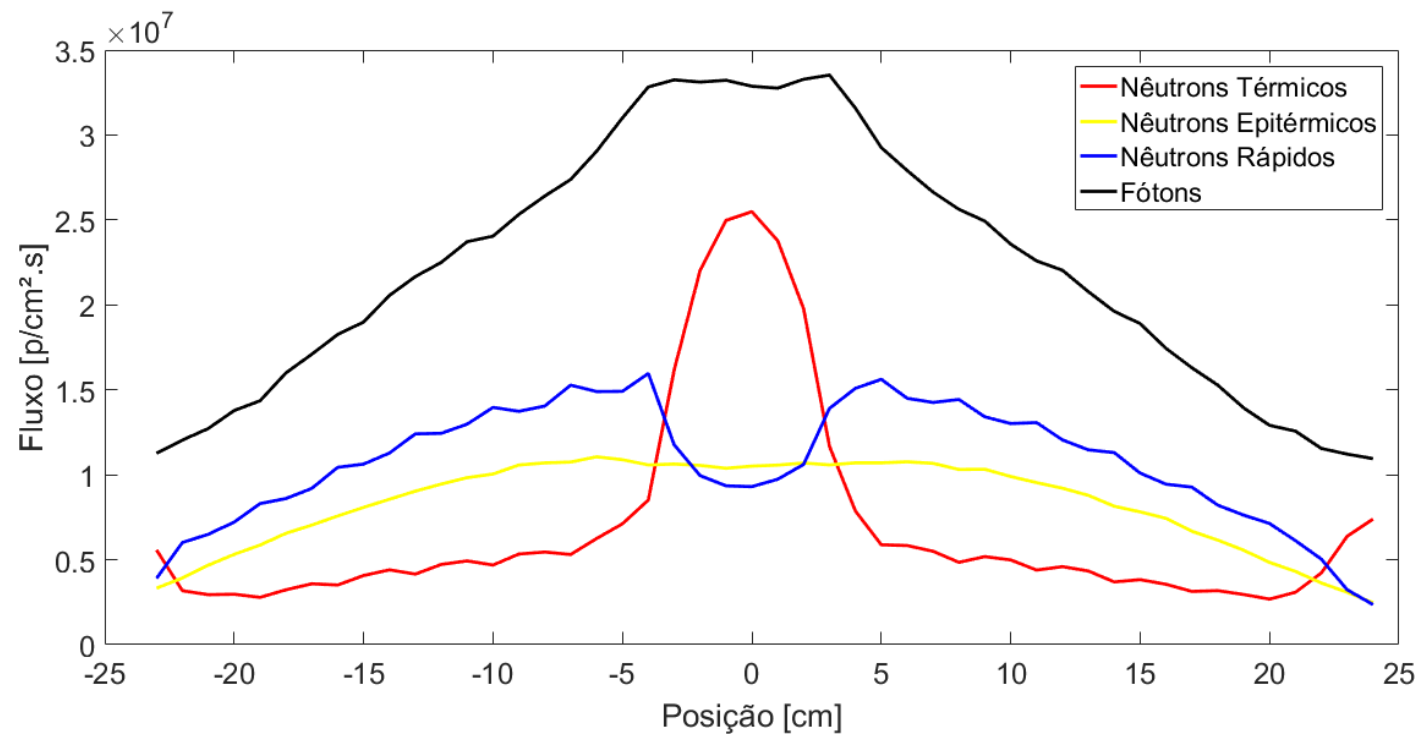

Figura 48 - Fluxos no interior do núcleo do reator IPEN/MB-01 na configuração cilíndrica com “flux trap' no canal 14-15 na posição $455 \mathrm{~mm}$ 
- Canal 2-3 ; Posição 273 mm:

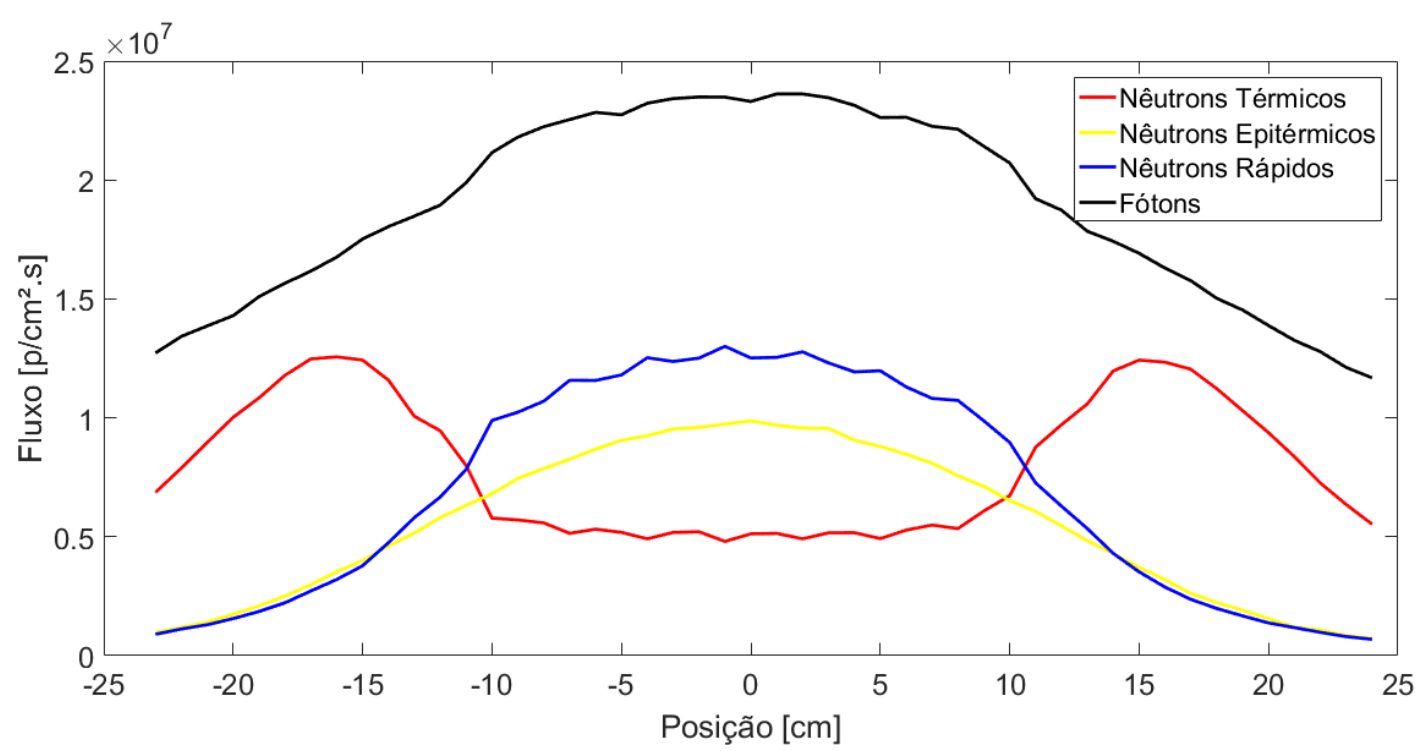

Figura 49 - Fluxos no interior do núcleo do reator IPEN/MB-01 na configuração cilíndrica com “flux trap' no canal 2-3 na posição $273 \mathrm{~mm}$

- Canal 2-3 ; Posição 445 mm:

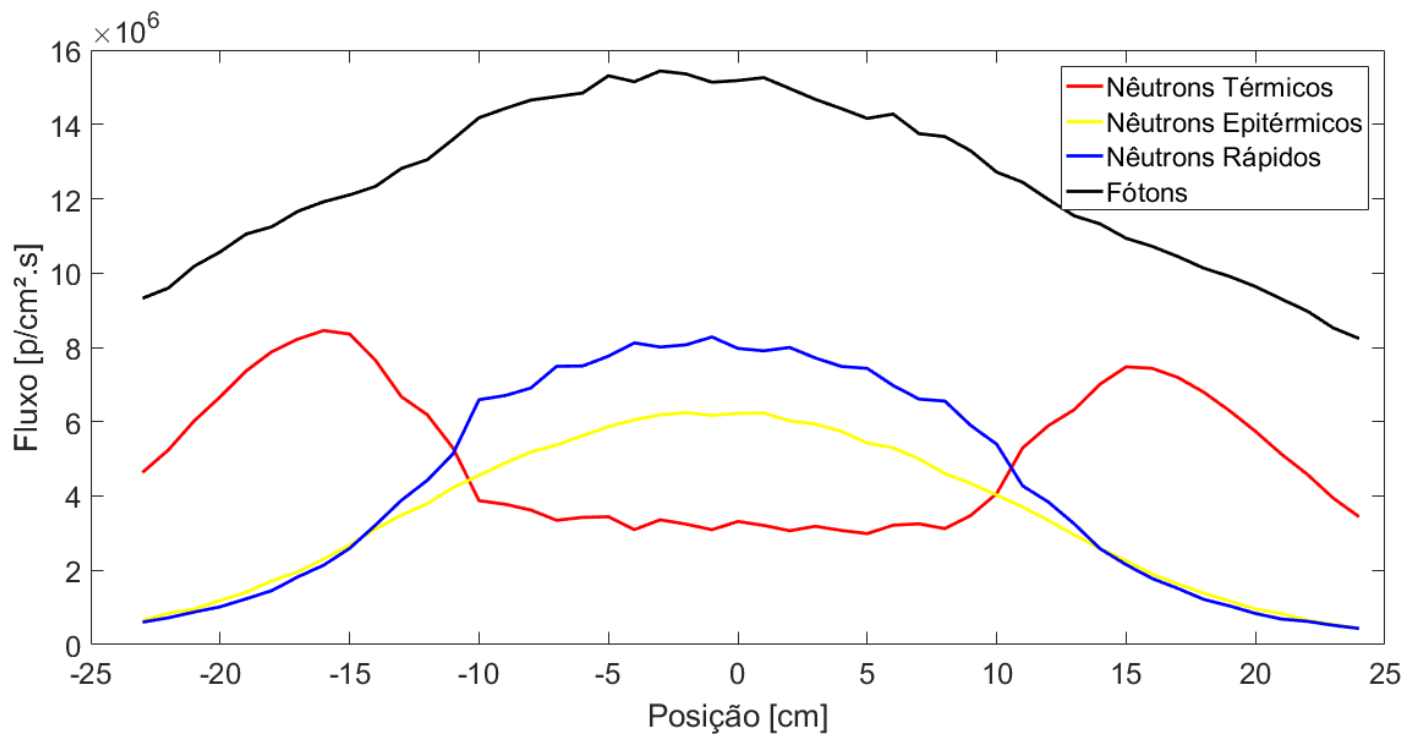

Figura 50 - Fluxos no interior do núcleo do reator IPEN/MB-01 na configuração cilíndrica com “flux trap' no canal 2-3 na posição $455 \mathrm{~mm}$ 


\section{APÊNDICE E - Características do Campo do Reator IPEN/MB-01 na}

\section{Configuração Retangular}

- Canal 14-15 ; Posição 273 mm:

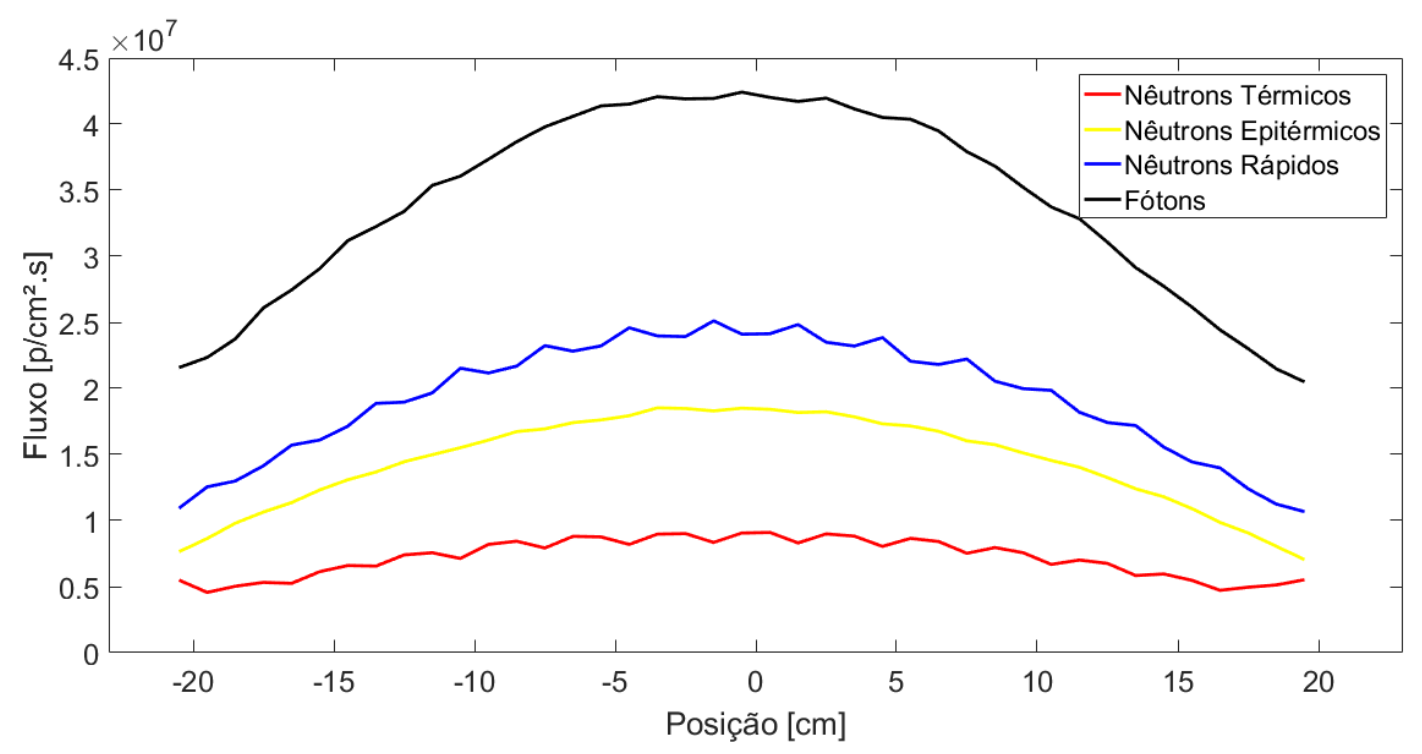

Figura 51 - Fluxos no interior do núcleo do reator IPEN/MB-01 na configuração retangular no canal 14-15 na posição $273 \mathrm{~mm}$

- Canal 14-15 ; Posição 455 mm:

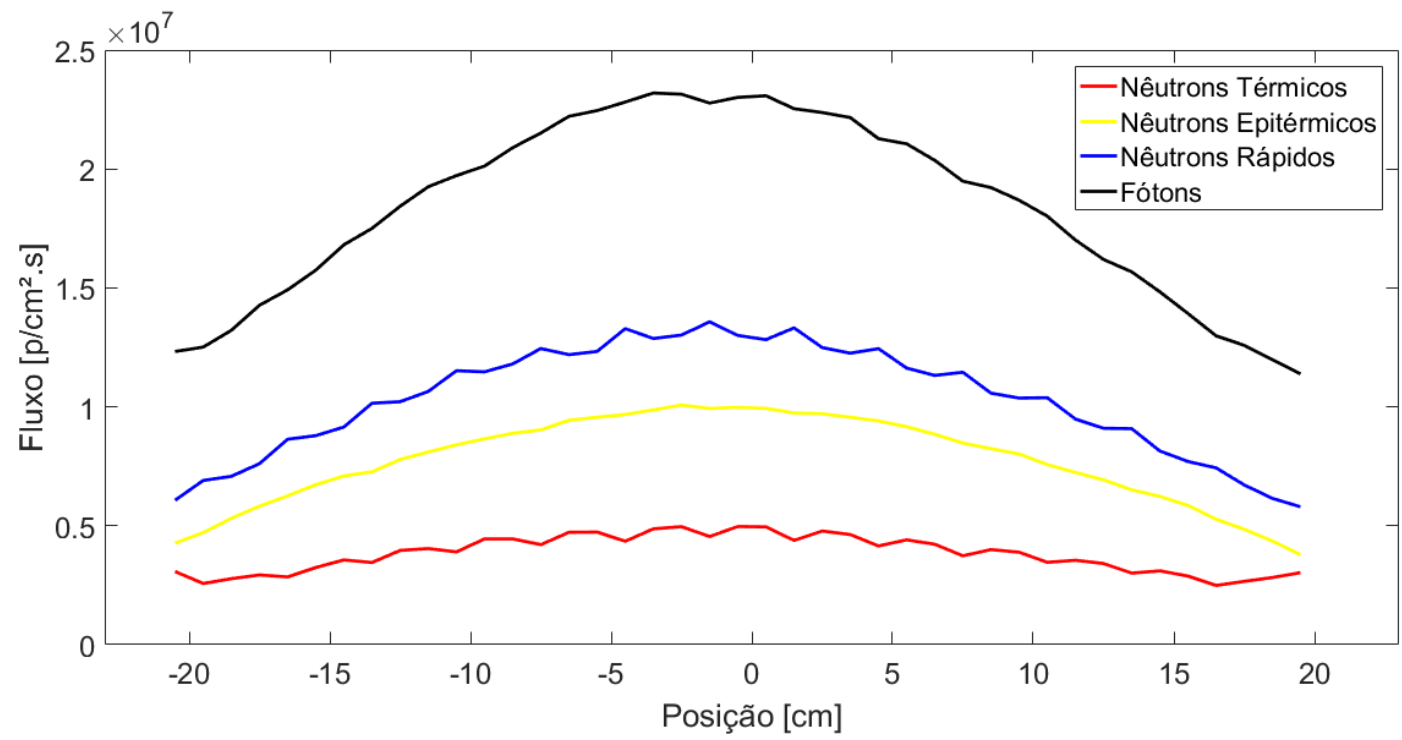

Figura 52 - Fluxos no interior do núcleo do reator IPEN/MB-01 na configuração retangular no canal 14-15 na posição $455 \mathrm{~mm}$ 
- Canal 2-3 ; Posição 273 mm:

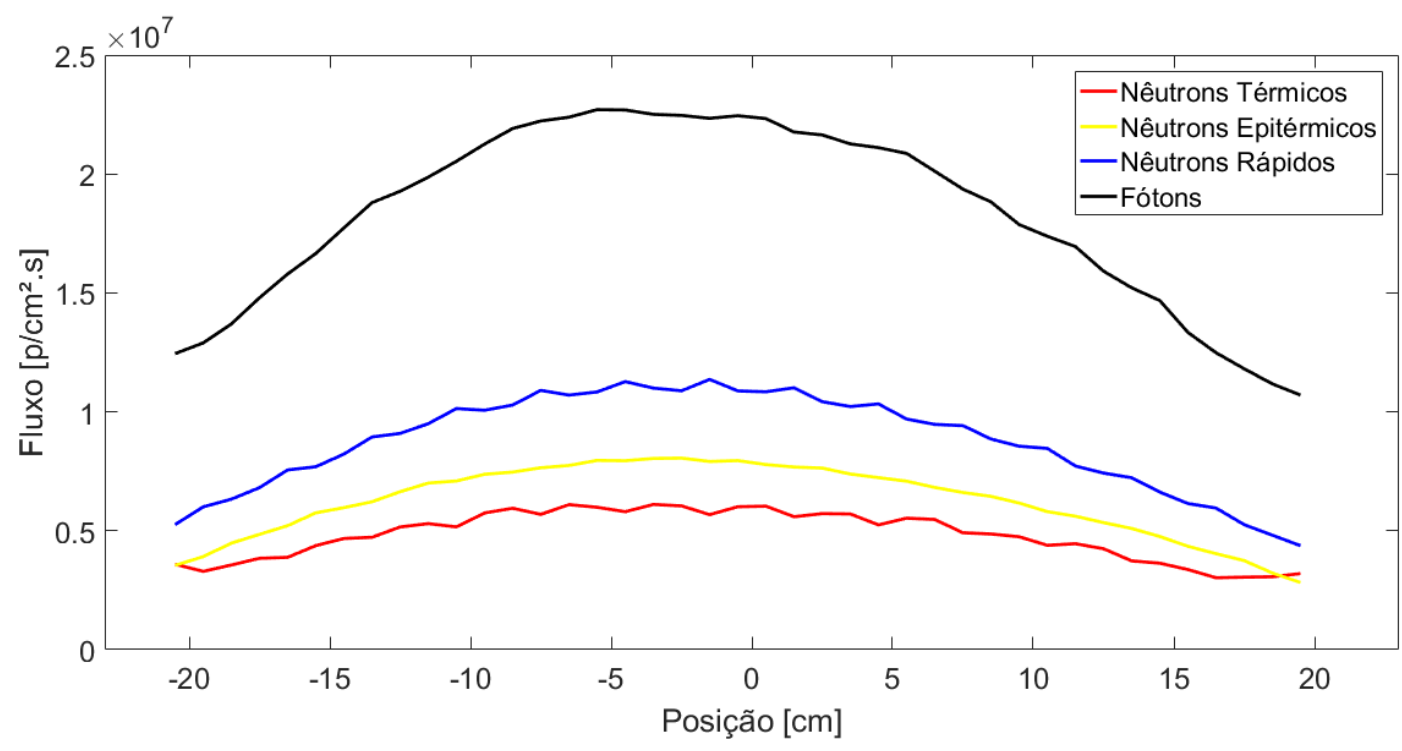

Figura 53 - Fluxos no interior do núcleo do reator IPEN/MB-01 na configuração retangular no canal 2-3 na posição $273 \mathrm{~mm}$

- Canal 2-3 ; Posição 455 mm:

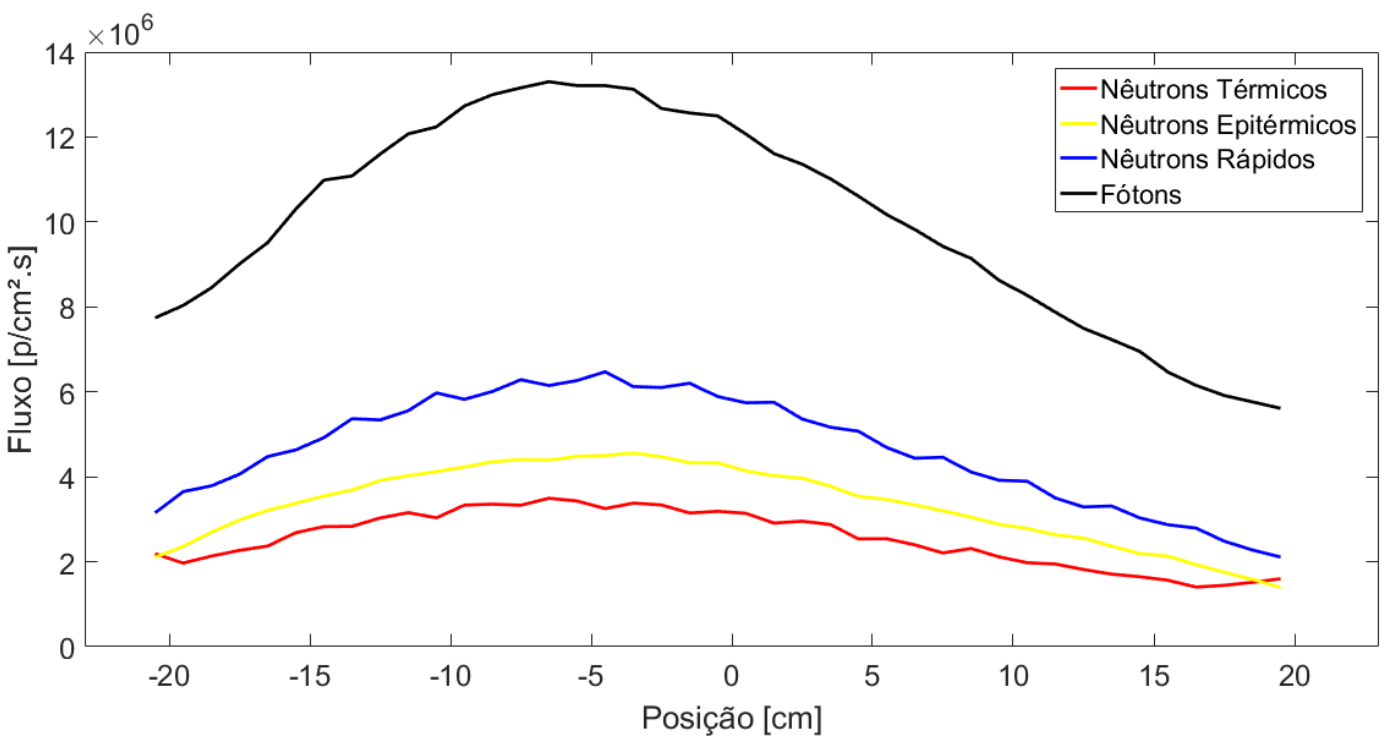

Figura 54 - Fluxos no interior do núcleo do reator IPEN/MB-01 na configuração retangular no canal 2-3 na posição $455 \mathrm{~mm}$ 


\section{APÊNDICE F - Dados TLD 100 nas Irradiações no Reator IPEN/MB-}

\section{1}

- Núcleo na configuração cilíndrica com "flux trap"

Tabela 14 - Resposta termoluminescente das regiões de interesse do TLD 100 nas irradiações no reator IPEN/MB-01 na configuração cilíndrica com "flux trap"

\begin{tabular}{|c|c|c|c|c|c|}
\multirow{2}{*}{ Canal } & \multirow{2}{*}{ Posição } & \multicolumn{2}{c}{ ROI 1 [nC] } & \multicolumn{2}{c}{ ROI 2 [nC] } \\
\cline { 3 - 6 } & valor & desvio & valor & desvio \\
\hline $\mathbf{1 4 - 1 5}$ & $\mathbf{2 7 3 - 0}$ & 1346,00 & 80,76 & 901,50 & 54,09 \\
\hline $\mathbf{1 4 - 1 5}$ & $\mathbf{2 7 3 - 9}$ & 252,90 & 15,17 & 131,20 & 7,87 \\
\hline $\mathbf{1 4 - 1 5}$ & $\mathbf{2 7 3 - 1 8}$ & 162,85 & 9,77 & 70,93 & 4,26 \\
\hline $\mathbf{1 4 - 1 5}$ & $\mathbf{4 5 5 - 0}$ & 954,20 & 57,25 & 586,90 & 35,21 \\
\hline $\mathbf{1 4 - 1 5}$ & $\mathbf{4 5 5 - 9}$ & 197,50 & 11,85 & 92,97 & 5,58 \\
\hline $\mathbf{1 4 - 1 5}$ & $\mathbf{4 5 5 - 1 8}$ & 120,75 & 7,25 & 51,31 & 3,08 \\
\hline $\mathbf{2 - 3}$ & $\mathbf{2 7 3 - 0}$ & 180,35 & 10,82 & 86,81 & 5,21 \\
\hline $\mathbf{2 - 3}$ & $\mathbf{2 7 3 - 9}$ & 148,85 & 8,93 & 52,24 & 3,13 \\
\hline $\mathbf{2 - 3}$ & $\mathbf{2 7 3 - 1 8}$ & 359,70 & 21,58 & 192,75 & 11,57 \\
\hline $\mathbf{2 - 3}$ & $\mathbf{4 5 5 - 0}$ & 117,05 & 7,02 & 49,56 & 2,97 \\
\hline $\mathbf{2 - 3}$ & $\mathbf{4 5 5 - 9}$ & 115,50 & 6,93 & 46,35 & 2,78 \\
\hline $\mathbf{2 - 3}$ & $\mathbf{4 5 5 - 1 8}$ & 285,15 & 17,11 & 151,10 & 9,07 \\
\hline
\end{tabular}


- Núcleo na configuração retangular

Tabela 15 - Resposta termoluminescente das regiões de interesse do TLD 100 nas irradiações no reator IPEN/MB-01 na configuração retangular

\begin{tabular}{|c|c|c|c|c|c|}
\multirow{2}{*}{ Canal } & \multirow{2}{*}{ Posição } & \multicolumn{2}{c}{ ROI 1 [nC] } & \multicolumn{2}{c}{ ROI 2 [nC] } \\
\cline { 3 - 6 } & & valor & desvio & valor & desvio \\
\hline $\mathbf{1 4 - 1 5}$ & $\mathbf{2 7 3 - 0}$ & 319,13 & 19,15 & 259,90 & 15,59 \\
\hline $\mathbf{1 4 - 1 5}$ & $\mathbf{2 7 3 - 9}$ & 256,10 & 15,37 & 195,30 & 11,72 \\
\hline $\mathbf{1 4 - 1 5}$ & $\mathbf{2 7 3 - 1 8}$ & 151,40 & 9,08 & 101,30 & 6,08 \\
\hline $\mathbf{1 4 - 1 5}$ & $\mathbf{4 5 5 - 0}$ & 187,56 & 11,25 & 138,44 & 8,31 \\
\hline $\mathbf{1 4 - 1 5}$ & $\mathbf{4 5 5 - 1 8}$ & 117,30 & 7,04 & 83,08 & 4,98 \\
\hline $\mathbf{2 - 3}$ & $\mathbf{2 7 3 - 0}$ & 195,70 & 11,74 & 140,03 & 8,40 \\
\hline $\mathbf{2 - 3}$ & $\mathbf{2 7 3 - 9}$ & 142,50 & 8,55 & 102,90 & 6,17 \\
\hline $\mathbf{2 - 3}$ & $\mathbf{2 7 3 - 1 8}$ & 108,20 & 6,49 & 68,75 & 4,13 \\
\hline $\mathbf{2 - 3}$ & $\mathbf{4 5 5 - 0}$ & 127,80 & 7,67 & 80,63 & 4,84 \\
\hline $\mathbf{2 - 3}$ & $\mathbf{4 5 5 - 1 8}$ & 88,33 & 5,30 & 52,37 & 3,14 \\
\hline
\end{tabular}


APÊNDICE G - Dados TLD 700 nas Irradiações no Reator IPEN/MB-

01

- Núcleo na configuração cilíndrica com "flux trap"

Tabela 16 - Resposta termoluminescente das regiões de interesse do TLD 700 nas irradiações no reator IPEN/MB-01 na configuração cilíndrica com "flux trap"

\begin{tabular}{c|c|c|c|c|c}
\multirow{2}{*}{ Canal } & \multirow{2}{*}{ Posição } & \multicolumn{2}{c}{ ROI 1 [nC] } & \multicolumn{2}{c}{ ROI 2 [nC] } \\
\cline { 3 - 6 } & & valor & desvio & valor & desvio \\
\hline $\mathbf{1 4 - 1 5}$ & $\mathbf{2 7 3 - 0}$ & 50,71 & 3,04 & 7,87 & 0,47 \\
\hline $\mathbf{1 4 - 1 5}$ & $\mathbf{2 7 3 - 9}$ & 39,04 & 2,34 & 4,22 & 0,25 \\
\hline $\mathbf{1 4 - 1 5}$ & $\mathbf{2 7 3 - 1 8}$ & 23,66 & 1,42 & 2,06 & 0,12 \\
\hline $\mathbf{1 4 - 1 5}$ & $\mathbf{4 5 5 - 0}$ & 48,17 & 2,89 & 9,41 & 0,56 \\
\hline $\mathbf{1 4 - 1 5}$ & $\mathbf{4 5 5 - 1 8}$ & 40,93 & 2,46 & 4,65 & 0,28 \\
\hline $\mathbf{2 - 3}$ & $\mathbf{2 7 3 - 0}$ & 21,33 & 1,28 & 1,92 & 0,12 \\
\hline $\mathbf{2 - 3}$ & $\mathbf{2 7 3 - 9}$ & 25,48 & 1,53 & 2,45 & 0,15 \\
\hline $\mathbf{2 - 3}$ & $\mathbf{2 7 3 - 1 8}$ & 21,81 & 1,31 & 2,07 & 0,12 \\
\hline $\mathbf{2 - 3}$ & $\mathbf{4 5 5 - 0}$ & 11,22 & 0,67 & 1,23 & 0,07 \\
\hline $\mathbf{2 - 3}$ & $\mathbf{4 5 5 - 1 8}$ & 22,09 & 1,33 & 2,00 & 0,12 \\
\hline
\end{tabular}


- Núcleo na configuração retangular

Tabela 17 - Resposta termoluminescente das regiões de interesse do TLD 700 nas irradiações no reator IPEN/MB-01 na configuração retangular

\begin{tabular}{|c|c|c|c|c|c|}
\multirow{2}{*}{ Canal } & \multirow{2}{*}{ Posição } & \multicolumn{2}{c}{ ROI 1 [nC] } & \multicolumn{2}{c}{ ROI 2 [nC] } \\
\cline { 3 - 6 } & & valor & desvio & valor & desvio \\
\hline $\mathbf{1 4 - 1 5}$ & $\mathbf{2 7 3 - 0}$ & 43,77 & 2,63 & 10,30 & 0,62 \\
\hline $\mathbf{1 4 - 1 5}$ & $\mathbf{2 7 3 - 9}$ & 39,30 & 2,36 & 9,04 & 0,54 \\
\hline $\mathbf{1 4 - 1 5}$ & $\mathbf{2 7 3 - 1 8}$ & 22,96 & 1,38 & 4,78 & 0,29 \\
\hline $\mathbf{1 4 - 1 5}$ & $\mathbf{4 5 5 - 0}$ & 37,75 & 2,26 & 8,73 & 0,52 \\
\hline $\mathbf{1 4 - 1 5}$ & $\mathbf{4 5 5 - 1 8}$ & 18,29 & 1,10 & 3,17 & 0,19 \\
\hline $\mathbf{2 - 3}$ & $\mathbf{2 7 3 - 0}$ & 24,25 & 1,46 & 4,41 & 0,26 \\
\hline $\mathbf{2 - 3}$ & $\mathbf{2 7 3 - 9}$ & 21,80 & 1,31 & 4,24 & 0,25 \\
\hline $\mathbf{2 - 3}$ & $\mathbf{2 7 3 - 1 8}$ & 11,22 & 0,67 & 1,79 & 0,11 \\
\hline $\mathbf{2 - 3}$ & $\mathbf{4 5 5 - 0}$ & 21,66 & 1,30 & 3,73 & 0,22 \\
\hline $\mathbf{2 - 3}$ & $\mathbf{4 5 5 - 1 8}$ & 10,22 & 0,61 & 1,45 & 0,09 \\
\hline
\end{tabular}




\section{BIBLIOGRAFIA}

ATTIX, F. H. Introduction to Radiological Physics and Radiation Dosimetry. $2^{\text {a }}$ Weinheim WILEY - VCH, 2004.

BARTH, R. F. et al. Current status of boron neutron capture therapy of high grade gliomas and recurrent head and neck cancer. Radiation Oncology, v. 7, n. 1, p. 146, 2012.

BIELAJEW, A. F. Fundamentals of the Monte Carlo method for neutral and charged particles transport. Michigan: The University of Michigan, 2016.

BITELLI, U. D.; GIADA, M. R. O REATOR IPEN/MB-01 E SEU USO EM EXPERIMENTOS E TREINAMENTO. 2000.

BUSUOLI, G. et al. Mixed radiation dosimetry with LiF (TLD-100). Physics in Medicine \& Biology, v. 15, n. 4, p. 673, 1970.

CARNEIRO-JÚNIOR, V. Caracterização do campo de nêutrons na instalação para estudo em BNCT no Reator IEA-R1. 2009. (Mestrado). Instituto de Pesquisas Energéticas e Nucleares, São Paulo.

CAVALIERI, T. A. EMPREGO DO MCNP NO ESTUDO DOS TLDs 600 E 700 VISANDO A IMPLEMENTAÇÃO DA CARACTERIZAÇÃO DO FEIXE DE IRRADIAÇÃO NA INSTALAÇÃO DE BNCT DO IEA-R1. 2013. (Mestrado). Instituto de Pesquisas Energéticas e Nucleares, São Paulo.

COELHO, P. R. P. et al. Radiation field characterization of the NCT research facility at IEA-R1. 13th International Congress on Neutron Capture Therapy, 2008. p.553-555.

DAVIS, D. et al. The response of LiF thermoluminescence dosemeters to photon beams in the energy range from $30 \mathrm{kV}$ X rays to ${ }^{60} \mathrm{Co}$ gamma rays. Radiation Protection Dosimetry, v. 106, p. 33-43, 2003.

DEWERD, L. Practical Aspects of Thermoluminescence Dosimetry Conference Report Series 43 edited by AP Hufton. Medical Physics, v. 13, n. 6, p. 968-968, 1986.

EKENDAHL, D. et al. Dosimetry With Salt In Mixed Radiation Fields Of Photons And Neutrons. Radiation Protection Dosimetry, v. 178, n. 3, p. 329-332, 2017. 
EVANS, R. D.; EVANS, R. The atomic nucleus. 1955.

GAMBARINI, G. et al. Methods for dose measurements in small phantoms irradiated at BNCT epithermal column. Applied Radiation and Isotopes, v. 88, p. 118-124, 2014.

GAMBARINI, G. et al. Fricke-gel dosimetry in epithermal or thermal neutron beams of a research reactor. Radiation Physics and Chemistry, v. 116, p. 21-27, 2015.

GAMBARINI, G. et al. Determination of gamma dose and thermal neutron fluence in BNCT beams from the TLD-700 glow curve shape. Radiation Measurements, v. 45, n. 3-6, p. 640-642, 2010.

GAMBARINI, G. et al. Study of a method based on TLD detectors for in-phantom dosimetry in BNCT. Radiation Protection Dosimetry, v. 110, n. 1-4, p. 631-636, 2004.

GAMBARINI, G. et al. Measurements of gamma dose and thermal neutron fluence in phantoms exposed to a BNCT epithermal beam with TLD-700. Radiation Protection Dosimetry, v. 161, n. 1-4, p. 422-427, 2014.

GONÇALVES, L. B. CALIBRAÇÃO DOS CANAIS NUCLEARES DO REATOR IPEN/MB-01, OBTIDA A PARTIR DA MEDIDA DA DISTRIBUIÇÃO ESPACIAL DO FLUXO DE NÊUTRONS TÉRMICOS NO NÚCLEO DO REATOR ATRA VÉS DA IRRADIAÇÃO DE FOLHAS DE OURO INFINITAMENTE DILUÍDAS. 2008. (Mestrado). Instituto de Pesquisas Energéticas e Nucleares, São Paulo/SP.

GOOGLE. Google Acadêmico. 2018. Disponível em: < https://scholar.google.com.br/ >. Acesso em: 21 de janeiro de 2018.

HANINGER, T.; HENNIGER, J. Dosimetric properties of the new TLD albedo neutron dosemeter AWST-TL-GD 04. Radiation Protection Dosimetry, v. 170, n. 1-4, p. 150$153,2016$.

HARSHAW. Materials and Assemblies for Themoluminescence Dosimetry.

HENDEE, W. R. History, current status, and trends of radiation protection standards. Medical Physics, v. 20, n. 5, p. 1303-1314, 1993. 
HSU, F. Y. et al. Estimation of photon and neutron dose distributions in the THOR BNCT treatment room using dual TLD method. Radiation Measurements, v. 43, n. 2-6, p. 1089-1094, 2008.

INTERNATIONAL ATOMIC ENERGY AGENCY. Compendium of Neutron Spectra and Detector Responses for Radiation Protection Purpose. Viena 2001.

INTERNATIONAL COMMISSION ON RADIATION UNITS AND MEASUREMENTS. Neutron Dosimetry for Biology and Medicine. S.1. 1984.

INTERNATIONAL COMMISSION ON RADIATION UNITS AND MEASUREMENTS. ICRU. 2018. Disponível em: < https://icru.org/ >. Acesso em: 26 de janeiro.

INTERNATIONAL COMMISSION ON RADIOLOGICAL PROTECTION. ICRP. 2018. Disponível em: < http://www.icrp.org/ >. Acesso em: 26 de janeiro.

INTERNATIONAL ORGANIZATION FOR STANDARDIZATION. Reference Neutron Radiations Part 3: Calibration of Area and Personal Dosimeters and Determination of Their Response as a Function of Neutron Energy and Angle of Incidence. Technical Report p.32. Suiça 1998.

IPEN. Reator de Pesquisa IPEN/MB-01. 2017. Disponível em: < https://www.ipen.br/portal_por/portal/interna.php?secao_id=723 >. Acesso em: $20 \mathrm{de}$ janeiro de 2017.

KIRK, B. L. Overview of Monte Carlo radiation transport codes. Radiation Measurements, v. 45, n. 10, p. 1318-1322, 2010.

KNOLL, G. F. Radiation detection and measurement Glenn F. 3rd. New York: J. Wiley, 2000.

KOREA ATOMIC ENERGY RESEARCH INSTITUTE. Nuclear Data Center. 2000. Disponível em: < http://atom.kaeri.re.kr/cgi-bin/endfform.pl >. Acesso em: 22 de julho de 2012.

KRÁLÍK, M.; VYKYDAL, Z. PRACTICAL METROLOGICAL ASPECTS OF NEUTRON PERSONAL DOSIMETRY. Radiation Protection Dosimetry, v. 170, n. 14, p. 54-57, 2016. 
MARSH, J. W.; THOMAS, D. J.; BURKE, M. High resolution measurements of neutron energy spectra from $\mathrm{AmBe}$ and $\mathrm{AmB}$ neutron sources. Nuclear Instruments and Methods in Physics Research Section A: Accelerators, Spectrometers, Detectors and Associated Equipment, v. 366, n. 2, p. 340-348, 1995.

MASSILLON-JL, G. et al. Influence of phantom materials on the energy dependence of LiF:Mg,Ti thermoluminescent dosimeters exposed to $20-300 \mathrm{kV}$ narrow $\mathrm{x}$-ray spectra,

${ }^{137} \mathrm{Cs}$ and ${ }^{60} \mathrm{Co}$ photons. Physics in Medicine and Biology, v. 59, n. 4149-66, 2014.

MCKEEVER, S. W. S.; MOSCOVITCH, M.; TOWNSEND, P. D. Thermoluminescence dosimetry materials: properties and uses. Nuclear Technology Pub., 1995.

MUNIZ, R. O. R. Desenvolvimento de um simulador antropomórfico para simulação e medidas de dose e fluxo de nêutrons na instalação para estudos em BNCT. 2010. (Mestrado). Instituto de Pesquisas Energéticas e Nuceares, São Paulo.

NAGELS, S. et al. Determination on the Irradiation Field at the Research Reactor TRIGA Mainz for BNCT. Applied Radiation and Isotopes, v. 67, p. 242-6, 2009.

NEDUNCHEZHIAN, K. et al. Boron Neutron Capture Therapy - A Literature Review. Journal of Clinical and Diagnostic Research : JCDR, Delhi, India, v. 10, n. 12, p. ZE01-ZE04, 2016.

NIST. X-Ray Mass Attenuation Coefficients. 2010. Disponível em: < http://physics.nist.gov/PhysRefData/XrayMassCoef/tab4.html >. Acesso em: 12 de setembro de 2013.

NUCLEAR REGULATORY COMMISION. 0751 - H122 - Basic Health Physics - 25 Neutron Sources 2010.

NUNN, A. A. et al. LiF:Mg,Ti TLD response as a function of photon energy for moderately filtered $\mathrm{x}$-ray spectra in the range $20-250 \mathrm{kVp}$ relative to ${ }^{60} \mathrm{Co}$. Medical Physics, v. 35, n. 5, p. 1859-69, 2008.

OBERHOFER, M.; SCHARMANN, A. Applied Thermoluminescence Dosimetry. Ispra: Adam Hilger Ltd., 1979. 
PAIVA, F. D. ESTUDO DAS RESPOSTAS DE TLD TIPO LiF PARA CARACTERIZAÇÃO DE CAMPOS MISTOS. 2016. (Mestrado). Instituto de Pesquisas Energéticas e Nucleares, São Paulo/SP.

POMP, S. Tutorial on neutron physics in dosimetry. Radiation Measurements, v. 45, n. 10, p. 1090-1095, 2010.

PRADHAN, A. S. Thermoluminescence Dosimetry and its Applications. Radiation Protection Dosimetry, v. 1, n. 3, p. 153-167, 1981.

RANK, E. X.; THEUS, R. B. Neutron dosimetry with CaF2: Tm. IEEE Transactions on Nuclear Science, v. 26, n. 1, p. 1590-1592, 1979.

SCIENCEDIRECT. Science, health and medical journal, full text articles and books. 2018. Disponível em: < https://www.sciencedirect.com/ >. Acesso em: 07 de Abril de 2018.

SHACHAR, B. B.; HOROWITZ, Y. Dosimetric characterisation of the high temperature peaks of $\mathrm{LiF}: \mathrm{Mg}$, $\mathrm{Ti}$ and $\mathrm{CaF}_{2}$ : Tm using computerised glow curve deconvolution. Radiation Protection Dosimetry, v. 22, n. 2, p. 87-96, 1988.

SHULTIS, J. K.; FAW, R. E. An MCNP primer. 2011

SILVA, A. F. P. D. Calibração da Potência do Reator IPEN/MB-01 na configuração cilíndrica de menor excesso de reatividade obtida a partir da medida absoluta do fluxo médio de nêutrons. 2014. (Mestrado). Instituto de Pesquisas Energéticas e Nuclear, São Paulo.

TAUHATA, L. et al. Radioproteção e Dosimetria: Fundamentos. Rio de Janeiro: Instituto de Radioproteção e Dosimetria / CNEN, 2003.

THERMO ELECTRON CORPORATION. Model 3500 Manual TLD Reader with WinRens. Ohio. 2005

THERMOFISHER. TermoFisher Scietific. 2018. Disponível em: < https://www.thermofisher.com >. Acesso em: 05 de abril de 2018. 
THOMPSON, M. N.; TAYLOR, J. M. Neutron spectra from Am- $\alpha$-Be and Ra- $\alpha-B e$ sources. Nuclear Instruments and Methods, v. 37, p. 305-308, 1965.

TORKZADEH, F.; MANOUCHEHRI, F. Thermal neutron fluence measurement in a research reactor using thermoluminescence dosimeter TLD-600. Journal of Radiological Protection, v. 26, n. 1, p. 97, 2006.

TRINKL, S. et al. Systematic out-of-field secondary neutron spectrometry and dosimetry in pencil beam scanning proton therapy. Medical Physics, v. 44, n. 5, p. 1912-1920, 2017.

TRIOLO, A. et al. Study of the glow curves of TLD exposed to thermal neutrons. Radiation Protection Dosimetry, v. 126, n. 1-4, p. 333-336, 2007.

TSAI, W.-C.; HUANG, C.-K.; JIANG, S.-H. QA measurement of gamma-ray dose and neutron activation using TLD-400 for BNCT beam. Applied Radiation and Isotopes, v. 137, p. 73-79, 2018.

TSOULFANIDIS, N. Measurement and detection of radiation. CRC press, 2010.

VEGA-CARRILLO, H. R. et al. Neutron and gamma-ray spectra of ${ }^{239} \mathrm{PuBe}$ and

${ }^{241}$ AmBe. Applied Radiation and Isotopes, v. 57, n. 2, p. 167-170, 2002.

X-5 MONTE CARLO TEAM. MCNP - A General Monte Carlo N-Particle Transporte Code. Los Alamos. v.5 2005.

YORIYAZ, H. Método de Monte Carlo: Princípios e Aplicações em Física Médica. Revista Brasileira de Física Médica, v. 3, p. 141-149, 2009.

ZAMBONI, C. B. Fundamentos da Física de nêutrons. Editora Livraria da Física, 2007. 


\section{INSTITUTO DE PESQUISAS ENERGÉTICAS E NUCLEARES}

Diretoria de Pesquisa, Desenvolvimento e Ensino

Av. Prof. Lineu Prestes, 2242 - Cidade Universitária CEP: 05508-000

Fone/Fax(0XX11) 3133-8908

SÃO PAULO - São Paulo - Brasil

http://www.ipen.br

O IPEN é uma Autaquia vinculada à Secretaria de Desenvolvimento, associada à Universiade de São Paulo e gerida técnica e administrativamente pela Comissão Nacional de Energia Nuclear, órgão do Ministério da Ciência, Tecnologia e Inovação. 